$$
\begin{gathered}
\text { Juan Luis } \\
\text { Manfredi Sánchez } \\
\text { (coordinador) }
\end{gathered}
$$

\title{
Innovación y Periodismo: emprender en la Universidad
}

\author{
Prólogo de James Breiner
}

CAC, Cuadernos Artesanos de Comunicación /76

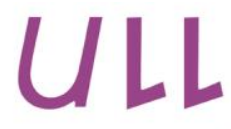

Universidad de La Laguna
Universitat d'Alacant Universidad de Alicante
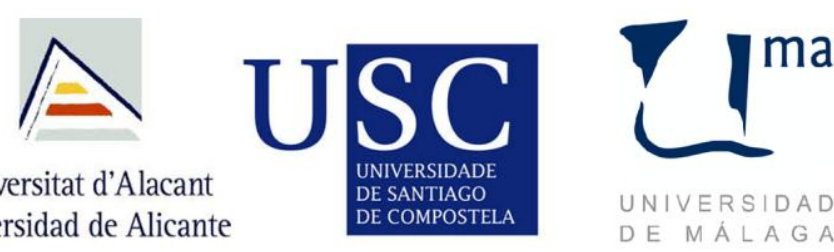

UNIVERSIDAD $D E M A L A G A$

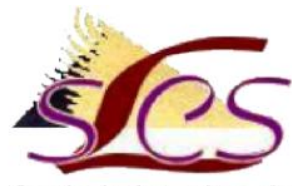

Sociedad Latina de Comunicación Social 
\#76 Cuadernos Artesanos de Comunicación - Comité Científico

Presidencia: José Luis Piñuel Raigada (UCM)

Secretaría: Concha Mateos (URJC)

- Bernardo Díaz Nosty (Universidad de Málaga, UMA)

- Carlos Elías (Universidad Carlos III de Madrid, UC3M)

- Javier Marzal (Universidad Jaume I, UJI)

- José Luis González Esteban (Universitas Miguel Hernández de Elche)

- José Luis Terrón (Universidad Autónoma de Barcelona, UAB)

- José Miguel Túñez (Universidad de Santiago, USC)

- Juan José Igartua (Universidad de Salamanca, USAL)

- Marisa Humanes (Universidad Rey Juan Carlos, URJC)

- Miguel Vicente (Universidad de Valladolid, UVA)

- Miquel Rodrigo Alsina (Universidad Pompeu Fabra, UPF)

- Núria Almiron (Universidad Pompeu Fabra, UPF)

- Ramón Reig (Universidad de Sevilla, US)

- Ramón Zallo (Universidad del País Vasco, UPV-EHU)

- Victoria Tur (Universidad de Alicante, UA).

\section{(9)}

* Queda expresamente autorizada la reproducción total o parcial de los textos publicados en este libro, en cualquier formato o soporte imaginables, salvo por explícita voluntad en contra del autor o autora o en caso de ediciones con ánimo de lucro. Las publicaciones donde se incluyan textos de esta publicación serán ediciones no comerciales y han de estar igualmente acogidas a Creative Commons. Harán constar esta licencia y el carácter no venal de la publicación.

* La responsabilidad de cada texto es de su autor o autora. 
Juan Luis Manfredi Sánchez (coordinador)

\section{Innovación y Periodismo: emprender en la Universidad}

CAC, Cuadernos Artesanos de Comunicación / 76

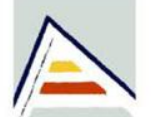

Universitat d'Alacant Universidad de Alicante
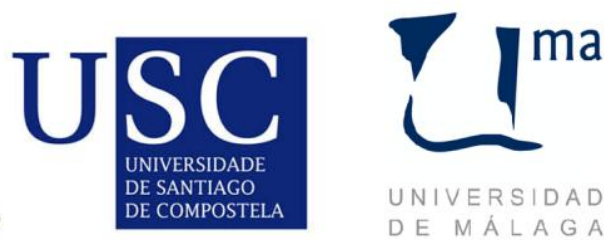

UNIVERSIDAD DE MÁLAGA

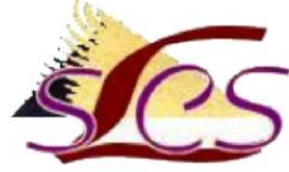

Sociedad Latina de Comunicación Social 


\section{CAC \# 76 - Innovación y Periodismo: emprender en la}

\section{Universidad}

Coordinador: Juan Luis Manfredi Sánchez

| Precio social: 6,95€| Precio en librería. 9,05€|

Editores: Javier Herrero y Alberto Ardèvol Abreu

Diseño: F. Drago

Ilustración de portada: Fragmento del cuadro Playa de Fuerteventura, de Guido Kolitscher (Austria - La Gomera).

Imprime y distribuye: F. Drago. Andocopias S. L.

c/ La Hornera, 41. La Laguna. Tenerife.

Teléfono: 922250554 | fotocopiasdrago@telefonica.net

Edita: Sociedad Latina de Comunicación Social - edición no venal

- La Laguna (Tenerife), 2015 - Creative Commons

(http://www.revistalatinacs.org/09/Sociedad/estatutos.html)

Catálogo: http://www.cuadernosartesanos.org

Protocolo de envío de manuscritos con destino a CAC:

http://www.cuadernosartesanos.org/protocolo.html

Descargar $p d f$ :

http://www.cuadernosartesanos.org/\#75

ISBN: 978-84-15698-93-7

DL: TF-57-2015

DOI: $\underline{10.4185 / \operatorname{cac} 76}$ 


\title{
Elementos del periodismo emprendedor
}

\begin{abstract}
El periodismo emprendedor es el fenómeno observado en la industria periodística después de 2008. Consiste en el conjunto de iniciativas lideradas por periodistas para la creación de nuevos medios promovidos por ellos mismos. Están alejados del modelo industrial cuyo accionariado corresponde a grandes grupos de comunicación o a empresas ajenas al sector. Se caracterizan por la primacía del ámbito digital (contenidos, aplicaciones) en detrimento de la estructura analógica (papel). Por último, se emplea intensamente la marca personal del periodista como motor de la promoción a través de las redes sociales. El fenómeno es mundial.
\end{abstract}

\section{Palabras clave}

Innovación, periodismo, emprendimiento, universidad

\section{Forma de citar este libro}

Juan Luis Manfredi Sánchez (Coordinador) (2015): Innovación y Periodismo: emprender en la Universidad. Cuadernos Artesanos de Comunicación, 76. La Laguna (Tenerife): Latina.

Dedicado a todos los profesores y profesoras que creemos en el Periodismo y la Universidad. 


\section{Índice}

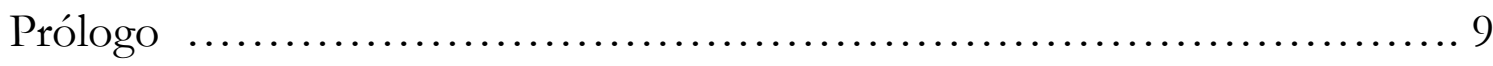

1. E1 nuevo ecosistema periodístico ………………………………………….... 21

2. Elementos del periodismo emprendedor …………………………………...... 23

3. Innovación y emprendimiento en la Facultad ............................................... 27

2. Innovación radical en los estudios de periodismo.....................35

2. Innovación gracias a nuestros ex alumnos ……………………………………... 36

3. Innovación en las ofertas laborales ................................................................. 38

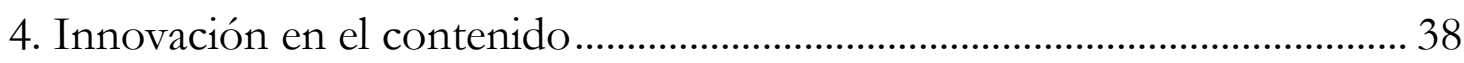

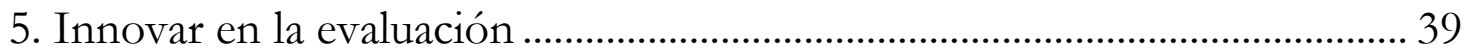

6. Innovar en la actitud ............................................................................................ 39

7. Innovación en la periferia del periodismo ........................................................ 40

8. Innovación en las plataformas ............................................................................ 41

9. Innovación en la Facultad: factorías de medios ................................................. 42

10.Innovación en la gestión del CV: la marca personal........................................ 43

11. Innovación en las narrativas, no en la tecnología ......................................... 43

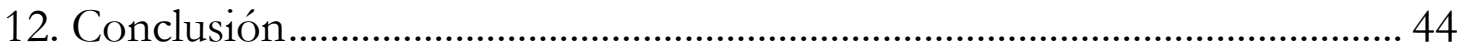

\section{Lean Startup y Design Thinking Nuevos métodos para innovar en}

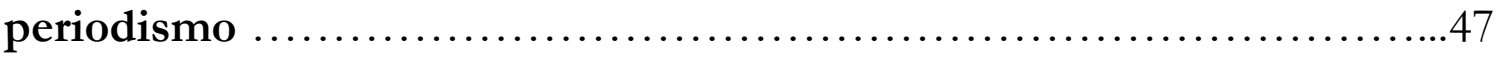

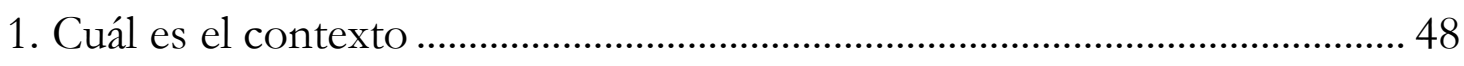

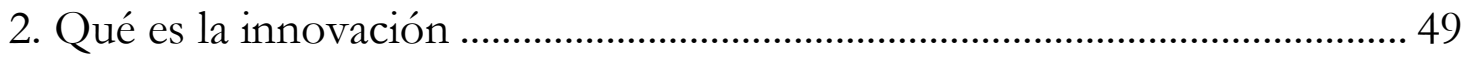

3. Design thinking, pensar fuera del esquema tradicional..................................... 50

4. Lean startup: equivócate pronto y barato ………………………………….... 52

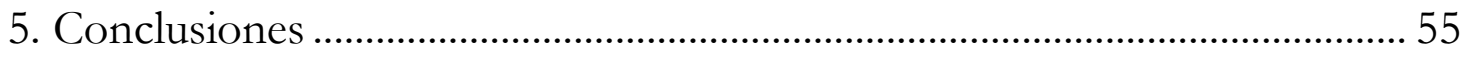

4. Metodología de trabajo para generar modelos de negocio y proyectos emprendedores en el ámbito periodístico ...........................57

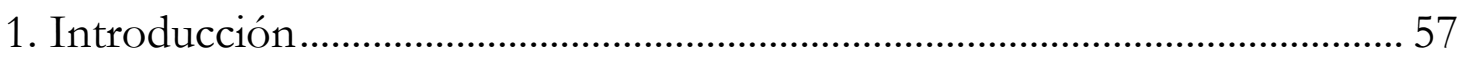

2. Del modelo de negocio al plan de negocio .................................................... 58

3. El lienzo o "canvas" como herramienta de trabajo para planificar el modelo de negocio

4. La prensa gratuita en España. El caso del diario Metro Directo y su proyección internacional. 
5. El Deporte Conquense: un proyecto real desarrollado en el aula. 65

6. Bibliografía. 70

\section{El plan de negocio en la formación en emprendimiento para}

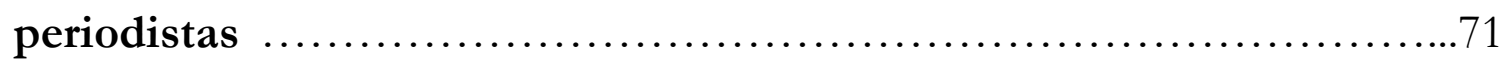

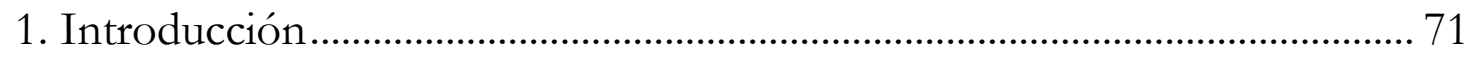

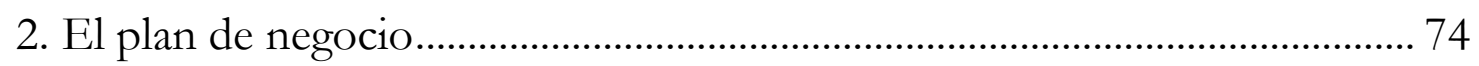

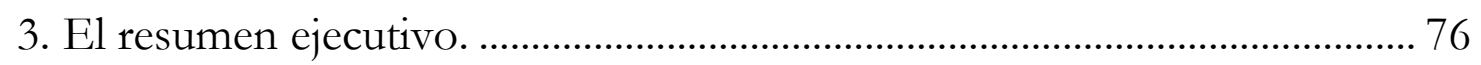

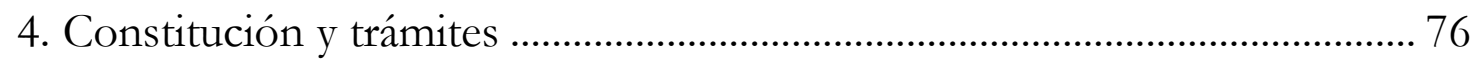

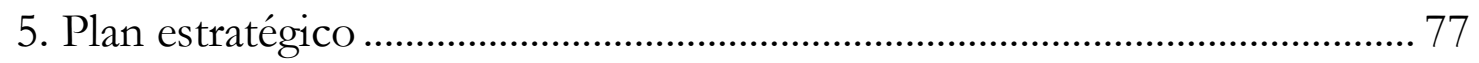

6. Plan de marketing y ventas ............................................................................... 78

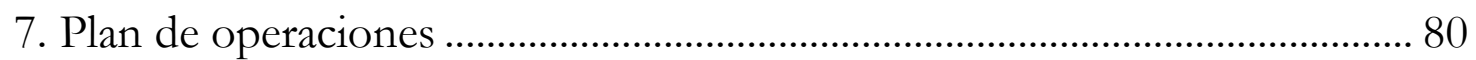

8. Plan de organización y recursos humanos........................................................ 81

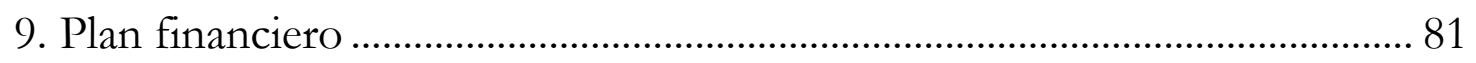

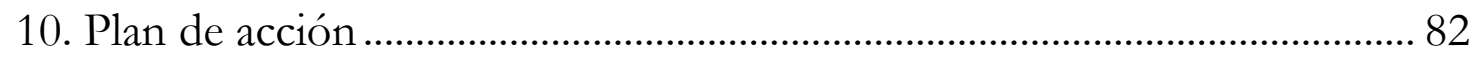

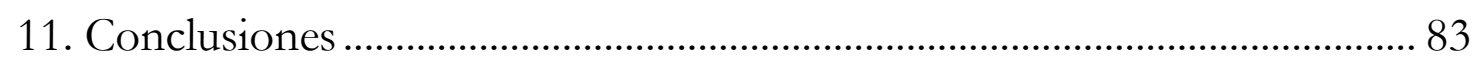

6. Experiencia en el aula. La asignatura de Creación de Empresas

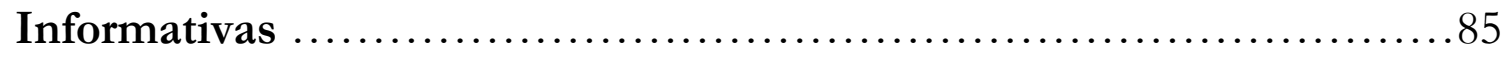

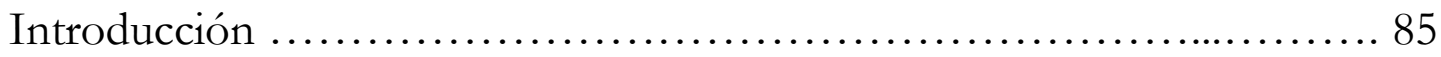

1. Estudio del caso de la asignatura Creación y Gestión de Empresas Informativas en la Universidad de Málaga ................................................................ 87

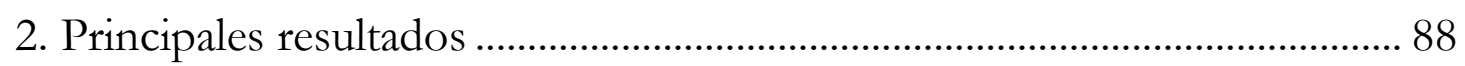

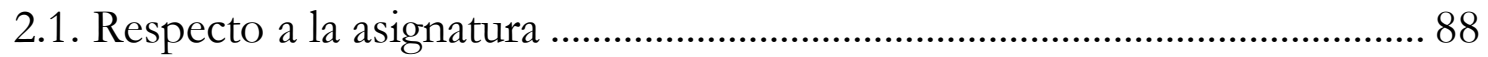

2.2. Sobre el trabajo individual ............................................................................. 94

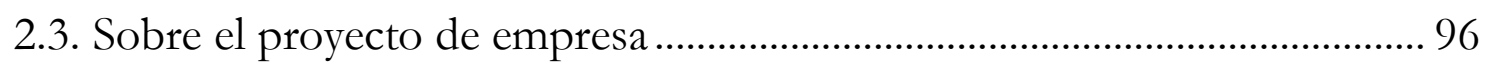

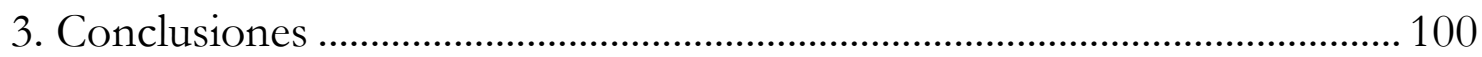

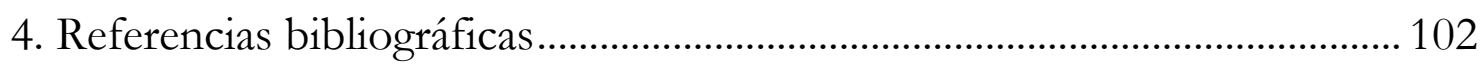

7. Las nuevas competencias de los graduados universitarios en

Periodismo ....................................................... 105

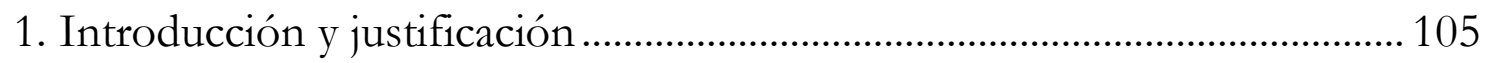

2. Marco teórico e interrogantes para la reflexión ................................................. 106

3. Un nuevo marco académico en un nuevo contexto socioeconómico........ 107

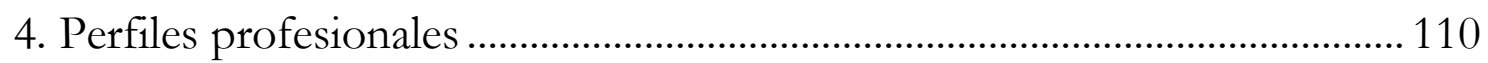


5. La formación en competencias ....................................................................... 111

6. Las competencias de los comunicadores según la ANECA. ........................ 113

7. Las competencias del profesional de la comunicación en la sociedad digital ........................................................... 115

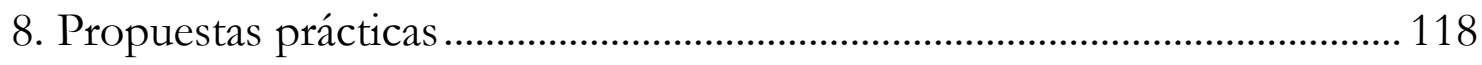

9. A modo de conclusión ........................................................................................ 120

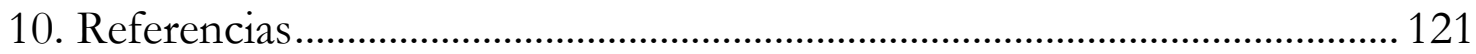

8. El valor y uso de Twitter en la enseñanza del periodismo ...........125

1. De sistema operativo del periodismo a herramienta docente ....................... 125

2. Cómo sacarle partido en el aula ..................................................................... 128

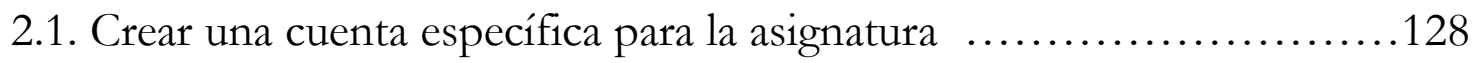

2.2. Dotarla de contenido ................................................................................... 128

2.3. Organizar las fuentes en listas ....................................................................... 129

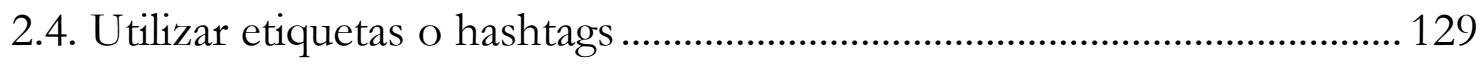

3. Cuándo y cómo lo utilizamos........................................................................... 130

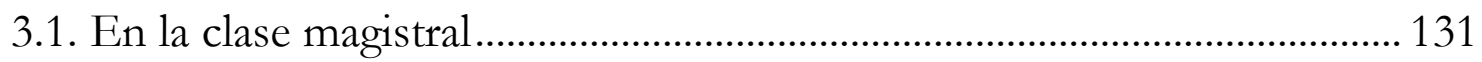

3.2. En las sesiones académicas prácticas ............................................................. 131

3.3. En exposiciones y debates ........................................................................ 132

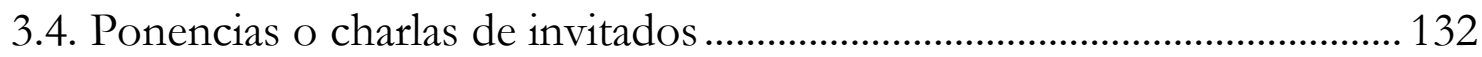

3.5. Tutorías específicas ....................................................................................... 133

4. Retroalimentación y medición de resultados.................................................... 133

5. Para ampliar conocimientos, una bibliografía práctica .................134

Epílogo ....................................................... 135

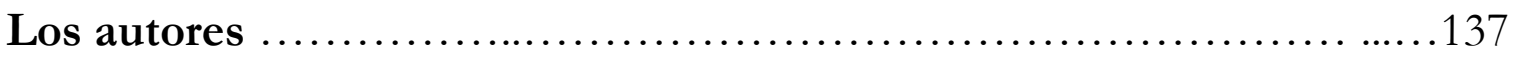




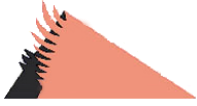 \\ Prólogo \\ El buen periodismo no es un negocio}

Por James Breiner

$\mathrm{E}$

STE LIBRO es un excelente manual para los periodistas y los profesores que quieren inventar los nuevos medios de comunicación para servir a las comunidades digitales del futuro. El camino por delante en el periodismo está envuelto en la oscuridad. No hay muchas señales para describir la ruta correcta. Pero cada capítulo de este libro contiene excelentes indicaciones de los caminos más prometedores y cuenta las experiencias de los exploradores que están creando los mapas del nuevo mundo periodístico. Para una persona que está iniciando su primera exploración o una que ya ha explorado hasta los límites del mundo conocido, hay direcciones que van a ahorrar tiempo y evitar los itinerarios más peligrosos. Es sumamente útil y práctico.

\section{E1 fin del monopolio}

Antes de las múltiples crisis, en la época dorada del periodismo, la industria y la profesión eran más sencillas. Seguían la lógica de cualquier monopolio: pocas opciones para los lectores, televidentes y oyentes; el control de la agenda pública en pocas manos; pocas opciones para los anunciantes y por eso altos precios para la publicidad; y puestos de trabajo bastante seguros. En el pasado, con 
el modelo industrial, en el que sólo algunos adinerados podían costear una imprenta o licencia para una emisora, era un negociazo muy rentable. El financiero Warren Buffettt -- dueño del diario Buffalo Evening News -- solía decir durante esa época que el modelo de negocio de un periódico diario era tan sencillo que su nieto idiota podría gestionar uno. De hecho, muchos lo probaron acertado en su observación.

Desde el punto de vista de un periodista, era un periodo maravilloso porque los poderes existentes debían comunicar sus mensajes al público a través de intermediarios, es decir nosotros, los periodistas. Teníamos un poder importante y pensábamos importantes; realmente, este rol nos hicimos indebidamente arrogantes. En la redacción de un gran diario donde yo trabajaba, decíamos que un acontecimiento no había ocurrido hasta que publicáramos la noticia en nuestras páginas. Y realmente era así. Dictábamos que se publicaba la noticia una vez al día, y si no le convenía al público, mala suerte para ellos.

\section{El nuevo dictador}

Pero con el fin del monopolio y el auge de la comunicación horizontal en Internet, los usuarios tienen miles de opciones. En vez de pocos medios masivos tenemos una masa de medios, como ha declarado el Profesor Rosental Alves de la Universidad de Tejas. Por tanto debemos reconocer que ya no somos las autoridades que dictamos el qué, cuándo y cómo del consumo de noticias. El público, el usuario es el nuevo dictador.

¿Y quién es? Esta cuestión de quién es nuestro usuario, quién es nuestro público, es la cuestión fundamental en el mundo del periodismo digital y representa un gran cambio en la manera en que debemos desempeñar el trabajo en las redacciones. 
Con un monopolio, no sabíamos mucho de los hábitos de los usuarios. En los semanarios económicos donde yo trabajaba por dos décadas, hicimos una encuesta de nuestros lectores cada dos años para mostrar a nuestros anunciantes que los lectores eran de cierta edad, nivel económico y educación; que tenían un patrimonio de cierto tamaño, coche de cierta marca y casa de cierto valor; que viajaban $\mathrm{X}$ veces al año y que eran presidentes o vice presidentes de su empresa; que su parte favorita del periódico era las noticias en la portada. ¡Les encuestamos sólo cada dos años! Conocíamos más de los lectores cuando nos topamos con ellos en los numerosos eventos de cámaras de comercio y otras organizaciones de negociantes en la ciudad. Ellos nos dijeron qué estaban leyendo en el periódico y qué les gustó o no. Este método de investigación del mercado era una de nuestras herramientas más efectivas para competir con los grandes medios y, mirando atrás, bastante primitiva.

\section{Conocer a la comunidad}

Hoy día, con Google Analytics y otras herramientas de medición de las actividades de los usuarios en línea, podemos saber mucho más del público. Y esta actividad de conocer al público es fundamental para crear nuevos medios de comunicación que sirven las necesidades informacionales de nuestras comunidades y de plantear nuevos modelos de negocios para sostener el servicio. Nosotros los periodistas y profesores de periodismo debemos cambiar nuestra mentalidad para pensar en comunidades activas de interés en vez de audiencias que son receptoras pasivas. El cambio revolucionario ya ha ocurrido. La nueva tecnología ha tumbado el periodista y el editor de su posición de importancia. La nueva autoridad, el tomador de decisiones sobre el cómo, cuándo y dónde se consumen las noticias, es el usuario. Por eso, nosotros necesitamos aprender todos los métodos para conocer al usuario. Por primera vez, el periodista necesita pensar como un "marketer" (mercadólogo) y la mera mención de la palabra le da asco a la mayoría de los periodistas. Es un 
reflejo automático. Hay algo sucio en eso de hablar de mercados en una sala de redacción, un templo sacro de la búsqueda de la verdad.

Esta transición revolucionaria requiere que derribamos la muralla china que ha separado la parte editorial del periodismo de la parte comercial. Eso conlleva riesgos enormes. La muralla china existía por buenas razones. Un periodista no puede ejercer su oficio efectivamente si tiene miedo de ofender a los anunciantes, a los poderes empresariales o a los gobernantes. No puede investigar bien si se preocupa por ofender a los cuates del dueño del medio de comunicación.

Otro territorio desconocido más allá de la muralla china ha sido la medición de las actividades de los usuarios en el sitio Web. En muchos medios los periodistas y editores no prestan mucha atención a las métricas salvo el número de clics en las notas más populares del día. Los técnicos que producen los reportes no entienden la parte periodística suficiente bien para elaborarlos de manera visualmente elocuente para que los periodistas puedan entender su significado y tomar acciones eficaces.

\section{La herramienta del diablo}

Muchos periodistas consideran que las métricas son una herramienta diabólica que inevitablemente guía las redacciones a devaluar el periodismo de calidad. $\mathrm{Y}$ hay malas prácticas, como medir la eficacia de un periodista por su total de clics y dar bonos basados en medidas superficiales. Se tiene miedo de que los periodistas vayan a complacer a los gustos más bajos de las audiencias en vez de informarles. Pero hay otra manera de usar las métricas. Si nuestra nota mejor del día no genera mucho tráfico, ¿qué podemos hacer para aumentarlo? Posiblemente necesitamos hacer más gancho el titular. $\mathrm{O}$ agregar tags para atraer a los buscadores. O agregar enlaces a otros artículos relacionados. O poner el título en un lugar más prominente en cada página. O llamarle la atención de un twitero con muchos seguidores 
que ha mostrado interés en el tema. O sincronizar las entradas en las redes sociales mejor para alcanzar a la gente que busca noticias en ciertas horas del día. Etc., etc., etc. Las métricas pueden ser los aliados del buen periodismo.

Y las métricas están en flujo en este momento. Se habla más de la "attention web" en la que la métrica más importante no es el número de visitas o usuarios mensuales sino el tiempo pasado en una página y el involucramiento del usuario, que se mide por el número de "shares" o recomendaciones u otras acciones concretas que muestran algo más que un uso pasivo. La ascendencia de los móviles ha rendido menos relevantes las métricas aceptadas. Las herramientas de medición de la Web no pueden rastrear y medir toda la actividad de usuarios de dispositivos móviles en las aplicaciones. Las reglas de juego están cambiando y tanto los marketers como los anunciantes están debatiendo cómo medir esta audiencia y cuánto cobrar por la publicidad.

\section{Los periodistas se juntan a los marketers}

En el nuevo mundo del periodismo digital, los marketers y los periodistas comparten algunas metas. Ambos quieren ofrecer un producto diferente, impactante, relevante. Ambos quieren atraer a un usuario leal que pasa mucho tiempo en el sitio y se convierte en un abogado por el sitio. Ambos quieren ganar una vida de su trabajo. Ambos quieren producir algo que tiene prestigio en la comunidad. Para los marketers, un producto de prestigio e integridad es más fácil de vender y de cobrar una prima por ello. Para los periodistas, el periodismo de calidad es su razón de ser.

Por todo eso, en el periodismo digital habrá situaciones que eran impensables en la época dorada. Nunca nos hubiéramos imaginado que tanto los periodistas como los vendedores de publicidad del medio podrían sentarse juntos alrededor de una mesa para hablar de cómo conocer a la comunidad, servir a la comunidad, fortalecer y 
expandir la comunidad. Pero eso ocurre en los mejores medios y debe ocurrir. A un lado de la mesa, los periodistas están intentando crear el producto mejor para la comunidad. Al otro lado los vendedores y marketers están plasmando como monetizar la lealtad y el interés de esta comunidad. Este tipo de reuniones nunca hubiera ocurrido en la época dorada del monopolio porque el usuario no tenía opciones y debía consumir el único producto disponible aun si el contenido fuera mediocre e irrelevante.

\section{Crear una comunidad}

Fijense en que he comenzado de hablar de comunidades en vez del público o la audiencia. Realmente nuestra actividad como periodistas hoy día no consiste sólo en investigar temas de nuestro propio interés sino de pensar en cómo servir a nuestra comunidad. Ahora, sin crear comunidad el periodismo no tiene razón por existir. Si producimos cosas que no le importan a nadie y no hay comunidad, no es periodismo. Es una carta a si mismo. Si no hay comunidad, no hay posibilidad de generar ingresos para apoyar al servicio de periodismo. No hay nada. En Internet, la comunidad decide, no el periodista o el editor.

Entonces, deberemos enfrentar una serie de nuevos desafíos éticos. Debemos tumbar la muralla china. Debemos cruzar esta frontera y debemos aprender nuevas habilidades mientras que mantenemos el sentido ético que separa el periodismo de la publicidad, las relaciones públicas y la propaganda política. Es un camino peligrosísimo con amenazas inesperadas por todos lados.

La incertidumbre de esta nueva aventura épica pone a prueba nuestro coraje y resolución. Requiere mucha humildad porque debemos admitir que ya no somos los expertos. Todos somos aprendices. Para los veteranos de la academia o del periodismo, admitir que no lo sabemos es sumamente difícil. Pero debemos hacerlo y, por la rapidez de los cambios tecnológicos, debemos hacerlo frecuentemente. Otra 
razón por la humildad es que vamos a fallar una y otra vez. Pero necesitamos adoptar la actitud de los ingenieros y los científicos cuando ellos están intentando encontrar soluciones a problemas. Ellos son exploradores del mundo desconocido y por eso cuando un experimento o proceso no funciona, consideran que han descubierto algo, no que han fallado. Luego intentan algo diferente, así en adelante. Por explorar territorio desconocido, debemos aceptar que vamos a hacer errores. Hay que fallar rápida y frecuentemente, se dice en Silicon Valley. El conocimiento ganado por este proceso se llama "aprendizaje validado" (validated learning) en el lenguaje de la esbelta (lean) startup de Eric Ries, citado muchas veces por los que han contribuido a este libro.

\section{Las malas palabras para aprenderse}

Para crear nuevos medios sostenibles, necesitamos aprender un nuevo lenguaje que anteriormente rechazábamos como algo asco. Creo que necesitamos incluir estos conceptos en nuestros planes de estudios en las universidades para mostrar a los alumnos las posibilidades de crear sus propios medios.

He escrito de eso en un blog, "5 malas palabras que los periodistas deben decir sin ruborizarse". Realmente son seis.

El primero es dinero. Si queremos fundar un medio, tenemos que reconocer por primera vez que el periodismo es un negocio, que alguien tiene que pagar las cuentas y que el periodismo involucra el intercambio de dinero. ¿Dinero? Es una mala palabra para los periodistas. Nos hace ruborizar. Se lo asocia con el tráfico de influencias, grupos de presión, el soborno, la corrupción y otros temas que suelen ser cubiertos por el periodismo de investigación. Pero el dinero es también el combustible de cualquier medio de comunicación. Sostiene el buen periodismo.

Otras malas palabras que los periodistas tendrán que aprender a decir sin ruborizarse: 
1. Negocio. El periodismo es un negocio. Sí, es un servicio público, pero es también un negocio. Si no fuera un negocio, los periodistas no podrían ganar un salario. Ahora que no es tan buen negocio como solía ser, los periodistas están dándose cuenta de que ellos mismos pueden hacerlo mejor que sus empleadores.

Consejo: Inicie su propio medio de comunicación, hágalo en línea a bajo costo y cree algo que sirva a su comunidad.

2. Mercadeo (marketing). Esta es la disciplina de identificar las necesidades y aspiraciones de un público objetivo, de crear un producto para servir a ese público y de hacerle llegar mensajes convincentes sobre el producto. El marketing nos ayuda a alcanzar y servir a más gente y servirle mejor. En su forma más básica, esta mala palabra significa conocer a sus clientes o lectores, satisfacer sus necesidades y ayudarles a solucionar los problemas de sus vidas.

Durante el pasado medio siglo, los periodistas hemos vivido en una burbuja, aislados de los lectores. Algunos de nosotros suponíamos que el público tenía la responsabilidad cívica de leer nuestros artículos aun cuando prestábamos poca atención a escribirlos bien. Con demasiada frecuencia escribíamos para impresionar a nuestros colegas o al pequeño círculo de nuestras fuentes.

La parte comercial de los periódicos funcionaba independientemente de la parte editorial y producía unos márgenes de beneficio excepcionales, incluso cuando escribíamos artículos aburridos, irrelevantes y mal investigados. No existía la competencia de decenas de miles de páginas web.

Esta mala palabra - mercadeo - significa escuchar a los lectores para entender sus necesidades y sus aspiraciones, tratarlos con respeto y encontrar maneras de servirles.

Herramientas como Google Analytics proveen una base estadística para conocer a los lectores. 
Consejo: Aprenda a medir su lealtad. Descubra las comunidades en dónde viven los lectores de su sitio web. Vea cuánto tiempo por visita pasan los diferentes públicos y cuáles son los contenidos preferidos, etc. No hay que complacer a la comunidad sino conocerla para servirle bien.

3. Ganancias (beneficios, utilidades). Incluso en una empresa de noticias sin fines de lucro, hay que gastar menos de lo que se genera. Si usted no está cubriendo sus gastos, no puede pagar los salarios, las prestaciones, el web hosting, la luz, los equipos informáticos, el transporte, el combustible, el alquiler, el teléfono, el agua...

Los periodistas emprendedores tienen que aprender la disciplina de controlar los ingresos y los gastos para generar beneficios.

La palabra "beneficios" no es una mala palabra, a pesar de que mucho del periodismo de investigación se centra en las personas que obtienen beneficios inmerecidos a través de la corrupción. Los beneficios son buenos cuando son justamente ganados. Permiten el mejoramiento de su producto para servir mejor a su comunidad. No hay nada sucio en eso.

Consejo: Aprenda lo básico de contabilidad. Hasta los especialistas en literatura (como yo era) pueden bacerlo.

4. Cliente (lector, usuario, suscriptor) - Esta es la persona que presuntamente se beneficia del periodismo que el medio produce. El cliente utiliza la información para tomar decisiones informadas acerca de los negocios, la salud, las elecciones, el medio ambiente, la educación, el entretenimiento, la vivienda, los juegos de computadora; las posibilidades son infinitas en el mundo online de las publicaciones de nicho.

Los periodistas tienden a hablar de los lectores en abstracto, pero 
ahora, con el surgimiento de las redes sociales, tenemos herramientas para interactuar con nuestros lectores y descubrir lo que realmente les importa.

Consejo: Conozca a sus lectores y usuarios y bájese del púlpito para tener una conversación con ellos en las redes sociales.

5. Anunciante (patrocinador, auspiciador) - Esta es la persona o institución que compra la publicidad u otro servicio del medio de comunicación. Los mejores clientes entienden las reglas de juego, es decir que la compra de un patrocinio o la publicidad no les da una voz en el producto editorial.

Mi consejo es poner esas palabras en el contrato y revisarlo en detalle con el cliente potencial. Podría ser algo así: "Dado que el valor de nuestro medio a los lectores, los anunciantes y los patrocinadores depende de la credibilidad, no vamos a permitir que cualquier cliente la ponga en peligro por intentar ejercer una influencia inmerecida en el producto editorial". Al mismo tiempo, una organización de noticias tendrá que ser más transparente que en el pasado acerca de los procesos de redacción y cómo se hacen las decisiones editoriales.

A menudo a los periodistas les resulta difícil manejar la relación con los anunciantes porque en los medios tradicionales no tenían nada que ver con ellos. La parte comercial del medio manejaba todo eso. Pero en el mundo digital, los periodistas deben conocer a la audiencia y su atractivo a los clientes. Deben identificar oportunidades para la parte comercial. Creo que los editores pueden ser los mejores vendedores de un medio de comunicación, ya que pueden describir el valor del producto mejor que nadie.

Consejo: Reúnase con algunos posibles patrocinadores y anunciantes, y explíqueles cómo la integridad editorial del medio podría reforzar su propia marca, ya que el estar asociado a un medio de comunicación de prestigio le da credibilidad. 


\section{E1 buen periodismo es un buen negocio}

Si usted comienza su propio medio de comunicación, es muy probable que un día tendrá que decirle "no" a un anunciantepatrocinador.

Cuando yo era jefe de redacción de Business First de Columbus, nuestro periódico publicó una investigación sobre las manipulaciones de un gran banco que buscaba que el gobierno del estado de Ohio se hiciera cargo de la hipoteca de un edificio de oficinas sin inquilinos y mudara sus empleados allí.

Para el banco habría sido una buena solución a un mal proyecto. Para el estado de Ohio y los contribuyentes, habría sido un mal negocio. El artículo hizo que las negociaciones colapsaran. El banco, nuestro mayor anunciante, canceló su contrato.

La reacción de la directora general del medio, Carole Williams, fue ejemplar. La pérdida del contrato y los ingresos nos dañará, dijo, pero no como para requerir recortes del personal. Tuvimos otros anunciantes. Este tipo de investigación reforzó nuestra credibilidad e hizo que otros anunciantes quisieran ser asociados con nosotros, dijo. En otras palabras, el buen periodismo era un buen negocio. A su vez, la rentabilidad salvaguardaba nuestra independencia editorial.

En este momento, el buen periodismo no siempre es un buen negocio, porque la profesión y la industria están luchando por redefinirse. Sin embargo, estoy seguro de que los periodistas pueden añadir nuevas palabras a su vocabulario sin comprometer su integridad. Los periodistas que aprenden a transformarse en emprendedores con habilidades y conocimientos comerciales van a definir el futuro de la industria. No sentirán ninguna vergüenza al pronunciar estas nuevas palabras. 



\title{
El nuevo ecosistema periodístico
}

\author{
JL Manfredi Sánchez CV • - Orcid G GS Profesor Contratado
} Doctor. Facultad de Periodismo. Universidad de Castilla-La Mancha (España) juan.manfredi@,uclm.es

$\mathrm{B}$ ASTA DE DUELO. Ya sabemos que el periodismo ha padecido la tormenta perfecta. La industria ha soportado la concatenación de cuatro crisis, que han mutado el ecosistema periodístico para siempre. La crisis ha devorado la publicidad en cualquiera de sus formas y ha detraído el consumo. En términos absolutos, la venta de espacios y otras fórmulas publicitarias ha caído el $60 \%$ y esa desinversión no va a volver. Se ha instalado en otros formatos, otros espacios y otros jugadores de la industria de la comunicación, la publicidad y la cultura. Sí, también en Google, Apple, Facebook, Twitter o Amazon.

La empresa periodística industrial no ha sabido adaptarse al ritmo de la innovación tecnológica. El dato más relevante lo aporta la OECD en un estudio de corte económico. La impresión representa el 28\% del coste, mientras que las ventas y distribución, el 24\%. Así, el 52\% de los costes son asociados al papel, aunque no haya podido incrementar sus ratios de beneficio. Esa estructura de costes es inviable en un escenario de móviles, tabletas y dispositivos digitales. La disrupción era esto. 
El epítome del cambio de paradigma es la venta de The Washington Post a Jeff Bezos, creador de Amazon. Se presume el ocaso de las familias fundadoras. En un mercado global y competitivo, los grandes diarios se han reconvertido en multinacionales que cotizan en bolsa. Liberty ha adquirido PRISA en España. En Estados Unidos, la inyección de capital del grupo inversor de Carlos Slim en The New York Times representa ya el 6,4\% del accionariado.

La tercera dificultad es la pérdida de la misión del periodismo. En sociedades abiertas y democráticas, consiste en publicar informaciones veraces y relevantes para el interés público con el objeto de consolidar el desarrollo económico, político y social. No depende del soporte tecnológico, sino del ejercicio de preguntar a quien tiene el poder, de verificar fuentes y datos, de contrastar la información y de respetar a los lectores. Si ésta es la definición, sobran los comentarios.

El cuarto elemento es el conflicto en las redacciones, la amenaza interna. Los malos resultados económicos han provocado numerosos despidos, el empeoramiento de las condiciones de trabajo y el abandono de profesionales. El talento se ha perdido y, con él, la experiencia. A cambio, tenemos becarios, redactores a tiempo parcial y colaboradores a la pieza. El periodismo profesional requiere experiencia, recurrencia, tiempo y credibilidad. Si no hay convivencia entre jóvenes y veteranos, se pierde la memoria institucional, el mayor activo del periodismo profesional en palabras de David Simon, creador de The Wire.

Ahora sabemos que 2007 fue el último año de la época dorada del periodismo contemporáneo. $\mathrm{O}$ del periodismo industrial, si preferimos la terminología clásica. Pero también es el primer año de una nueva edad de oro del periodismo emprendedor. Todo depende de cómo queramos enfocar y dónde queramos poner el acento. Este libro pretende abordar el periodismo emprendedor como una auténtica oportunidad para poner en marcha proyectos alternativos, alejados del modelo convencional y sostenidos en el sistema digital. 


\section{Elementos del periodismo emprendedor}

Desde 2008, la radical transformación de la industria ha conducido a la aparición de nuevas iniciativas periodísticas. Son innovadores porque en vez de intentar mantener el actual modelo analógico, los nuevos proyectos son de naturaleza digital, lo que significa más flexibilidad, dinamismo y velocidad en la capacidad de adaptación al cambio. La variedad y la diversidad de empresas nacidas en el nuevo entorno comprende información generalista, información especializada, ediciones digitales, propuestas híbridas, mezclan el periodismo escrito convencional con el audiovisual. Todos los formatos y modelos están presente en este periodo expansivo: no hay patrones de viabilidad, estructura o inversión. Antes al contrario, cada iniciativa responde a las características personales de sus fundadores.

Por eso, en las Facultades de Periodismo, debemos estar abiertos a esta propuesta empresarial que combina la innovación, el periodismo, el negocio y la tecnología. No es necesario replicar los viejos modelos del periodismo industrial ni son necesarias las inversiones multimillonarias, sean de naturaleza empresarial o filantrópica. Con una inversión mínima, los graduados en Periodismo pueden competir en el mercado de la información. El perfil responde a las empresas creadas en España, si bien un análisis internacional nos refleja unas ideas parecidas, adecuadas por supuesto a un entorno dado. Es la segunda razón que nos anima a la internacionalización de la docencia y la investigación en el emprendimiento periodístico. En tercer lugar, aparece la idea de crear y acceder a los mercados globales del idioma. El español, su lengua y cultura, se consolida como un idioma global. La suma de España, México, Colombia, Brasil, Estados Unidos y el norte de Marruecos da una idea de las posibilidades de un periodismo internacional en lengua española.

A mi entender, encontramos cinco ejes sobre los que pivotan los proyectos periodísticos de nueva planta. Son los siguientes: la naturaleza de la propiedad empresarial, el entorno digital y móvil, la marca personal de los periodistas al servicio del proyecto y de la 
información, la transformación de la propuesta de valor y el empleo intensivo de herramientas vinculadas a las nuevas narrativas.

En relación con la propiedad, hay que señalar que los dueños del nuevo periodismo son los propios periodistas y otros inversores alejados de la industria convencional. Resulta que muchos periodistas han tomado el dinero de los despidos para apostar por proyectos propios, por aquello que les apetecía y nunca podía ser "por razones editoriales". Ahora, y dentro del marco legal, muchos periodistas han aprovechar la indemnización para capitalizar un nuevo negocio. Un ejemplo recurrente es Lamarea.com, una cooperativa creada por periodistas procedentes del diario Público. Cada miembro ha contribuido con un capital inicial de 1.000 euros. Tal decisión les convierte en propietarios del medio. Además, han abierto la propiedad a los lectores que pueden convertirse en accionistas. Otro ejemplo reciente es Alternativas Económicas, también fundado por ex empleados del diario Público y con una filosofía parecida.

La propuesta empresarial es realmente seductora. Se trata de recuperar el ideal del fundamento de la empresa: la idea empresarial y la idea social, fundamental en la misión del periodismo profesional, son respaldados por la persona física y la jurídica. Empresario, directivo y propietario se alinean en el proyecto de forma más visible que en los proyectos de la etapa industrial. En suma, la organización, la ejecución y la toma de decisiones recuperan su matriz periodística. Los riesgos y los beneficios de la actividad empresarial no dependen ahora de otras actividades económicas (derechos audiovisuales o salidas a Bolsa), sino de los productos y servicios periodísticos.

La segunda pieza es la apuesta por el modelo digital. Hasta ahora, los diarios digitales habían sido creados como subproductos de una cabecera en papel, que determinaba los temas, los tiempos de producción y las entregas. Este modelo de producción periodística genera costes elevados (distribución, promoción y ventas) que ahora son difíciles de cubrir. La apuesta digital utiliza, además, las herramientas que le son propias, como las licencias de Creative Commons. Eldiario.es emplea la licencia más abierta que permite 
copiar, difundir y remezclar los contenidos en Internet siempre que se mantenga la misma licencia, se cite la fuente y se enlace al original. Este posicionamiento es el opuesto a la denominada "tasa Google" y similares, que pretende el pago por el uso de la información dispuesta en las redes. El negocio del emprendimiento periodístico no está en recoger beneficios procedentes de los buscadores, sino en la fidelización de los lectores, la estimulación de la demanda y la difusión de sus contenidos.

La segunda variable es la apuesta móvil. Con un parque móvil en fase expansiva, la consolidación de la plena conectividad y la normalización del uso de los teléfonos inteligentes, los nuevos proyectos crean aplicaciones y soluciones nativas. El valor añadido depende de la naturaleza del servicio. Puede ser la comodidad, la innovación, la comercialización o la creación de una comunidad de usuarios. El proyecto periodístico persigue al lector allí donde se radica. No se trata, pues, de una versión para el móvil, sino de un producto pensado para ser digital.

El tercer elemento es el auge de la marca personal del periodista. Sin capital social, no hay marca personal por lo que estila la conexión con la comunidad y el entorno en el que se opera. Es una suerte de recuperación del compromiso cívico del periodista. Las redes sociales rompen las barreras de la redacción y permiten la promoción de los contenidos propios y ajenos. Se pueden compartir de forma rápida, en tiempo real. Esto genera una audiencia fiel, probablemente un nicho que se puede rentabilizar en términos económicos. Como estrategia general, el periodismo emprendedor abandera la defensa de la identidad digital como una actualización de la firma.

El cuarto punto es la propuesta de valor. La empresa periodística requiere pensar de nuevo cómo se generan los ingresos. No vale el timo del todo gratis, sino que es necesario establecer una nueva relación entre las audiencias, los mercados publicitarios y las empresas periodísticas. Hay multitud de fórmulas que parecen dar resultado. Eldiario.es ha apostado por el freemium, una mezcla de publicidad y de suscripciones. Como resultado, el modelo no levanta un muro de 
pago al uso ante los contenidos, sino que prima a aquellos lectores/socios que se implican y contribuyen económicamente con el proyecto. Otras iniciativas periodísticas han descubierto el filón de la formación y la consultoría. ¿Por qué no enseñar a nuestros potenciales clientes qué se puede conseguir en el entorno digital? Así lo piensan tanto en Yorokobu, revista especializada en diseño y cultura digital, que además realiza marketing de contenidos y revistas corporativas. El periodismo hiperlocal ha apostado por esta fórmula en gran medida en tanto que muestra a su tejido empresarial contiguo cómo desenvolverse en las redes sociales. También hay espacio para el crowdfunding y otros métodos innovadores. España en Llamas o Via 52 han empleado este sistema para financiar proyectos.

La quinta característica es la creación de nuevas narrativas. Los nuevos proyectos han utilizado la visualización de los datos, la infografía, el análisis de los big data y otras herramientas innovadoras para captar la atención del lector. No procede el texto lineal o la supeditación de los contenidos al estilo de la cabecera de papel. Sin esas barreras, los periodistas han transformado y mejorado los productos, al tiempo que han dedicado más recursos al diseño.

El periodista tiene que conocer varias facetas de su trabajo para que éste salga adelante. Por un lado, tiene que volver a los fundamentos del periodismo profesional: hay que publicar información veraz y de interés público, alejándose de los confidenciales y los rumores. Hay que poner el acento en la información (datos, hechos) antes que en la opinión. En mi opinión, crece el rol del periodista como contextualizador, una función que consiste en ser capaz de contar las historias, pero además de explicar por qué son urgentes, importantes o relevantes para el interés público. Así, cambia la función, la forma y la narrativa.

En la práctica, el periodista ha ampliado su catálogo de tareas. Es ahora también un redactor para nuevas redes (Twitter, redes sociales y otros instrumentos como los lectores de RSS), así como un editor, que dirige su propio sitio web, que escribe de forma regular en uno o dos blogs, que mantiene contacto con las redes de lectores y que 
difunde sus propias historias en red. Con estas nuevas funciones, el periodista se resitúa en la cadena de valor. No basta con redactar (bien) un texto de interés para la audiencia, sino que además hay que poner el énfasis en la verificación y en la interpretación. Ante el caudal de información que fluye en Internet y los nuevos medios, la tarea del periodista tiene que orientarse hacia la capacidad de organizar dichos flujos.

\section{Innovación y emprendimiento en la Facultad}

¿Y ahora qué? El periodismo es una actividad innovadora que requiere una permanente actualización. El despiece persigue orientar el trabajo en clase, con el alumnado, de modo que los elementos que vertebran el periodismo emprendedor estén recogidos. Estos elementos son los siguientes: periodismo, tecnología, emprendimiento y libertad de expresión. Por su dinámica, deberemos adaptar y actualizar la propuesta a cada contexto.

La metodología que empleamos en la Facultad de Periodismo de la Universidad de Castilla-La Mancha es resultado del la práctica, la investigación y la innovación docente. En este ámbito, el proyecto "La web social en la planificación y la evaluación del trabajo de fin de grado", se ha desarrollado en la Facultad de Periodismo de la Universidad de Castilla-La Mancha en el curso 2012/2013. En el mismo, se planteaba cómo la redacción del trabajo de fin de grado no escapa a la constelación de cambios y es contingente innovar en la forma de diseminar los resultados y mejorar la visibilidad de los proyectos. La cuestión reside en cómo se pueden aprovechar las herramientas de la web social para la mejora de los resultados académicos y la empleabilidad del graduado. En el plano investigador, la metodología bebe del seminario "Periodismo emprendedor, una esperanza renovada" celebrado en la misma Facultad en junio de 2014. El propósito es, pues, conocer el estado del arte, la naturaleza de estos proyectos, su dispersión geográfica, su tipo de especialización y la estructura y viabilidad de los mismos. En el ámbito más teórico del emprendimiento, la propuesta de trabajo bebe del lean startup. Hay que aligerar el emprendimiento y convertir la 
innovación en algo ágil, esbelto. Lean significa ser capaces de tener una visión, un mapa de tesoro que señale dónde está la X. En síntesis, se trata de capturar el modelo de negocio y no solo el plan de resultados en la hoja de cálculo

Como fruto de estos trabajos, hemos definido diez elementos para pensar el proyecto de emprendimiento periodístico. Se cursa de manera obligatoria en "Sistema de medios", la materia de Tercero de Periodismo que explica los fundamentos de empresa periodística, y en "Periodismo digital", también en Tercero. En éste u otro orden, el trabajo de clase ha de responder a las preguntas que planteamos para que conozca las dimensiones del negocio, para que entienda las dificultades del empleo por cuenta propia y para que acerque el resultado final a la realidad. Por su condición, se pueden adaptar a otras disciplinas vinculadas a la comunicación y las profesiones liberales.

Se pueden plantear dos itinerarios de trabajo para el trabajo con el alumno. El primero consiste en la creación de una revista especializada. Consiste en un ejercicio muy interesante en la medida en que supone la puesta en marcha de un medio completo. Tiene que definir muy bien cuál es el público objetivo y qué necesidades se pretenden cubrir. No se aceptarán revistas generalistas o sin interés periodístico. El segundo itinerario pasa por la creación de un medio hiperlocal. La recuperación del periodismo local es una constante del periodismo emprendedor. Frente a la crisis de la prensa local tradicional, el periodismo emprendedor ha demostrado que existe un nicho de mercado interesado en conocer la realidad cotidiana y cercana. Tal oportunidad responde, en cada contexto, a un modelo concreto de periodismo hiperlocal. En grandes ciudades, como Madrid o Barcelona, la proximidad se ha concretado también en medios de barrio o zonas residenciales.

Los diez puntos son los siguientes.

1. La descripción del producto, del bien o del servicio periodístico. ¿En qué consiste tu proyecto? ¿Es una revista, un diario o un 
blog? Cuanto más acertada sea la definición, mejor podremos afinar los siguientes pasos. Es recurrente que el portavoz del grupo te responda: quiero hacer la revista que no encuentro en el quiosco. Pues adelante. Si eres capaz de dar con un grupo de personas interesadas como tú en "ese" tema, tendrás una publicación líder. La descripción tiene que ser intensa, apasionada y real. La descripción contribuye a delimitar los temas, las responsabilidades y las funciones de cada miembro del equipo. También ayuda a dimensionar el volumen económico de inversión que se necesita. Quizás, el elemento que el profesor ha de vigilar con especial atención es la visión. Interesa el periodismo antes que el negocio y se resume en la pregunta clave: ¿por qué alguien leerá tu revista o verá tu programa?

2. La enumeración de las necesidades sociales que cubre. El proyecto tiene que mostrar y ser capaz de explicar por qué es necesario un nuevo diario generalista en papel o bien qué aporta un diario deportivo. No hay que poner en duda que existan estas o aquellas necesidades, pero sí es preceptivo dotarse de datos. Las encuestas, los estudios de opinión pública, las noticias en prensa o el olfato empresarial pueden ayudar. Pero si no el proyecto no acota las necesidades, le auguro poco futuro. Las necesidades son reales y aún hay grandes oportunidades en el periodismo. Otra cosa es que esos proyectos sean fáciles o que se pueda acometer la empresa de fundar un diario generalista en papel que sea sostenible. Entre las funciones a cubrir por los proyectos encontraremos los servicios informativos, documentales, recreativos o ocio

3. La ventaja competitiva. Dos caminos aparecen en el bosque: precio o calidad. Hay que definirse uno mismo y precisar en el proyecto cómo se mide la calidad, qué efectos tiene en la producción, cómo afecta a la contratación o la demanda de profesionales o cómo se eligen los temas y los enfoques. La experiencia nos indica que es muy complicado estar a medio camino de las dos variables. Ambas ventajas son ganadoras cuando empezamos el proyecto, pero hay que llevarlas hasta las 
últimas consecuencias. En mi opinión, la gratuidad deja poco margen de maniobra, es replicable y reduce los ingresos sin razón justificada. La calidad, por el contrario, es más compleja porque exige comprender bien qué espera el lector de nosotros y cómo se lo proporcionamos. No obstante, hay que trabajar en las tutorías la idea de calidad en tanto que se percibe como un abstracto ("mi proyecto es de calidad") y no como una función de la empresa que se mide, se gestiona y se concreta.

4. Los principios editoriales son el fundamento del proyecto. Probablemente, son ese indicador inicial de calidad y la palanca que permite aterrizar el proyecto. ¿Sabes ya qué temas irán en portada, cuáles no aparecerán nunca o qué tipo de lenguaje vas a emplear? No se trata de exigir un manual de estilo antes de empezar, pero sí es recomendable leer algo sobre el tema. Recomiendo aquí trabajar con los libros de estilo consolidados, conocer los códigos deontológicos, promover el uso correcto del lenguaje y otros principios de producción periodística.

5. El pacto de lectura asegura un proyecto editorial con vocación de estabilidad, permanencia y publicidad, una posición ante los grandes temas y un marco de trabajo para los redactores. Se entiende que el lector conoce el pacto, lo que facilita la identificación con los contenidos que se publican. Sobre esos principios se cimenta el pacto, que puede ser un elemento que ayude al lector a saber qué tipo de publicación estamos elaborando.

6. En tutorías de grupo, puedes plantear tres preguntas como lector tipo. La primera es la utilidad de la información que se oferta. La segunda es la periodicidad y su combinación con el ritmo de vida del lector tipo. La tercera parte es la profundidad periodística de los contenidos. Se plantean entonces varias preguntas al trabajo del estudiante: ¿Cómo quieres que te vea el lector? ¿qué le vas a ofrecer? ¿qué normas vas a seguir? ¿qué criterios se siguen? El pacto de lectura consiste en la relación que se establece entre el 
autor de un texto y su lector. Si tienes las respuestas, puedes continuar.

7. El nombre comercial. Importa, sí. Y mucho. Ya existe El País o Marca, pero nadie había registrado eldiario.es Es relevante para la dirección comercial, para la comunidad lectora, para el SEO y para todos. Dedícale unos minutos, mira si existe algo parecido en Latinoamérica o piensa en todas las connotaciones posibles. Vale la pena y, además, es irreversible.

8. Formato. No es igual un berliner que una sábana que un tabloide. En la web, no es igual un diseño que otro. Sucede lo mismo que las tabletas o en los móviles. Todos son legítimos, pero afectan sustancialmente al producto periodístico. Ve al quiosco. Compra todo tipo de periódicos y revistas españolas y extranjeras. Poco importa que no hables el idioma. Mira cómo se distribuyen los contenidos. Solo después de hojear y ojear 50 medios podrás saber bien qué tipo de formato conviene a tu proyecto.

9. Planillo (o escaleta). ¿Puedes mostrarme el primer programa o el número cero? Quiero ver cómo se distribuyen los contenidos, las imágenes y la publicidad. ¿Abrimos con deporte o con economía? ¿Habrá una entrevista diaria en la contraportada? Seguro que es aleatoria la decisión que tomes. Me gustaría ver en tu proyecto ese primer número... es la única manera de plasmar las ideas y convertirlas en realidades. $\mathrm{Y}$ ya se sabe: las ideas cuestan un euro, pero los desarrollos, un millón.

10. Contenidos. Aquí hay que mojarse aún más. La producción periodística permite el largo plazo, la elaboración de contenidos interesantes para el lector y el ajuste de éstos a una fecha de calendario. El mejor periodismo, como el teatro, es el que se improvisa después de horas y horas de preparación. Al final del semestre, hay que enseñar los contenidos reales del número de cero. Los contenidos tienen que estar listos para ser publicados. 
11. En nuestra Facultad, empleamos la revista El Observador para apalancar los proyectos. Una iniciativa de periodismo emprendedor tiene que basarse en una oferta concreta de productos y servicios periodísticos. Vamos a ofrecer algo que nos haga diferente y luego pensaremos en la financiación o la forma legal de la empresa. A menudo, sucede que uno tiene en la mente un plan de negocio que no responde... pero seguro que sí responde un modelo de contenidos.

12. Mención especial merece el empleo de imágenes y vídeo dentro de los criterios de publicación. Las nuevas narrativas exigen el uso de infografía, representación gráfica y visualización de datos con el ánimo de contar historias periodísticas. No basta con una diapositiva, sino que se persigue el gráfico explicativo por sí solo, contextual o de apoyo a textos.

13. Características técnicas del proyecto. La tecnología repercute en la organización del trabajo y en el soporte. Cuando ya hemos definido el proyecto editorial y la propuesta de valor, toca ponerlo en marcha y decidir si las fotografías son en blanco y negro o en color, la resolución de las mismas, si optamos por un diseño que premie la tableta sobre la web o viceversa, si los colores corporativas son éstos o aquellos, si queremos que el papel sea satinado y todo ese lío técnico que es fundamental para el proyecto salga adelante. Repito una idea recurrente: puede que no sepas programas o diseñar, pero no tienes que entender de qué va esto. Solo así podrás sacar adelante el proyecto. La primera idea fundamental para su trabajo en la tutoría personalizada es la selección del soporte. No vale con la teoría. Hay que escoger una tecnología concreta y comprobar si se ajusta a las necesidades del proyecto.

14. El discurso se completa con la selección de normas para la elección del formato, el acuerdo sobre los tipos y las familias de letras, la presentación de los titulares, la selección de imagen, el uso de color o blanco y negro, la distribución de las secciones o los criterios de admisión de publicidad. 
15. Las personas importan; las tecnologías y los objetos, no. Incentivar y promover el emprendimiento periodístico no puede hacerse con las puertas cerradas. Hay que abrir el aula a nuevas disciplinas, conectar con las escuelas de ingeniería y las facultades de administración de empresas, invitar a profesionales y conectar con los actores sociales (cámaras de comercio, centros de emprendedores). Solo así podremos conseguir que nuestro alumnado entienda que la vida es rica, diversa y dispersa. De ahí, de esa confusión de ideas y personas, puede salir un buen proyecto. 



\title{
Innovación radical en los estudios de periodismo
}

\author{
José Manuel Noguera Vivo
}

\section{Introducción}

$\mathrm{D}$

ECÍA EL GURÚ de la creatividad y la educación, Sir Ken Robinson, que enseñar no es una simple manera de transmisión de conocimientos sino una forma de arte, relacionado con el juicio y la intuición. "No sé cuándo empezamos a confundir enseñar con FedEx", resumía. A la crítica no le falta razón si nos detenemos a observar el paulatino proceso de burocratización de la universidad. Bajo este proceso, el profesor parece una mera pieza, sustituible por otra en cualquier momento, que se dedica a transmitir conocimientos y competencias, reflejados a priori en unos "resultados del aprendizaje". Pero si fuera así de simple no se explicaría que pasados unos años nos cueste incluso recordar el nombre de las asignaturas mientras que, por el contrario, nunca olvidamos el nombre de aquellos profesores que nos enseñaron a ver las cosas desde una óptica diferente.

Como la propia profesión, la docencia del periodismo se enfrenta a un momento de incertidumbre marcado por la convergencia de tecnologías, modelos de negocio y narrativas. En este punto, los mayores desafíos docentes oscilan entre evitar una utopía marcada por el determinismo tecnológico de alabar siempre lo nuevo y las 
reticencias a desprenderse de las herencias, narrativas y estructurales, marcadas por los medios tradicionales.

A su vez, el profesor de periodismo no es ajeno al proceso general de burocratización de la enseñanza universitaria, donde cada vez se dedica más tiempo a la elaboración de informes sobre mejora de la enseñanza y menos a la preparación de esa enseñanza. En otras palabras, se confunde el diseño de competencias y propuestas de mejora con la mejora efectiva de la docencia.

Este capítulo pretende ofrecer soluciones a la docencia de una disciplina marcada tradicionalmente por la dicotomía que originan las tensiones no solo entre viejos y nuevos medios periodísticos, sino sobre todo entre formas tradicionales de enseñar periodismo y otras más innovadoras. Se ofrecerán pistas, consejos y métodos para innovar en la docencia del periodismo. Una innovación que estará marcada sobre todo por la recuperación del optimismo, la exploración y la búsqueda del valor diferencial que puede tener el periodismo frente a la docencia de otros estudios universitarios.

Así, pretendemos ofrecer diez pistas donde pensamos que cualquier profesor de periodismo podrá encontrar recursos e ideas para mejorar en sus clases. Estas pistas proceden de la reflexión, la investigación en el área y sobre todo, de diez años de experiencia docente en la universidad, siempre en asignaturas del área de periodismo vinculadas a las tecnologías de la información, la innovación y los nuevos medios.

\section{Innovación gracias a nuestros ex alumnos}

Existen muchos puntos donde los profesores podemos poner nuestra mirada para buscar y encontrar posibles vacíos en nuestra docencia. Uno de ellos es sin duda la trayectoria de nuestros alumnos una vez que acaban el Grado en Periodismo. Tanto aquellos que se ubiquen rápidamente en el mercado laboral como los que opten por continuar con estudios de postgrado o especialización constituyen una inestimable muestra involuntaria de cómo les acoge el mercado. A su vez, en las elecciones de los que optan por seguir estudiando vamos a encontrar una información valiosa sobre cómo siguen enriqueciendo su currículum. 
¿Por qué optan por ese curso de postgrado en particular? ¿Han notado poca formación en un área concreta o fue precisamente gracias a una asignatura que despertó su interés sobre el tema? Detalles como seguir en la distancia a nuestros egresados a través de las redes sociales nos puede permitir obtener esa información tan relevante sobre su formación de postgrado.

Materias como el periodismo de datos, la ciberdemocracia o el marketing digital son ejemplos de temas donde un egresado en periodismo puede tener grandes motivaciones para especializarse. La periferia del periodismo es rica en matices y los años de carrera no suelen ser suficientes para abordar el carácter tan multidisciplinar de un mercado en constante transformación y al que se enfrentan nuestros alumnos.

Por otro lado tenemos un incipiente número de alumnos que al acabar trabajarán de inicio en medios creados por ellos mismos. ¿Cuántos de ellos necesitarán hacer a corto o medio plazo una ampliación de capital? ¿Cuántos sabrían hacerla? ¿Deberíamos enseñar en periodismo cómo se plantea una ampliación de capital? ¿Y cómo se busca un business angel?

La monitorización de su formación tras la carrera, así como los perfiles profesionales de nuevo cuño que se están originando en ese mercado nos ofrecen pistas para enriquecer nuestros contenidos docentes y enfoques.

Nuestros alumnos suelen ser conscientes del camino que deberán transitar tras acabar la carrera. No son buenos tiempos para el periodista pero esta profesión puede que nunca haya tenido buenos tiempos (y ahí radique parte de su encanto). Aún así, los mejores alumnos son aquellos que saben transformar los retos en oportunidades y los que obtienen de cada experiencia un aprendizaje. Es especialmente a este perfil de alumno al que debemos seguir el rastro. Como decía una de mis alumnas, con motivo de la obtención de su primer contrato real tras cinco años como becaria: "No todas las etapas han sido apasionantes ni tan gratificantes como otras pero, gracias a ello, he aprendido a adaptarme a las situaciones concretas de cada empresa y a cada puesto de trabajo". En la vida a veces se gana y 
otras se aprende, se suele decir. Nunca podremos simular la realidad en el aula pero, con el seguimiento de quienes ya están dando sus primeros pasos en la profesión, podemos anticipar situaciones y experiencias para que los todavía alumnos se preparen mejor para un camino tan difícil de transitar como apasionante.

\section{Innovación en las ofertas laborales}

Como recordaba la periodista Delia Rodríguez en su blog, en un artículo que cualquier alumno de periodismo debería leer antes de acabar la carrera ("Consejos que me hubiera gustado recibir cuando estudiaba periodismo", 12 de noviembre de 2013), el mercado de las ofertas laborales en el periodismo es "invisible, subterráneo, injusto, basado en contactos y muy difícil de atacar desde fuera".

Y reflejo de ese carácter invisible y opaco son las facultades de Comunicación, en las que periódicamente recibimos ofertas laborales de compañeros que trabajan en medios y que preguntan por perfiles muy determinados.

Estas ofertas también nos están ofreciendo una información valiosa sobre las necesidades del mercado. Recientemente, en una de esas ofertas, una empresa nos pedía alguien que "manejara redes sociales, supiera SEO, SEM y planificar campañas en Internet". Se trata de un perfil específico por un lado pero tan amplio a la vez que podría ser candidato cualquier alumno de las diferentes ramas de Ciencias de la Comunicación. ¿En qué medida estamos formando a nuestros alumnos en las destrezas y habilidades que ya nos está demandando el mercado de forma explícita?

\section{Innovación en el contenido}

No podemos obviar una innovación que se presupone a cualquier profesor: la actualización y mejora de sus contenidos. Como apuntaba el Instituto Poynter en un reciente informe sobre las competencias del periodismo, existe toda una pirámide de conocimientos que aún no tienen suficiente presencia en los planes de estudio. Y en contra de lo que podría pensarse, no se trata exclusivamente de materias vinculadas a las nuevas tecnologías. 
Según Poynter, el fomento del pensamiento crítico, de educación cívica, de tecnología (en un sentido amplio, no instrumental), aritmética, cultura o storytelling, entre otras, son áreas que deberían abarcarse desde la enseñanza del periodismo.

Investigación, gestión de datos, estrategias narrativas, diseño, aplicaciones móviles, uso de buscadores, estadística, modelos de negocio... ¿podría decirse que alguno de estos ámbitos no son en la actualidad poco menos que imprescindibles para ejercer el periodismo?

\section{Innovar en la evaluación}

Tras la innovación en los contenidos, el paso siguiente obligado radica en la mejora de las formas de evaluación. A menudo se confunde el concepto de "evaluación continua" con el hecho de ponerle calificación a todas y cada una de las actividades del alumno durante el curso. Pero esto, además de situar al profesor con una carga de trabajo difícil de gestionar, plantea una tensión innecesaria al alumno, que fruto de la fiscalización constante puede caer en el error de poner su foco más en la nota obtenida que en el aprendizaje.

Se habla mucho de la investigación colectiva entre universidades, al igual que de una investigación más cercana a la industria, pero ¿por qué no plantear también una evaluación inter-universitaria y en colaboración con profesionales? Son ya varios los profesores que, en asignaturas vinculadas a proyectos, realizan (parte) de la evaluación de dichos proyectos con tribunales formados por colegas de otras universidades, profesionales de los medios o, por qué no, una mezcla de ambos. Los beneficios para el alumno son evidentes. De repente, se enfrenta a una situación nueva: no me evaluará mi profesor, sino un agente externo. Cuidado.

\section{Innovar en la actitud}

Como decíamos al inicio, debemos ser optimistas. En primer lugar porque es una obligación nuestra como profesores (no somos mejores docentes por pintar el panorama negro). Y en segundo lugar, porque tenemos motivos para serlo. 
Según el listado que mantiene la Asociación de la Prensa de Madrid, entre enero de 2008 y mayo de 2014 se crearon más de 400 nuevos medios de comunicación, la gran de mayoría de ellos nativos digitales, sin un referente o una matriz de papel. Si bien es cierto que la mayoría son medios pequeños (unipersonales incluso), no conviene una lectura negativa apresurada, tal vez simplemente es el nuevo escenario mediático que debemos enfrentar en el futuro: menos medios grandes y más pequeños medios, pero también más ágiles, flexibles, viables y conectados entre sí.

De otro lado, si planteamos un cambio de paradigma desde la actitud, conviene recordar que no solo estamos hablando de la del profesor sino también, de la actitud del alumno. Si como anticipaba Robinson al inicio de este capítulo, la educación no es una comunicación unidireccional sino bidireccional, de poco servirán los esfuerzos de los docentes si no se atisba un mínimo de predisposición en el alumnado.

¿Quiere el alumno una clase diferente a la típica charla magistral? ¿Está dispuesto a afrontar los retos de participación y colaboración que exigen las nuevas metodologías? El optimismo del profesor debe venir acompañado de un marcado carácter proactivo y creativo en el alumno.

\section{Innovación en la periferia del periodismo}

El periodismo, como sector profesional, tiene muchas más habilidades de las que tradicionalmente ha comercializado para desarrollar sus modelos de negocio. Como señalaba Alberte González Patiño en junio de 2014, durante un seminario para profesores de periodismo en el campus de Cuenca de la UCLM ("Periodismo emprendedor: una esperanza renovada"), la distribución es el último eslabón de la tradicional cadena de valor del periodismo, pero no el único.

Además de la distribución, los medios (y periodistas) crean contenido y lo editan. Son capacidades que en pocas ocasiones se han puesto al servicio de otro tipo de clientes más allá de la Redacción, en lo que podríamos definir como todas aquellas actividades que se encuentran en la "periferia del periodismo". 
En esa periferia se encuentra el contenido elaborado para marcas, más conocido como branded content y que cuando procede directamente de los medios puede denominarse brand journalism. Medios de referencia como The Guardian ya saben lo que es negociar determinadas secciones para que éstas sean financiadas por marcas. Así, por ejemplo, este medio lanzó en 2014, a través de su división Guardian Labs, una agencia dedicada a gestionar contenido para marcas. De esta forma, paradójicamente, podríamos señalar que la solvencia e independencia económica del periodismo también está fuera, o al menos, en la periferia.

\section{Innovación en las plataformas}

Estamos formando futuros periodistas que no trabajarán en medios tal y como los conocemos en la actualidad. De hecho, muchos de ellos trabajarán en medios que ni siquiera existían cuando estaban en el primer curso de carrera.

El actual escenario comunicativo ya nos introduce nuevos medios profesionales híbridos, de autoría múltiple y con funciones muy diferentes a las de los medios que siempre hemos conocido. Se trata de medios mucho más focalizados en un tema que en la actualidad, más verticales que generalistas y, en algunos casos, contenedores de proyectos periodísticos, donde lo que se pretende es articular un metamedio que ofrezca visibilidad y modelo de negocio para cada uno de los proyectos que contiene. El caso Wikileaks o el auge de las plataformas de micro-mecenazgo (más conocidas como plataformas de crowdfunding) suponen marcos de referencia en ese sentido.

Fíltrala, Contributoria, InformaciónSensible.com o PorCausa.org son solo algunos de los exponentes de esa nueva generación de plataformas periodísticas que enriquecen la diversidad de opciones que tendrán los futuros egresados. Bajo cabeceras como las citadas u otras, los nuevos medios serán más pequeños, pero también mucho más focalizados en un tema a la vez que diversos en sus modelos de negocio. Tenemos la obligación en el aula de anticipar ese escenario. 


\section{Innovación en la Facultad: factorías de medios}

Dentro de las particularidades y ventajas de la enseñanza del periodismo, podemos señalar que nos encontramos en un tipo de Facultad que permite una inmersión en la realidad laboral mucho más cercana que la de otras carreras. Siempre fue así (un periódico de estudiantes $\mathrm{o}$ una radio universitaria mantienen estructuras $\mathrm{y}$ dinámicas similares a las de medios profesionales), pero la estandarización de gestores de contenido web, así como la popularización de otras tecnologías (plataformas de vídeo, microblogging, redes sociales...) ha permitido que la barrera en la Web para crear un medio sea ínfima. Potencialmente, cualquiera puede dirigirse a una audiencia global y real.

Bajo este contexto, son las Facultades de Comunicación las que tienen la obligación de tutelar a todos aquellos estudiantes que quieran plantear proyectos periodísticos. Dichos proyectos serán reales o no serán, porque tienen la oportunidad de dirigirse desde el inicio a audiencias reales. La evaluación del profesorado quedó atrás, quien juzga ahora es la audiencia.

En este sentido, cualquier Facultad de Comunicación es una factoría de nuevos medios en potencia. Podcasts, canales temáticos en Youtube, publicaciones digitales de nicho, redes de blogs... el catálogo de nuevas iniciativas puede ser tan amplio como los alumnos quieran (aquí cabe reseñar el Trabajo Fin de Grado como una excelente oportunidad para dar el apoyo definitivo a proyectos que quedaron pendientes durante la carrera).

Otro aspecto clave es el entorno de cada universidad. Esas factorías de medios no solo deben responder a las necesidades del entorno cultural, económico y social, sino que pueden erigirse como señal distintiva de la propia universidad. ¿Qué medios estamos ayudando a crear? ¿Ayudan a resolver las necesidades de las comunidades que nos rodean?

Aquí el medio universitario constituye una innegable parte de la imagen de marca no solo de la Facultad, sino de la propia universidad. 


\section{Innovación en la gestión del CV: la marca personal}

El contacto directo con audiencias reales no es solo para los medios creados desde la universidad, lo es sobre todo para el propio estudiante de periodismo, que aborda esta oportunidad como la responsabilidad y obligación de gestionar su identidad online desde el primer instante. Desde el primer post, el primer tuit o la primera imagen publicada.

No cabe duda que el alumno se enfrentará a tensiones, como la que representa gestionar una identidad personal dentro del proceso de creación de una identidad profesional, pero no viene mal, porque son exactamente las mismas tensiones que enfrenta a diario un periodista cualquiera en las redes, donde una mala elección puede dañar la imagen de la cabecera para la que trabaje.

La concienciación sobre la importancia de gestionar la marca personal online como comunicador debe comenzar ya en primer curso. No se trata tanto de forzar una profesionalización prematura de los contenidos publicados en cuentas personales, sino más bien de fomentar desde lo antes posible un uso crítico y selectivo de las numerosas posibilidades que permite la Web. Un uso que refleje alumnos conscientes de lo que están comunicando y proyectando con cada una de sus publicaciones digitales. En ese punto, habrán adquirido la libertad para decidir en qué momento quieren empezar a construir de forma proactiva su identidad profesional online, su marca personal como periodistas.

\section{Innovación en las narrativas, no en la tecnología}

La universidad como institución tiene, respecto a su entorno y la industria mediática que le rodea, una tradicional lentitud que le acarrea varios problemas pero también algunas ventajas. Esta bendita lentitud permite a la universidad poner el foco en lo importante y no en lo urgente.

La tecnología es lo urgente, pero las narrativas son lo importante. Sin un storytelling genuino y de calidad las historias no llegarían a nadie y los profesionales capaces de contar historias no dependen de tecnologías, muy al contrario, saben aprovecharlas. En cambio, aquel 
periodista que no tenga las habilidades mínimas para articular estrategias discursivas y de comunicación, poco podrá hacer aunque esté a la última técnicamente.

Como se habrá observado con claridad a lo largo de este capítulo, se ha abandonado de forma premeditada cualquier enfoque tecnodeterminista que pusiera el foco en el aprendizaje de lo instrumental. Ninguna universidad, facultad o carrera tiene el tiempo suficiente como para enseñar al alumno el manejo de todos los programas y equipos que necesitará a lo largo de su carrera. $\mathrm{Y}$ además le haría un flaco favor si se centrará solo en eso, ya que el nuevo escenario demanda, paradójicamente, un rescate de la tradicional inquietud y curiosidad intelectual que ha caracterizado a cualquier periodista.

\section{Conclusión}

La innovación universitaria en los estudios de periodismo puede tener dos niveles, macro y micro. Como macroeconomía y microeconomía. El primer nivel depende de los que tienen el poder en la toma de decisiones estructurales y organizativas, atañe a los procesos de mejora de la calidad docente, las supervisiones de las agencias nacionales de calidad y la revisión periódica de competencias y resultados de aprendizaje. En suma, a todo ese proceso heredado del Plan Bolonia que se ha criticado notablemente al inicio del capítulo (en realidad no tanto las intenciones del plan sino su forma de ejecución).

El segundo nivel de innovación, el micro, era el verdadero tema de este capítulo. Este nivel de innovación atañe directamente a las decisiones tomadas por el profesor y a sus negociaciones tácitas con el alumno. Aquí la velocidad es mayor, la flexibilidad es una de las normas y los resultados se obtienen en el corto plazo.

Además de una innovación micro, el foco se ha puesto de forma premeditada en los contenidos, las narrativas y la creatividad por encima de la tecnología. Las tecnologías de la información y la comunicación son cambiantes por definición, con sufren continuas mediamorfosis como describía Fidler y suponen un complicado objeto de estudio o especialización si ponemos la vista en el corto plazo. En cambio, la especialización en temas y narrativas permite una 
proyección profesional constante.

Las diez pistas señaladas reflejan esta filosofía de aprendizaje, donde sobre la tecnología lo que se pide esencialmente es una actitud creativa y crítica constante, para centrar la aptitud en los contenidos, que forzosamente serán multiplataforma, hipermedia, líquidos.

La enseñanza del periodismo dispone de ventajas de las que carecen muchas otras disciplinas universitarias. Por ejemplo, los estudiantes de periodismo pueden dirigirse desde el primer instante a una audiencia real que va a evaluar sus proyectos y eso no debe suponer un desprecio de la necesaria evaluación del profesor (entre otras cosas para distinguir que los gustos de la audiencia no siempre son un indicador de calidad), más bien se trata de complementar una información con otra, la del aula con la del entorno, la del público con la del profesor-tutor de proyectos.

Por último, podemos recordar un principio básico para una era caracterizada por la infoxicación donde el paradigma, también en la universidad, ya no es la falta de información sino el exceso y por tanto, la capacidad para seleccionar, filtrar y editar. El consejo sería: si el alumno puede cometer plagio en ese trabajo, meditemos si el único que se está equivocando es el alumno. Un buen trabajo desde el punto de vista docente es aquel en el que cometer plagio es imposible. 



\title{
Lean Startup y Design Thinking Nuevos métodos para innovar en periodismo
}

\author{
Miguel Carvajal, Universidad Miguel Hernández
}

\section{Introducción}

7 AVID COHN es un periodista estadounidense, licenciado por la Universidad de Columbia (2008). Lidera el equipo de engagement de una de las aplicaciones móviles de moda, AJ+, un experimento de Al Jazeera News en Manhattan. Recién graduado y con 25 años, Cohn fundó Spot.us, la primera plataforma de crowdfunding para periodismo y una de las primeras en la industria de la creatividad. También ha estado detrás del nacimiento de una de las aplicaciones que ha revolucionado el periodismo en soportes móviles, Cir.ca. Y ahora, tras un fichaje galáctico, trabaja para $\mathrm{Al}$ Jazeera.

Conocí a David Cohn en 2010 en un congreso donde había presentado algunas ideas relacionadas con Spot.us. El crowdfunding era un fenómeno incipiente por estos lares en aquel entonces. Uno de sus profesores en Columbia, Sree Sreenivasan me había contado que Cohn ya había puesto en marcha algunos proyectos durante sus años universitarios. En uno de los descansos, en un bar de Austin, hablé con él. Cuando nos fuimos, me quedé pensativo. ¿Puede surgir un David Cohn de nuestras carreras de Periodismo? 
Este texto quiere responder a esa pregunta: cómo podemos incentivar la innovación en periodismo desde la universidad. En concreto, cómo podemos ayudar a los estudiantes a identificar y descubrir oportunidades para acelerar la innovación, prepararles de manera adecuada ante los retos del sector y ayudar a cambiar el ecosistema periodístico inmediato.

\section{Cuál es el contexto}

Vivimos en la época dorada del periodismo digital, crece el consumo de contenido, aumenta el tiempo de uso de las redes sociales y la sociedad está más interconectada que nunca. Del mismo modo, aumenta la saturación informativa y la confusión sobre lo real e irreal, lo útil y lo superficial. Disminuye la paciencia del usuario ante el contenido irrelevante, repetitivo, que no le aporta valor.

Las marcas y los anunciantes en general buscan desesperadamente captar la atención y parece que los periodistas son buenos en mantener el interés del lector. Sin embargo, bombardeamos la experiencia del usuario y nos olvidamos de crear valor para el anunciante, generar un momento único donde su marca sea bien percibida por el individuo.

Sabemos que la audiencia busca información práctica y útil que les ayude a tomar decisiones; también sabemos que es cada vez más importante estar donde están los usuarios, en las redes sociales, y que el contenido y la marca no pueden ser esclavos del canal. Intuimos que la viralidad conseguida a golpe de frivolidad y superficialidad es barata y quizá rentable a corto plazo, pero también es fácilmente imitable y de escaso valor ético.

Advertimos la emergencia de la industria mediática del individuo: probablemente hay ahora un nuevo youtuber que está ganando más dinero que veinte presentadores de televisión o que algún que otro director de prensa. Además asistimos a un proceso paradójico de destrucción creativa en el cual se dan noticias sobre la precariedad laboral mezcladas con un entusiasmo inusitado por la aparición de nuevos medios, proyectos o startups. 
Reconocemos que hay espacio para innovar dentro y fuera de las empresas periodísticas, como autónomos, como intra-emprendedores o como estudiantes aventurados. Pero perdemos el tiempo -peor aún: se lo hacemos perder a los estudiantes- realizando estudios de mercados en descomposición, preparando informes o planes de negocio construidos sobre hipótesis no contrastadas o presunciones sin confirmar.

Al final, tenemos mucha información sobre el usuario y sobre experiencia de uso, pero no generamos ideas innovadoras y proyectos finales que satisfagan esas necesidades. En esa continua batalla por la búsqueda de un modelo, la universidad debe ayudar a entender mejor la transformación de la industria para así fomentar entre los estudiantes la percepción de que, aunque el escenario haya empeorado, ellos pueden ser parte de la solución.

\section{Qué es la innovación}

La innovación no consiste en adoptar nuevas tecnologías para maquillar el mismo producto de siempre, carente de valor para el usuario. La innovación tampoco consiste en gastar varios miles de euros en montar una sala con ordenadores muy potentes o en contratar una consultora para que rediseñe la web del medio. La innovación es resolver los verdaderos problemas y necesidades de la gente de una manera más eficaz.

Clayton Christensen observó que no solo la tecnología puede provocar un cambio de juego en el sector: pequeñas innovaciones no necesariamente tecnológicas pueden alterar el contexto competitivo. Por eso, debemos reconocer que existen tantas oportunidades como necesidades y deseos en la sociedad. Al final, las ideas suelen ser variaciones leves de propuestas universales: satisfacer necesidades y deseos de bienestar material e intelectual.

La innovación por tanto es descubrir y proponer una forma más eficaz de resolver los problemas nuevos y viejos que impiden alcanzar esas necesidades y deseos universales. Christensen utiliza la expresión there is a job to be done que puede ayudarnos a entender mejor este punto de vista: hay una tarea pendiente, una innovación viene al rescate. 
Si entendemos el periodismo más como servicio que como producto, descubriremos muchas más tareas pendientes conectadas con las necesidades reales de la gente. Sin embargo todos reconocemos, alumnos y docentes, de una manera u otra, tareas pendientes que luego no superan el escenario de lo real. Es decir, somos capaces de verbalizar la necesidad, pero no encontramos la fórmula para convertirla en real. A veces, sabemos incluso cuál es la fórmula, pero no funciona nuestro plan porque lo importante es la ejecución.

Para superar esa dificultad, hay dos metodologías que pueden ayudarnos a encontrar y diseñar de una manera más eficiente una propuesta de valor y a agilizar el paso de la idea al desarrollo: el design thinking y el lean startup. Estas dos formas de trabajar se han popularizado en distintos ámbitos de la creación y el desarrollo de software y se ha contrastado su capacidad de incentivar la innovación y el emprendimiento. En el campo del periodismo, varias instituciones en Estados Unidos han puesto en marcha iniciativas apoyadas en estos enfoques, como el título de Journalism + Design $^{1}$ de The New School en Nueva York o la aceleradora de startups periodísticas, Matter ${ }^{2}$, en la órbita de la Knight Foundation. Más cerca, y ya desde hace dos años, trabajamos con esa filosofía en el Máster en Innovación en Periodismo de la Universidad Miguel Hernández ${ }^{3}$. Nuestro cometido será ahora presentar estas dos metodologías y realizar una síntesis aplicada a la innovación en periodismo en general y a los planes formativos en particular, apoyados en la experiencia del máster.

\section{Design thinking, pensar fuera del esquema tradicional}

El design thinking ofrece un método claro y un esquema de trabajo para institucionalizar la creatividad, aunque parezca un oxímoron. Es un proceso que se puede usar para afrontar cualquier tipo de problema, por tanto, también puede ayudarnos a desarrollar una innovación o impulsar un proyecto. No es una receta mágica, pero sí señala una hoja de ruta. La innovación enfocada así puede ayudarnos a alinear las

\footnotetext{
${ }^{1}$ Sitio web: http://journalismdesign.com/

${ }^{2}$ Sitio web: http://matter.vc/

${ }^{3}$ Sitio web: http://mip.umh.es/
} 
necesidades y experiencias negativas del usuario con las características del producto y la forma de producirlo. Si se plantea adecuadamente, puede funcionar también para preparar un reportaje, una entrevista o un documental.

El primer paso de esa hoja de ruta propuesta por el design thinking es empatizar con los usuarios. Gracias a la empatía podemos hablar con alguien sin prejuicios, entender qué le gustaría saber. Es clave fomentar en los estudiantes el interés por saber qué le interesa a la audiencia, para eso deben preguntar y escuchar mucho. En el ámbito periodístico, este carácter se emplea a menudo en la observación de la realidad, en las entrevistas, con lo cual, será fácil de entender y aplicar en nuestros programas formativos.

Una vez conocida la experiencia del usuario, afrontamos la segunda fase: definición del problema. En este apartado conviene reducir el enfoque al máximo para encontrar la verdadera esencia del problema, el dolor que realmente necesita ser curado. Ya hemos pasado de reconocer una necesidad a crear un proyecto para resolverla. Conviene escribir un resumen del problema y los objetivos. Este briefing nos ayudará concentrar los esfuerzos, pero no puede limitar el pensamiento. El proyecto debe moverse en tres grandes vértices, según uno de los impulsores de esta filosofía, Tim Brown, fundador de Ideo, la consultora más importante del mundo en innovación (Brown, 2009): lo realizable (recursos materiales y tecnológicos), lo viable (financiación y vías de negocio) y lo deseable (audiencia e interés).

El tercer paso es idear, realizar una tormenta de ideas y escuchar qué piensan los demás sobre ellas. Conviene que el equipo sea multidisciplinar, diverso, a veces integrado por gente que no conozca el problema de origen. Brown ha identificado que este paso tiene dos partes; la inspiración, donde se reconoce o se experimenta el problema o la oportunidad; y la ideación propiamente, donde se generan nuevas ideas y se someten al test de los demás.

El cuarto paso del design thinking es el diseño del prototipo. En este punto se debe recrear mediantes esquemas visuales la propuesta ideada anteriormente y comprender si es posible ejecutarla. El 
prototipo debe mantenerse entre los vértices de lo realizable, lo viable y lo deseable, de tal forma que el equipo de estudiantes se equivoque pronto, rápido y barato. Dibujar, crear representaciones visuales, mapas mentales que muestren las múltiples conexiones entre los objetivos y las necesidades será útil. El prototipo no puede ser caro ni tiene que ser perfecto, debe ayudar a sintetizar la solución: cuanto más ligero y rápido mejor, porque antes se podrá obtener una respuesta.

Por último, el quinto paso es testar el prototipo. El proyecto adopta ahora la forma de un producto mínimo viable, que debe ser puesto en circulación de inmediato entre compañeros, amigos y redes para obtener un feedback. Este paso conecta con el siguiente método, el lean startup.

Como se ve, el design thinking es un método para trabajar sobre problemas habituales desde un prisma distinto partiendo desde la experiencia del usuario. Nos ayudará a salir del círculo vicioso y a pensar out of the box. Con esta metodología, nuestro actividad mental atraviesa cuatro estados: a) pensamiento divergente que genera alternativas a la realidad conocida y aporta nuevas elecciones (es la fase de tormenta de ideas); b) pensamiento convergente, que discrimina entre las sugerencias y elige las mejores; c) pensamiento analítico para separar y organizar; y d) la síntesis para identificar los patrones relevantes del comportamiento.

Quizá algunos alumnos o docentes piensen que el método design thinking no vale para ellos porque no tienen una visión estética definida o, peor aún, porque consideran que el diseño es algo superficial. Pero no se trata de eso: este método es un enfoque para resolver problemas, puede mejorar nuestra forma de contar e inspirar creatividad, puede ayudarnos a formar a los periodistas y a eliminar las barreras entre programadores, diseñadores y reporteros.

\section{Lean startup: equivócate pronto y barato}

El lean startup es una metodología popularizada en el libro del mismo nombre escrito por Eric Ries. Este método nos ayuda a entender la idea de producto o servicio como una hipótesis: este usuario concreto 
tiene un problema determinado que puede ser resuelto con esta solución especifica. El lean startup nos dice que ahorremos tiempo y dinero en realizar un plan de negocio o de desarrollo y que hagamos un pequeño experimento: presentar un producto mínimo viable en el mercado, analizar la respuesta y comprobar si valida o no la hipótesis de partida.

El método lean tiene tres fases: a) diseñar una hipótesis; b) crear un producto mínimo viable para recibir datos; c) pivotar y trazar un nuevo producto. Con este sistema, ahorramos tiempo y dinero en recursos y acortamos las distancias entre la idea y el mercado. Es muy costoso conseguir el primer cliente, pero también lo es diseñar un producto equivocado. Por eso, conviene no perder el tiempo en largos ciclos de desarrollo y planificación. El enfoque puede ayudar a los estudiantes a lanzar productos y servicios que los usuarios realmente necesitan de una manera más rápida y económica que el método tradicional. Esto no anula ni desacredita la planificación estratégica y de negocio, pero sí agiliza el proceso para aquellos que aún no han encontrado el modelo definitivo.

Para plantear la hipótesis, hay una herramienta muy popular llamada lean canvas, una adaptación del business model canvas propuesto por los autores Pigneur y Osterwalder, padres del concepto de modelo de negocio contemporáneo ${ }^{4}$. Ellos nos han ayudado a descubrir que el modelo de negocio no es una foto fija ni un documento de cincuenta páginas plagado de tablas. El modelo de negocio es un concepto que sintetiza cómo crea, captura, genera y recibe valor una empresa o un proyecto en su mercado o entre sus usuarios. Para diseñarlo, popularizaron el famoso canvas que ahora se ha aligerado con el método lean y contiene una representación visual de los principales apartados de la creación de valor (problema, solución, propuesta de valor, métricas clave, ventaja, clientes, canales, costes e ingresos).

El producto mínimo viable (PMV) es la materialización de la hipótesis y debe ayudarnos a validarla, por eso debe contener la esencia de la propuesta de valor. A todos los emprendedores, jóvenes y no tanto, nos cuesta entender muchas veces que nuestro producto

\footnotetext{
${ }^{4}$ Debe referenciarse el capítulo de Caro, que explica y amplía este concepto.
} 
puede no tener ningún interés. Por eso, un PMV permite saberlo pronto, bien para pivotar y alterar algunas de las funciones del producto o bien para desenchufar la máquina y ponerse a otra cosa.

En el ámbito educativo esto es sano. A veces el docente no quiere ser foco de la frustración del estudiante y quizá le anima a emprender proyectos de gran envergadura, que a la larga pueden originar un problema emocional o curricular. Como dijo Mike Tyson, "todo el mundo tiene un plan hasta que le dan un puñetazo en la cara". El lean startup evita filosofar o construir castillos en el aire: el estudiante lanza un PMV y, si no funciona, pivota. Si tampoco funciona, lo abandona: en el camino, algo habrá aprendido.

Como dice Steve Blank, otro de los padres fundadores de esta filosofía, las compañías asentadas ejecutan modelos de negocio, las startups los buscan. Por eso, se podría decir que las startups informativas son organizaciones diseñadas para buscar un modelo de negocio repetible y escalable.

¿Por qué es muy interesante este método aplicado al periodismo? En tiempos de incertidumbre, cuando los planes de negocio envejecen rápido y las tecnologías quedan obsoletas pronto, merece la pena testar el producto y recibir datos mediante la analítica para entender si funciona o no. En la comunicación digital es muy fácil obtener feedback, reunir un conjunto de métricas y trazar los cambios necesarios en el producto mínimo para volver finalmente a repetir el proceso. Este proceso, combinado con el design thinking, agiliza el time to market $\mathrm{y}$, por tanto, acelera la innovación orientada a la experiencia de usuario.

Algunos productos mínimos viable aplicados al periodismo pueden ser un blog especializado, una newsletter construida mediante Mailchimp, una cuenta de Twitter, una página de Facebook o un canal en Instagram o Youtube. Si ese mínimo producto viable no funcional, no le interesa a nadie. No hay problema, modificamos la estrategia o lo olvidamos.

A veces, un simple post en un blog puede darnos una pista y convertirse en un mínimo producto viable. En el peor de los casos, si 
no hemos conseguido validar nuestra hipótesis, hemos aprendido algo. Como dice James Breiner (2014), este PMV nos ayudará a entender que las métricas son relevantes, algo que hemos minusvalorado los periodistas porque pensamos que nos condena a la superficialidad. Sin embargo, la analítica y el estudio de las redes sociales o el consumo del sitio web nos ayudan a encontrar la mejor forma de conectar con la audiencia.

\section{Conclusiones}

El design thinking y el método lean startup tienen en común una filosofía user centric, es decir, ponen en el centro del proceso innovador la experiencia de uso y consumo del usuario. El primero, mediante la empatía, y el segundo, mediante el análisis de las métricas clave, pueden ayudarnos a entender la eclosión digital, y que no todos los productos y servicios periodísticos valían tanto como pensábamos. Esta filosofía también debe ayudarnos en las facultades, en los programas de las asignaturas, a terminar con el planteamiento de medio omnicomprensivo. Debemos dejar de lado la mentalidad all the news that fit to print, para buscar servicios y productos con enfoques más modestos, ajustados a las necesidades reales de la audiencia. Esto no quiere decir que limitemos o rebajemos nuestras expectativas, sino que no nos lancemos sin probar primero en las distancias cortas.

Conviene también reorientar los programas de las asignaturas y de las propias prácticas: se trata de construir para pensar. El proceso de construcción (empatizar, inspirar, idear, prototipar barato y probar rápido) será fértil y el estudiante aprenderá: construir cualquier cosa más o menos orientada generará un conocimiento del usuario y, finalmente, contribuirá a encontrar la mejor solución.

En esa tarea de construir de prototipos, de práctica, se activan en nuestro cerebro zonas que nos ayudan a aprender de una manera más eficiente. ¿Qué pasaría si aplicamos estos métodos a las materias más humanísticas y teóricas? Probablemente alcanzaríamos mejor los objetivos propuestos de una manera más atractiva para los estudiantes y les aportaríamos nuevas vías de desarrollo profesional. 
La idea de fallar pronto, barato y rápido, de estar en fase beta constante, es también una de los grandes hallazgos de los dos métodos. Las compañías que mejor se adaptan al reto digital hoy día no dejan de probar nuevos experimentos que asumen o descartan rápido: al final, lo cuentan ellos mismos, la validación de la hipótesis no es la clave, es el aprendizaje obtenido gracias al experimento.

$\mathrm{Si}$ al menos conseguimos que en las asignaturas de empresa y economía los estudiantes entiendan la distinción entre administrar un negocio y buscar un modelo de negocio, aceleraremos el proceso de cambio e incentivaremos el periodismo emprendedor. Deberíamos extender estas formas de trabajar al propio diseño de la universidad: probar con retos, concursos, hackatons, actividades que rompan los esquemas de aprendizaje tradicional. Es probable que las limitaciones de tiempo y espacio o la masificación en el aula neutralicen este fervor, pero, ¿no sería sin duda un buen punto de partida para incentivar la innovación en el periodismo y facilitar la aparición de más David Cohn en nuestras carreras?

\section{Bibliografía útil}

Ries, Eric (2011): The Lean Startup, Crown Publishing Group

Brown, Tim (2009): Change by Design: How Design Thinking Transforms Organizations and Inspires Innovation, HarperBusiness

Christensen, C., Skok D., Allworth, J. (2012): Mastering the art of disruptive innovation in journalism, Nieman Reports, Vol. 66 Nº. 3.

C. W. Anderson, E. Bell y C.Shirky, (2012): Post-Industrial Journalism: Adapting to the Present, informe publicado por el Tow Center for Digital Journalism, Columbia University.

Breiner, James (2014): "For digital startups, dealing with extreme uncertainty", entrada en el blog del autor Newsentrepreneurs: http:/ / newsentrepreneurs.blogspot.com.es/2014/07/ for-digitalstartups-dealing-with.html

Blank, Steve (2013): "Why the Lean Start-Up Changes Everything, Harvard Business Review, no de mayo, 2013. 


\title{
Metodología de trabajo para generar
} modelos de negocio y proyectos emprendedores en el ámbito periodístico

\author{
José María Herranz de la Casa (Universidad de Castilla-La \\ Mancha)josemaria.herranz@uclm.es
}

\section{Introducción}

$\mathrm{E}$

L OBJETIVO de este capítulo es aportar una herramienta de trabajo para los docentes, de manera que puedan desarrollar proyectos de creación de modelos de negocio con sus alumnos en el ámbito del periodismo y de la comunicación.

Este capítulo está basado en el libro Generación de modelos de negocio, escrito por Alexander Ostewalder y Yves Pigneur". Este capítulo expone la herramienta de trabajo que utilizan, el lienzo o "canvas" y lo aplico a dos casos reales: uno malogrado, el diario gratuito Metro Directo en España, a pesar de su éxito internacional; y otro que es un proyecto emprendedor en desarrollo, puesto en marcha por ex alumnos de la Facultad de Periodismo de la Universidad de CastillaLa Mancha, El Deporte Conquense.

${ }^{5}$ http://www.generaciondemodelosdenegocio.planetadelibros.com/ 
Este capítulo es una mínima reflexión y aplicación de la metodología utilizada en el libro de Ostewalder y Pigneur. En el libro se ofrece una explicación pormenorizada de la generación de modelos de negocio, te invito a leerlo para su completa compresión. Aquí solo quiero destacar algunos aspectos significativos, que pueden servir para iniciarse en la comprensión de la metodología aplicada al ámbito periodístico.

\section{Del modelo de negocio al plan de negocio}

El principal problema con el que nos encontramos los periodistas es que la economía, la empresa y los números, en muchos casos, nos son incómodos. Y por lo tanto, hablar de plan de negocio, propuesta de viabilidad, presupuesto, etc. nos puede superar.

Sin embargo, cualquier proyecto emprendedor, y lo que es más importante, su viabilidad futura, depende de una buena planificación. La búsqueda de inversores y financiación, la viabilidad económica y la rentabilidad están claramente unidas a una buena planificación y un plan de negocio.

Pero, para que nuestros alumnos cambien la forma de pensar y para que nos resulte más cómodo a nosotros empezar a trabajar en ello, esta herramienta plantea cómo se crea un modelo de negocio, y toda una serie de pautas básicas para poner en marcha una idea, de manera más fácil.

Esta es la razón que me llevó a adentrarme en esta metodología que plantean Osterwalder y Pigneur (2011), y que se puede aplicar a cualquier tipo de negocio. Su idea, y en consecuencia, su libro surge a partir de la tesis doctoral de Osterwalder sobre la innovación en modelos de negocio en el año 2004, y que es dirigida por Pigneur. A partir del año 2006 se plantean el reto de elaborar un libro sobre metodología en los modelos de negocio, y ponen en marcha una plataforma (hub) en línea abierta a todos los innovadores del mundo, 
para que puedan desarrollar el proyecto de forma colaborativa. Después de 9 años de investigación y práctica, y de la colaboración de 470 autores de 45 países, el resultado es el lienzo o "canvas".

Me gusta definir emprendimiento, en su sentido más amplio. Cuando cualquier proyecto se inicia o se empieza a desarrollar, se puede hablar de emprendimiento: una empresa, una organización social, un prototipo, una idea. Cuando por primera vez hice una paella, sabía que probablemente sería la peor paella que haría en mi vida. A partir de esa paella, ha habido muchas más, buenas, sublimes, mejores y peores, pero me atreví a emprender esa primera vez. Cuando hablamos de emprendimiento empresarial, lo que puede empezar como un proyecto en el aula, puede acabar siendo la empresa que me permite tener un sueldo al mes. Y con esta idea está elaborado este capítulo, con la idea de que los profesores podamos motivar a los alumnos para que emprendan proyectos que no sabemos a dónde les llevarán; pero que probablemente les ayuden a seguir aprendiendo.

Y para todo ello las aportaciones y la metodología de Osterwalder y Pigneur (2011) pueden ser muy interesante por su simplicidad, concisión y lo visual.

\section{E1 lienzo o "canvas" como herramienta de trabajo para planificar el modelo de negocio}

Osterwalder y Pigneur utilizan un modelo, una plantilla que llaman lienzo o "canvas" (en inglés) donde se puede resumir todo el modelo de negocio. Lo realmente interesante de este lienzo son los puntos que se abordan y las preguntas a las que hay que responder para poder acercarnos a lo que sería la segunda parte del proceso emprendedor, el desarrollo de un plan de negocio. Este lienzo tiene 9 partes y distintas preguntas que el futuro emprendedor debe preguntarse: 
1. Segmento de mercado

¿Para quién creamos valor?

¿Cuáles son nuestros clientes más importantes?

2. Propuestas de valor

¿Qué valor proporcionamos a nuestros clientes?

¿Qué problema de nuestros clientes ayudamos a solucionar?

¿Qué necesidades de los clientes satisfacemos?

¿Qué paquetes de productos o servicios ofrecemos a cada segmento de mercado?

\section{Canales}

¿Qué canales prefieren nuestros segmentos de mercado?

¿Cómo establecemos actualmente el contacto con los clientes?

¿Cómo se conjugan nuestros canales?

¿Cuáles tienen mejores resultados?

¿Cuáles son más rentables?

¿Cómo se integran en las actividades diarias de los clientes?

4. Relaciones con clientes

¿Qué tipo de relación esperan los diferentes segmentos de mercado?

¿Qué tipo de relaciones hemos establecido?

¿Cuál es su coste?

¿Cómo se integran en nuestro modelo de negocio?

5. Fuentes de ingresos

¿Por qué valor están dispuestos a pagar nuestros clientes?

¿Por qué pagan actualmente?

¿Cómo pagan actualmente?

¿Cómo les gustaría pagar?

¿Cuánto reportan las diferentes fuentes de ingresos al total de ingresos?

\section{Recursos clave}

¿Qué recursos clave requieren nuestras propuesta de valor, canales de distribución, relaciones con clientes y fuentes de ingresos? (Físicos, intelectuales, humanos, económicos). 
7. Actividades clave

¿Qué actividades clave requieren nuestras propuestas de valor, canales de distribución, relaciones con clientes y fuentes de ingresos?

Producción, resolución de problemas, plataforma,

8. Asociaciones clave

¿Quiénes son nuestros socios clave?

¿Quiénes son nuestros proveedores clave?

¿Qué recursos clave adquirimos a nuestros socios?

¿Qué actividades clave realizan los socios?

9. Estructura de costes

¿Cuáles son los costes más importantes inherentes a nuestro modelo de negocio?

¿Cuáles son los recursos clave más caros?

¿Cuáles son las actividades clave más caras?

A partir de la respuesta a estas preguntas se puede establecer cuál es el modelo de negocio, y se puede pasar a elaborar un plan de negocio que permita buscar financiación. Este lienzo logra condensar las ideas principales de un posible proyecto empresarial, de manera que visualmente se puedan analizar las principales debilidades, amenazas, fortalezas y oportunidades. Asimismo, en el libro se pueden encontrar muchos ejemplos de empresas que están triunfando y cómo están respondiendo a estas preguntas. Nosotros vamos a fijarnos en uno de los ejemplos planteados y su desarrollo en España.

\section{La prensa gratuita en España. E1 caso del diario Metro Directo y su proyección internacional.}

El auge de los periódicos gratuitos en España se produce a partir del año 2001. Los más grandes y relevantes se puede decir que fueron los siguientes: primero fue Madrid y M@s que nace en el 2000 y un año después pasa a ser 20 minutos (Schibsted Media); a continuación Metro Directo (Metro International), que nace en 2001 y desaparece en el año 2009; el diario Qué (Grupo Recoletos y después Vocento) nació 
en 2005 y desapareció en junio de 2012; y por último ADN (Grupo Planeta) que nació en marzo de 2006 y desapareció en diciembre 2011 (Marqués, 2012).

El periódico 20 minutos pasó de ser en la $2^{\text {a }}$ oleada del Estudio General de Medios de 2003, el segundo periódico de información general con 1.232.000, detrás de El País (1.866.00) y Marca, a pasar a ser en la $1^{\circ}$ oleada del EGM de 2007, el periódico con mayor número de lectores de España (2.368.000 lectores), delante de Marca (2.302.00) y El País (2.091.000). Ha sido el único en aguantar el brutal descenso de la inversión publicitaria, como se puede ver en el gráfico 1, y en la actualidad, según los datos de la $2^{\text {a }}$ oleada del EGM de 2014, 20 minutos tiene 1.083.000 lectores, ocupando el cuarto lugar después de Marca (2.601.000), El País (1.685.000) y As (1.343.000). Según los últimos datos encontrados, el diario 20 minutos ha perdido 18,3 millones desde 2011 hasta $2014^{6}$.

En España, el auge de los gratuitos se debió a distintas circunstancias, pero si hay que señalar una en particular es el incremento de la inversión en publicidad y las ventajas para la inversión publicitaria de este soporte. Como se puede observar en el gráfico 1, el año 2000 es el comienzo de un incremento de la inversión que llega hasta el desplome a partir del 2007. Es en este espacio de tiempo cuando se empiezan a desarrollar muchos proyectos periodísticos gratuitos, que como señalan los datos, acabaron por desaparecer. Entre 2009 y 2010, en España llegaron a desaparecer 500 cabeceras gratuitas $^{7}$.

Asimismo, otras circunstancias que favorecieron el gran desarrollo de los diarios gratuitos fueron: la fidelidad del lector diario debido a su distribución, la incorporación de nuevos lectores de prensa diaria como mujeres, jóvenes e inmigrantes, que normalmente no leían prensa diaria; la flexibilidad e innovación en los formatos

\footnotetext{
${ }^{6} \mathrm{http}: / /$ www.prnoticias.com/index.php/prensa/561/20135647-perdidas-20minutos

${ }^{7}$ http://www.prnoticias.com/index.php/home/46-entrevistas/10066045desde-que-comenzo-la-crisis-han-desparecido-600-cabeceras-gratuitas
} 
publicitarias, con posibilidad de promociones directas; y el tipo de publicación de fácil lectura.

Gráfico 1. Inversión Real Estimada en Diarios (en millones de Euros)

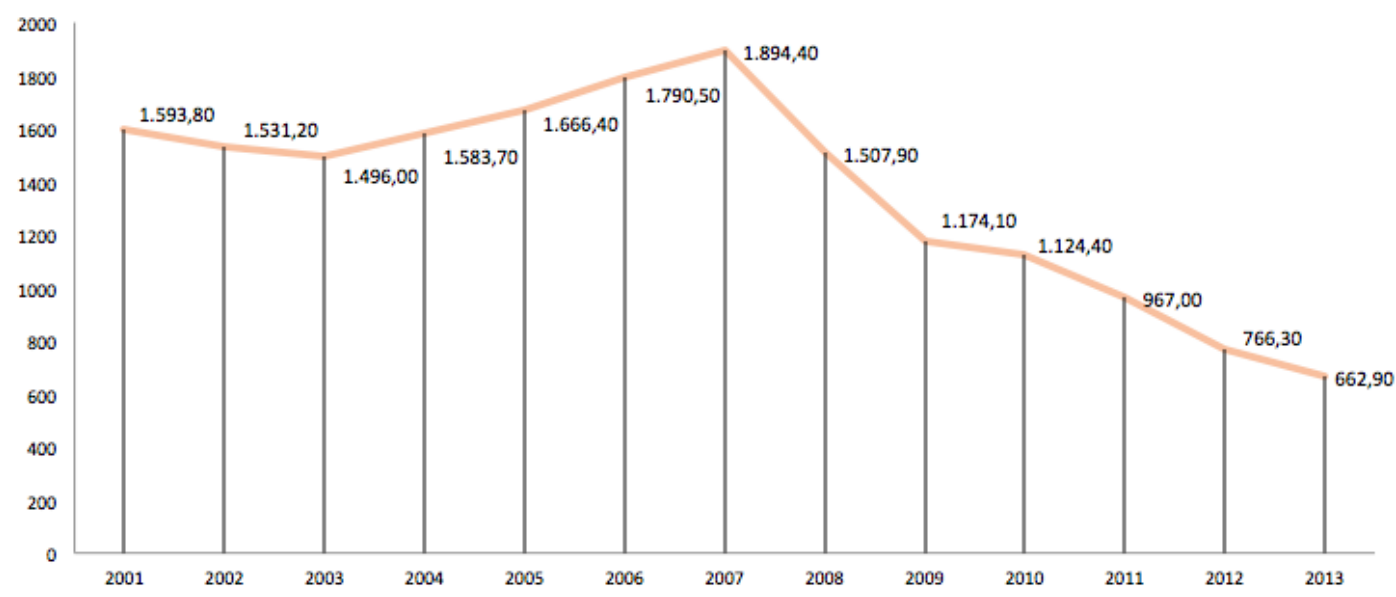

Fuente: Elaboración propia a partir de los datos de los Informes InfoAdex (2001-2014).

En cuanto a las principales debilidades de este modelo de prensa gratuita se encuentran: el perfil heterogéneo del lector, que en ocasiones no cuadraba con el perfil del anunciante; la corta vida del soporte, ya que su lectura era a lo largo de los trayectos al trabajo; o al ser gratuito era más fácil que perdiera valor y se tirara rápidamente; menor vinculación entre lector y el soporte; la distribución geográfica, muy limitada al ámbito urbano; la saturación de publicidad en estos soportes y la limitación en paginación o los emplazamientos de la publicidad.

El 29 de enero de 2009, el diario Metro Directo cerraba todas sus delegaciones, después de nacer en el año 2001 como una fuerte apuesta de Metro Internacional para ampliar cabeceras en español (sólo contaba en ese momento con Santiago de Chile y Buenos Aires). Desaparecía este periódico con 1,8 millones de lectores diarios. Según Mikael Jensen, consejero delegado y presidente de Metro International, "el empeoramiento de la economía española, que durante el inicio de 2009 ha llevado al colapso del mercado publicitario, ha provocado un incremento inesperado en las pérdidas. Esto, unido a la fuerte competencia en un mercado cada vez más débil, ha provocado que la única solución viable sea el cierre de la 
empresa. En este punto, no se justifica continuar con la inversión en España, por lo que Metro International centrará sus recursos en áreas de crecimiento donde podamos crear valor a largo plazo para nuestros accionistas".

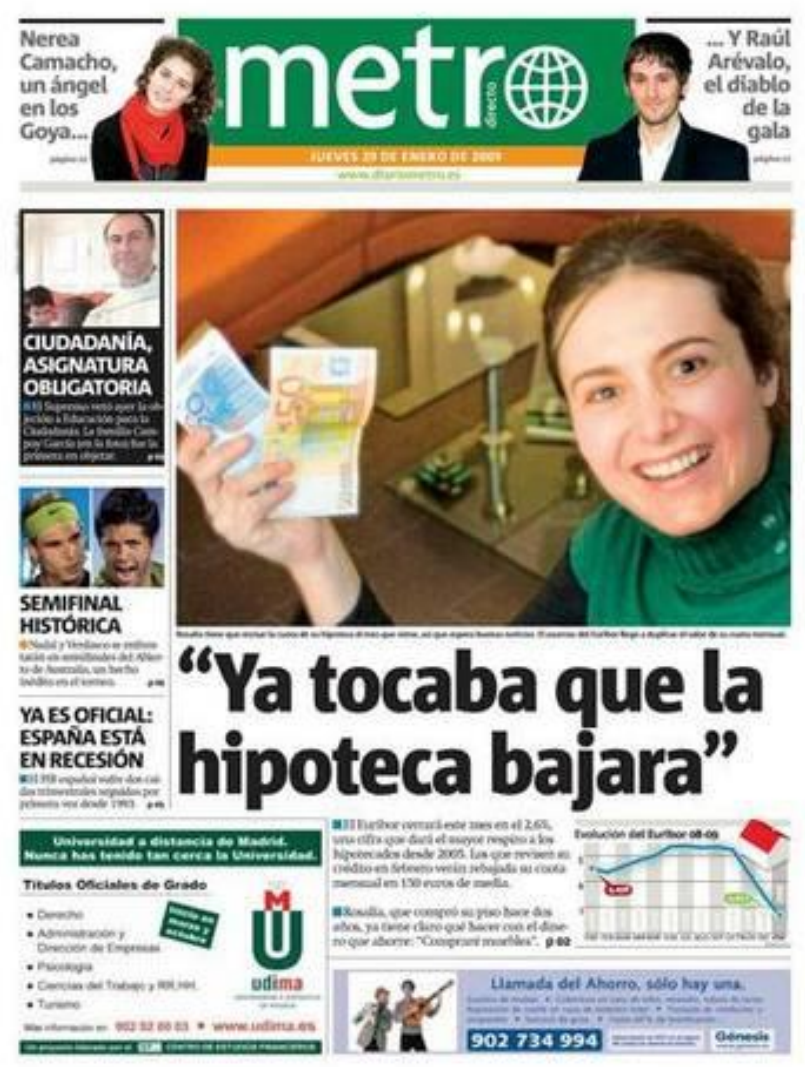

Efectivamente, Metro abandonaba España, pero seguía funcionando con su modelo de negocio en otros países. En la actualidad, Metro Internacional es el mayor periódico gratuito del mundo que está en estos momentos implantado en 24 países del mundo (10 en América, 2 en Asia y 11 en Europa), tiene 72 ediciones, una circulación de 8.301.000 periódicos y 18.271.000 lectores.

¿Pero qué es lo que ha hecho que en el resto de países el modelo siga funcionando? Pues según explican Osterwalder y Pigneur (2011:92), a través del lienzo: ofreciendo el periódico gratuito; concentrando su distribución (manual y en expositores) en los lugares y zonas de pasos con mucho tránsito, además de las redes de transporte público; y recortando los costes editoriales utilizando un papel de baja calidad. Ofrecer el periódico gratuito a cambio de encontrar los recursos a 
través del pago por espacio publicitario es la clave en la fuente de ingresos. Sin embargo, en países como España, con una competencia grande, Metro no pudo sobrevivir. En otros países, el control de Metro de los expositores instalados en las estaciones de tren y autobuses ha supuesto una ventaja competitiva frente a sus rivales. Los acuerdos de distribución con redes de transporte público han marcado la diferencia (Asociaciones clave). La propuesta de valor es su capacidad en desarrollar un periódico gratuito para transeúntes en toda la ciudad, que además se convierte en un espacio publicitario con mucha circulación. De esta manera, el segmento de mercado lo integran los transeúntes / lectores y los anunciantes. En cuanto a los recursos clave, tanto la marca como la red de distribución y logística son el principal activo; mientras que la actividad clave sigue siendo la elaboración y producción de un periódico diario.

Todos estos puntos dibujan un modelo de negocio que ha funcionado en muchos países, mientras que en otros, como España, no se han consolidado, principalmente por la competencia y el devenir de la economía.

\section{5.- E1 Deporte Conquense: un proyecto real desarrollado en el aula}

A continuación explicaré el ejemplo real, del trabajo realizado en distintas sesiones con varios alumnos, y de qué manera el trabajo con el lienzo les ha permitido ir perfilando su proyecto emprendedor periodístico y empezar a establecer un plan de negocio más robusto. El Deporte Conquense es un medio de comunicación diario, referencia en la información deportiva de la provincia de Cuenca. En él, se realiza una labor de promoción y difusión de los clubes, deportistas y aficionados al deporte que están ligados con la provincia de Cuenca. Fue creado en febrero de 2013 por un grupo de alumnos de la Facultad de Periodismo de la Universidad de Castilla-La Mancha. Su filosofía es informar y dar voz a todos aquellos que practiquen deporte, independientemente de su nivel y resultados, así como del deporte que realizan. Su apuesta por el deporte local y minoritario le han permitido obtener varios galardones: La Junta de 
Comunidades de Castilla-La Mancha les premió en 2013 y 2014 por su labor de difusión del deporte escolar; el Club Piragüismo 'Cuenca con Carácter' también los premió en su comida anual, celebrada en noviembre de 2013.

El proyecto comenzó con 4 periodistas y en la actualidad se han sumado nuevos periodistas y varios colaboradores. En julio de 2014, fecha de la finalización de sus estudios, deciden apostar firmemente por seguir adelante con el proyecto, dedicarle el mayor número de horas posibles e intentar que se convierta en su forma de vida.

En este apartado explicaré como a través de la herramienta del lienzo, los miembros de El Deporte Conquense y yo como profesor de periodismo, hemos transformado el proyecto para que se acerque a una empresa viable.

Si se analiza la situación de este proyecto empresarial conforme al lienzo habría que decir que el producto que desarrollan es elaboración de información deportiva local y regional de Cuenca, que se centra especialmente en deportes minoritarios y que ofrece una variedad de contenidos multimedia a través de la web. Por lo tanto su actividad clave es la producción de información y el recurso clave son los periodistas que trabajan en la elaboración de las piezas informativas. Esta actividad clave es fundamental no perderla de vista porque la gran mayoría del tiempo debe dedicarse a este objetivo.

El segmento de mercado está constituido por deportistas, aficionados y clubes deportivos, especialmente de la provincia de Cuenca. Las redes sociales (Twitter y Facebook) son el mejor canal para llegar hasta los lectores; y las relaciones personales que mantienen los miembros del medio con deportistas y clubes son la garantía de obtener información de calidad y diferenciada. Asimismo, los clubes deportivos, las administraciones públicas (Ayuntamientos, Diputación y Junta de Comunidades), y medios de comunicación son las principales asociaciones clave del proyecto.

En cuanto a las estructuras de costes, además de la logística de la web y el material básico para realizar fotografías y elaborar los contenidos, 
el trabajo periodístico de los miembros de la organización, supone el mayor coste. Mientras que entre las fuentes de ingreso, o lo que Briggs (2011:67) llama "your money plan", la publicidad, la venta de contenidos para otros medios y en menor medida, un proyecto de elaboración de Póster-Cromos de deportistas, y la organización de un torneo de fútbol sala, suponen la principal fuente de ingresos.

Algunos puntos que hay que potenciar para hacer el proyecto viable económicamente son:

- Ampliar el área de influencia a toda Castilla-La Mancha o algunas provincias colindantes con Cuenca.

- Ampliar las asociaciones clave con empresas de productos deportivos, ya que la audiencia del medio es proclive al consumo de dichos productos.

- Ampliar la oferta de productos y servicios hacia la ventas de productos a través de la web, la organización de eventos deportivos o la gestión de la comunicación para entidades / eventos deportivos.

- Incrementar la diversidad de fuentes de ingresos, con publicidad y proyectos nuevos.

Todo este esfuerzo y análisis, a partir del lienzo, ha supuesto tomar decisiones importantes que han tenido impacto cualitativo $y$ cuantitativo. Ha supuesto incrementar las visitas diarias a la web de 800 a 1.500; incrementar el número de seguidores en Twitter y Facebook, llegando a los 1.600 y 1.800 , respectivamente, con un incremento mensual de 100 seguidores; pasar de 4 anunciantes a 5 grandes anunciantes institucionales y empresariales (Ayuntamiento Cuenca, Diputación Cuenca, Junta de Comunidades de Castilla-La Mancha; Globalcaja y McDonalds), además de más de 15 pequeñas y medianas empresas, y 3 patrocinadores de secciones de fútbol y atletismo. Esto les ha permitido incrementar la facturación mensual de $150 €$ a $2.000 €$.

Como conclusión, me gustaría ofrecer una serie de ideas y reflexiones que han surgido a lo largo de estos meses de trabajo junto con ellos, y que pueden servir a otros futuros emprendedores a la hora de 
ponerse en marcha. Son muy básicas y en algunos casos muy lógicas, pero tienen que estar especialmente interiorizadas para lograr el éxito:

En cuanto a las IDEAS...

1. Estar convencido de que quieres apostar por el proyecto (dedicarles muchas horas, a remuneración escasa) y que se puede vivir de trabajar en él.

2. Siempre hay que pensar a lo grande. Entre el cuento de la lechera (soñar) y el pensamiento poco ambicioso y pesimista, me quedo con la motivadora idea de que puedo llegar lejos, pero siempre dentro de unos parámetros de realismo.

3. Lo que no pongas por escrito, se te olvidará, no lo podrás medir dentro de tres meses y no podrás exigírselo a tus compañeros.

4. Tener una rutina de horarios, espacios y hábitos de trabajo, te ayudará a lanzar el proyecto.

5. La asistencia a foros, jornadas, seminarios, reuniones te ayudará a conocer gente y a presentar tu proyecto. El networking es la mejor forma de expandir tu proyecto.

6. Ten preparado y actualizado siempre un buen dossier/presentación de tu proyecto donde expliques quién eres, qué haces, con quién colaboras y cómo pueden participar en tu proyecto/idea.

7. La compra de material como ordenadores, cámara de fotos/video, smartphones, tabletas, software para el desarrollo de tu proyecto es una inversión, no un gasto.

8. La opinión de familiares y amigos alienta, pero no debe ser concluyente a veces. Déjate asesorar por profesionales externos y desvinculados a tu entorno emocional.

9. Cualquier alianza puede ser interesante, no desprecies la posibilidad de colaborar con personas u organizaciones más pequeñas que tu. 
10. Sé honesto con tu trabajo y con tu forma de afrontar las dificultades. No hagas lo que no te gustaría que te hicieran a ti.

En lo que respecta a las reflexiones...

1. Para que $3 / 4 / 5$ personas puedan "comer" de este proyecto, hay que diversificar el producto/servicio. A veces no solo se puede vivir del trabajo periodístico, hay que ampliar a todo lo que implica la comunicación: organización de eventos, gestión de la comunicación, diseño, fotografía, etc.

2. El compromiso de los participantes y su dedicación siempre tiene que estar por escrito y firmada para evitar equívocos y malas interpretaciones. Lo personal y lo profesional, son espacios distintos, pero compatibles.

3. Cada persona en el proyecto tiene una función principal y apoya el resto de acciones secundarias. Todos somos periodistas o comunicadores, pero cada uno tenemos una habilidad más desarrollada para las cuentas, el diseño, las redes sociales, la venta del producto, las relaciones públicas.

4. Piensa que aunque no empieces ingresando nada de dinero, todo el tiempo que le dedicas al proyecto es tu mejor inversión. ¿’ prefieres trabajar gratis para otro?

5. Tu trabajo tiene un precio y por lo tanto, tienes que ponerle un valor aunque no lo cobres.

6. Piensa a medio y largo plazo, porque un proyecto empresarial es una carrera de fondo. Que el éxito o fracaso inicial, no te condicionen en exceso.

7. Piensa en los escenarios posibles y en los objetivos que te planteas a tres, seis y doce meses. 
8. Los proyectos son personas y por lo tanto, las personas que entran y salen de él, condicionan su futuro. No te obsesiones con los que empiezan, ya que puede que no sean los que están contigo hasta el final.

El lienzo es una de las muchas herramientas que pueden utilizar profesores y alumnos para diseñar y poner en marcha un proyecto emprendedor. Lo importante es el objetivo final, que el proyecto sea viable, los caminos pueden ser muchos. Invito también a los lectores a bucear en otras aventuras emprendedoras periodísticas (Domínguez y Pérez, 2012 y 2013) o a bucear en las presentaciones de los Congresos de Periodismo Digital de Huesca para aplicarles el modelo de generación de negocios, y seguir aprendiendo. Y también no hay que perder de vista el nuevo libro de Osterwalder y Pigneur, Value proposition Design.

\section{Bibliografía}

Briggs, Mark (2011). Entrepreneurial Jornalism: how to build what's next for news. Sage. London.

Domínguez, Eva y Pérez Colomé, Jordi (2012). Microperiodismos. Aventuras digitales en tiempos de crisis. Editorial UOC. Barcelona.

Domínguez, Eva y Pérez Colomé, Jordi (2013). Microperiodismos II. Aventuras digitales en tiempos de crisis. Editorial UOC. Barcelona.

Marqués Pascual, Joaquín (2012). La caída de difusión en los diarios de pago. Principales causas y su relevancia en el caso español. Tesis doctoral. Facultad de Comunicació Blanquerna. Universidad Ramón Llull.

Osterwalder, Alexander y Pigneur, Yves (2011). Generación de modelos de negocio. Deusto. Barcelona. 


\title{
El plan de negocio en la formación en emprendimiento para periodistas
}

\author{
Francisco Javier Caro González Universidad de Sevilla
}

(fjcaro@,us.es)

\section{Introducción}

UCE 23 años cuando empecé a impartir la asignatura (ya 1 extinguida) de Empresa Informativa en $4^{\circ}$ curso de Licenciatura de Periodismo de la Universidad de Sevilla, los futuros periodistas contemplaban la materia como una pérdida de tiempo, un capricho de los diseñadores de planes de estudio. En esa época los esfuerzos docentes se centraban en llamar la atención de los estudiantes, en hacerle atractiva una materia desconocida y alejada de su vocación de reporteros indómitos y brillantes comentaristas económicos y políticos. Los objetivos que se planteaban eran mostrar que el periodismo necesitaba de un entramado empresarial para existir, que era necesario algo más que la redacción para que un medio de comunicación pudiese cumplir con la importante misión de ejercer de cuarto poder. Se destacaba la importancia del enfoque sistémico de las organizaciones, de la sinergia, de los departamentos de gerencia, de marketing, de producción o de finanzas.

Al mismo tiempo se incidía en las funciones clave que desempeñan los administradores: planificar, organizar, dirigir y controlar. Con estos conocimientos el alumnado podría desenvolverse en las organizaciones periodísticas y gestionar de forma eficiente los recursos, siempre escasos, si accedía a puestos directivos. 
Con el paso del tiempo llegó el Plan Bolonia y muy cerca en el tiempo la crisis económica.

Conceptualmente Bolonia implicaba un cambio en los métodos de enseñanza. Metodologías participativas, aprendizaje significativo, énfasis en enseñar a aprender. Lamentablemente este planteamiento no fue acompañado de los recursos necesarios por lo que todo cambió para seguir siendo lo mismo, o lo que es peor, más de lo mismo. Es cierto que a algunos profesores esto les sirvió como acicate para reflexionar acerca de los contenidos y la forma de enseñanza que venían utilizando y se produjeron ciertos cambios metodológicos vinculados a proyectos personales.

Con la crisis económica los recursos destinados a la educación experimentan importantes recortes, los grupos de vuelven a ser numerosos, no se pueden contratar a nuevos profesores, no se pueden dotar a las aulas de las últimas tecnologías y los gestores universitarios tienen que hacer verdaderas filigranas para garantizar el mantenimiento de las infraestructuras existentes.

Al mismo tiempo, en el sector de la comunicación se reducen los ingresos por publicidad y venta de ejemplares. Los directivos apuestan por la reducción de costes abaratando la remuneración del personal. Se cierran medios, los ERE se suceden y la tasa de desempleo en la profesión se incrementa un 132\% en el periodo 2008-2013.

Año tras año se modifican los contenidos de la asignatura Empresa Informativa. En 2007 se incluye un capítulo sobre creación de empresas en el libro "Gestión de Empresas Informativas" que se utiliza como manual y cada vez se dedica más tiempo en el aula a presentar iniciativas de nuevos negocios que están surgiendo con la revolución digital y se les pide a los alumnos que elaboren planes de negocio sencillos como trabajo de curso de la asignatura.

El aula se transforma en un punto de encuentro entre los conocimientos tradicionales de la gestión de empresa periodística con las innovaciones en gestión y modelos de negocios que se están produciendo en el mundo de las empresas. La combinación de estos dos territorios tiene como objetivo sugerir a los estudiantes nuevas 
oportunidades de negocio que pueden aprovechar con los principios básicos del management.

El Plan Bolonia conlleva la transformación de los planes de estudio, el paso de la licenciatura al grado. Sorprendentemente, en esta época en la que cada vez es más necesaria fomentar la vocación emprendedora, la asignatura Empresa Informativa, troncal en los antiguos planes de estudios, se considera optativa. Los profesores de la materia observamos atónitos cómo, mientras el resto de la sociedad está dando un giro en la potenciación del emprendimiento en todos los niveles educativos, los diseñadores de planes abogan por restarle importancia.

En cualquier caso en la nueva asignatura "Organización y Gestión de Empresas Periodísticas" se apuesta por utilizar el emprendimiento como eje vertebrador y enseñar la economía de la empresa aplicada a la empresa informativa a partir del diseño de modelos y planes de negocio.

En este contexto la metodología docente que se consolida es la enseñanza por proyectos (plan de empresa). Este sistema responde a las directrices del Plan Bolonia y a las exigencias del mercado de trabajo y de la sociedad. El principal resto es tutorizar adecuadamente los proyectos de grupos de más de 80 alumnos.

El resultado más importante de esta forma de enseñanza es el cambio de actitud de los estudiantes que aprenden a identificar oportunidades de negocio, que entienden que hay que contemplar el fracaso como una inversión en aprendizaje, que es necesario desarrollar la inteligencia ejecutiva que los impele a actuar llevando a cabo los proyectos y que, sobre todo, hay que pensar en términos de innovación planteando negocios orientados a satisfacer necesidades en el mercado o la sociedad de forma rentable.

Las competencias que se cultivan también son muchas: diseño de proyectos, trabajo en equipo, toma de decisiones y comunicación interpersonal.

En definitiva, la enseñanza de la organización y gestión de empresas 
periodísticas bajo el prisma del emprendimiento y la metodología de proyectos contribuye a que los graduados en periodismo dispongan de más herramientas de cara a su inserción laboral, tanto por cuenta ajena como propia. Al mismo tiempo el cambio de actitud facilita la innovación, la competitividad y la necesaria renovación de los modelos de negocios en el sector.

El objetivo de la enseñanza en emprendimiento debe de ser, sobre todo, provocar el cambio de actitudes. Esto implica un aprendizaje significativo y experiencial. También hay que apostar por el diseño de modelos de negocio que vayan más allá del autoempleo. Si queremos que se creen empresas periodísticas sólidas, con capacidad de influencia social y capacidad de crear empleo, hay que apostar por proyectos ambiciosos, basados en las estructura de redes y alianzas, con capacidad de crecimiento y con presencia en un mundo globalizado. El autoempleo está bien pero no es suficiente si queremos un sector de la comunicación fuerte y con proyección de futuro.

\section{El plan de negocio}

El proyecto docente con el que se trabaja en la enseñanza de la empresa informativa en la Universidad de Sevilla se divide en tres bloques.

Un primer bloque orientado a encajar el periodismo como actividad empresarial. A los alumnos de tercero de grado se les explica el concepto de empresa y su importancia en un sistema económico de libre mercado.

En este bloque se ponen de manifiesto las particularidades de las empresas de comunicación frente a empresas de otros sectores: la naturaleza perecedera de la información, la función social de los medios de comunicación, el tipo de trabajo (intelectual y creativo), la bicefalia de las estructuras organizativas o el doble mercado al que atienden.

A partir de este momento se empieza a pensar en términos de proyectos empresariales. Los primeros esbozos de la idea de negocio 
se perfilan utilizando el método Canvas de Osterwalder y Pigneur. Los estudiantes tienen que situar en el centro de sus proyectos una necesidad o un problema informativo que resolver en un grupo homogéneo de clientes dispuestos a pagar por ello. Se insiste en la orientación al mercado de las propuestas y su diferenciación respecto a la oferta existente.

El modelo de negocio con sus nueve bloques es la base para empezar a trabajar en el Plan de Negocio. Éste, en definitiva, se utiliza como estrategia para explicar las diferentes partes de la organización y sus interrelaciones.

La estructura del plan de negocio ayuda a organizar los llamados subsistemas físicos (operaciones, comercialización y financiación) y administrativos de la empresa.

Las funciones secuenciales de la administración (planificación, organización, gestión de personas, dirección y control) acaban recogidas en los planes estratégico (planificación y control) y de organización y recursos humanos.

Además se añaden elementos práctico-legales como la elección de la forma jurídica o los trámites necesarios para poner en marcha una actividad económica.

De esta forma el plan de negocio queda estructurado de la siguiente manera:

1. Índice

2. Resume ejecutivo

3. Constitución y trámites

4. Plan estratégico

5. Estudio de mercado

6. Plan de marketing y ventas

7. Plan de operaciones/producción

8. Organización y recursos humanos 


\section{Plan económico-financiero}

10. Plan de acción

A continuación se analizan someramente los contenidos de cada uno de estos apartados, así como las dificultades que los alumnos tienen a la hora de enfrentarse a ellos.

\section{E1 resumen ejecutivo}

Todo proyecto debe ir acompañado de un resumen de unas dos páginas en el que se destaquen los aspectos más relevantes del mismo. La extensión máxima debe de ser de 2 páginas y describir sucintamente el proyecto empresarial, la forma jurídica, la misión, el servicio informativo, los competidores, el mercado objetivo, el plan de marketing, el plan de operaciones, el plan organizativo y de recursos humanos y por supuesto el plan financiero. El resumen ejecutivo se realiza una vez finalizado el proyecto. La razón de ser de este documento es facilitar la comprensión del negocio a un futuro inversor o colaborador, despertar el interés en el proyecto para que luego profundice en aquellos asuntos que más le interesen. Para el estudiante es un magnífico ejercicio de síntesis, ya que tiene que aprender a priorizar los elementos diferenciadores de su plan.

\section{Constitución y trámites}

En este apartado los estudiantes deben elegir la forma jurídica adecuada para el proyecto empresarial. Tienen que ser conscientes de las implicaciones fiscales, administrativas y de gestión de cada figura y seleccionar de forma argumentada una de ellas. Al mismo tiempo deben de conocer los pasos a seguir para constituir el negocio en el contexto temporal y espacial en el que se desarrolle. Es recomendable que busquen y rellenen los documentos reales como si fueran a poner en marcha la empresa, esta práctica les ayuda a percibir que es posible emprender al visualizar el camino administrativo del emprendimiento: certificación negativa del nombre, alta en la seguridad social, registro mercantil, licencias de apertura, etc. En el contexto económico actual se está produciendo la proliferación de propuestas de negocios de autónomos. Del mismo modo están apareciendo las cooperativas de 
periodistas. Un buen ejemplo es la cooperativa andaluza SBP-CA Impulso Empresarial que se define como "la iniciativa de un grupo de profesionales de trabajar para mejorar la situación laboral del sector, y recuperar el prestigio y la credibilidad de los medios informativos ante la opinión pública

\section{Plan estratégico}

En el plan estratégico se debe definir la misión del negocio, quiénes son, a qué se dedican, qué necesidad pretenden satisfacer en sus clientes y cómo van a hacerlo. En la misión se incluye los valores y la filosofía que va a imperar en la empresa, desde la línea editorial del medio, a temas tan trascendentes como el respeto a los trabajadores, al medioambiente o la preocupación por la calidad o la innovación tecnológica. Los estudiantes tienen problemas a la hora de asociar la oferta informativa en términos de la necesidad que satisfacen en los clientes. Por regla general su propuesta se limita a definir el producto o servicio que quieren llevar a cabo.

En un segundo apartado se aborda la definición de objetivos tanto económicos, como técnicos y sociales. Hay que insistir en la necesidad de que estos objetivos sean realistas y medibles, tienen que cuantificarse y contar con una limitación temporal para que puedan servir como indicadores de control en la ejecución del plan.

En tercer lugar, se debe hacer un análisis estratégico del entorno, recopilando información del macroentorno y del microentorno de la futura organización e identificando los puntos fuertes y débiles de los promotores del proyecto. En este análisis se estudian con detenimiento a los competidores, tanto directos como indirectos y se contempla la posibilidad de que otros empresarios o emprendedores entren en el sector como competidores.

La conclusión de este apartado es un análisis DAFO (Debilidades, Amenazas, Fortaleza y Oportunidades). La información recogida en este documento sustentará la toma de decisiones en las siguientes fases del plan de negocio. Los estudiantes deben buscar información primaria y secundaria que les ayude a decantarse por alguna de las alternativas estratégicas. 
El plan estratégico culmina con la elección de la ventaja competitiva que prefija las estrategias genéricas y de crecimiento adecuadas para el cumplimiento de la misión y de los objetivos. La ventaja competitiva puede residir en la diferenciación del producto o servicio o bien en conseguir los costes de producción más bajos. La primera opción es la más habitual en el caso de las empresas de comunicación.

En este apartado el profesor debe sugerir diversas fuentes de información primarias y secundarias que ayude al estudiante a fundamentar sus análisis estratégicos.

\section{Plan de marketing y ventas}

En el plan de marketing se describe con detalle el producto/servicio del futuro negocio y cuál será la forma adecuada de llegar al público objetivo. En él se presenta la idea empresarial de la manera más atractiva y completa posible.

Las fases que se siguen para elaborar el plan de marketing son: segmentación, posicionamiento y diseño de la mezcla de marketing.

El primer paso es conocer al público o públicos potenciales. Esto implica la elaboración de un estudio de mercado. Los recursos con los que cuenta un estudiante son limitados para conseguir esta información. Por ello el profesor debe sugerirles diferentes estrategias para obtenerlas, desde la búsqueda en fuentes secundarias como informes profesionales; o la realización de pequeñas encuestas, o grupos de discusión, que les ayude a conocer el comportamiento de sus futuros clientes.

El conocimiento del mercado permite decidir la segmentación del mismo y la selección de los nichos más adecuados. En los medios de comunicación se suele hacer una segmentación en función de los intereses informativos. La segmentación geográfica es habitual debido al interés de las audiencias de conocer lo que ocurre en su entorno inmediato. Los segmentos de mercado dan lugar a medios hiperlocales (por ejemplo granadaimedia.com), pero también a medios que nacen con una clara vocación internacional. 
Una vez seleccionado el segmento o segmentos cuya necesidad se quiere satisfacer, se tiene que elegir el posicionamiento de la empresa. El posicionamiento consiste en ubicar el producto/servicio en la mente del consumidor en relación con los productos de la competencia. Es un buen ejercicio que los estudiantes resuman en un eslogan el posicionamiento elegido.

Desarrollamos a continuación las variables del mix de marketing.

En la variable producto/servicio hay que definir, de la manera más detallada posible, cuál es el producto/servicio que se oferta y sus características: temática, periodicidad, papel, impresión, formato...

Se describen aspectos como la interfaz seleccionada, la marca, los infográficos, las secciones, el estilo narrativo, la actualización de los contenidos, las formas de relacionase con las audiencias, el uso de las redes sociales, etc.

La segunda variable a desarrollar es el precio.

En este punto hay que detallar cómo se fijará el precio del producto o servicio. Los estudiantes deben determinar el precio en función de los costes de producción, de los precios fijados por los competidores o el valor que le otorgue la demanda a su oferta.

Asimismo se hace referencia a la existencia de políticas de descuentos y rebajas, los sistemas de cobro que se emplearán para con cada tipo de público: final, intermediario, por suscripción...

Hay que tener en cuenta el doble mercado al que atiende la empresa informativa y fijar un precio de venta a los compradores y otro para los anunciantes por la compra del espacio o el tiempo publicitario.

En la variable de comunicación se diseñan las acciones que va a acometer el emprendedor para dar a conocer el nuevo producto/servicio. Entre las acciones de comunicación más comunes suelen estar: las redes sociales, las promociones de lanzamiento, las campañas publicitarias, las relaciones públicas o los objetos promocionales. 
Por último, la empresa debe elegir los canales de distribución de los productos o servicio. Decidir cómo va a llegar la propuesta de valor a los clientes. Aquí hay una gran diferencia entre los medios impresos y los digitales. Los impresos necesitan contemplar un sistema de distribución y venta, que suele encarecer la oferta informativa, mientras que los digitales hacen un uso intensivo de los formatos móviles para llegar a sus consumidores.

\section{Plan de operaciones}

En el plan de operaciones hay que describir los medios materiales y técnicos que se necesitan para llevar a cabo el proyecto. También se detalla el proceso para su elaboración, desde que se detecta la necesidad en el cliente, pasando por la recolección de la información, su manipulación y transformación, su difusión y el control de los resultados obtenidos.

Los promotores especificarán qué parte del proceso productivo tendrá lugar en el seno de la organización y que parte será subcontratado.

En la descripción del proceso hay que indicar los pasos que se siguen e imputar a cada uno el tiempo y los recursos necesarios para su ejecución, así como asignar a los miembros de la organización que son responsables.

También se lleva a cabo un análisis de los diferentes proveedores de materias primas o servicios. Esta información permite seleccionar a los más adecuados y negociar en función de sus características. En los medios de comunicación es habitual considerar proveedores de información, de recursos digitales, de equipos informáticos, de servicios de asesoría y consultoría, etc.

Este apartado está directamente vinculado con lo que los alumnos estudian en las asignaturas de producción periodística por lo que es conveniente recomendarles que revisen el material de esa asignatura. 


\section{Plan de organización y recursos humanos}

En este apartado se diseña la estructura organizativa del negocio, los mecanismos de coordinación y las personas necesarias para llevarlo a cabo.

Los organigramas de los nuevos negocios suelen ser simples y basados en estructuras participativas en red, pero es importante que los estudiantes se esfuercen en delimitar, al menos teóricamente, las tareas y responsabilidades de cada uno de los participantes en el proyecto y sus relaciones. Hay que definir los puestos de trabajo necesarios (descripción y especificación), agruparlos en unidades organizativas y diseñar los mecanismos de coordinación. Todas las tareas necesarias para elaborar el producto (definidas en el plan de operaciones) tienen que estar cubiertas por los puestos propuestos por los emprendedores.

También se determinará la cantidad y calidad de personas necesarias y la forma de trabajar con ellos, desde el procedimiento de reclutamiento y selección al sistema de remuneración, pasando por la formación y el tipo de contrato.

\section{Plan financiero}

El plan financiero sirve para estudiar la viabilidad económica del proyecto empresarial. El alcance temporal que se propone es de tres años, que se considera el tiempo medio que tarda una nueva empresa en consolidarse. En él se va recogiendo la información que se genera en los diferentes planes parciales: previsión de ventas, precios, inversión inicial, costes de producción, salarios, subcontrataciones, etc.

El plan financiero recoge las estimaciones de inversión y de financiación. Por una parte hay que determinar la inversión inicial necesaria: oficinas, ordenadores, rotativas, patentes, derechos, etc. Y por otra las fuentes de financiación: aportaciones de los socios, préstamos, créditos, ayudas, subvenciones, crowfunding, etc.

También contempla la previsión de ventas en el periodo de tres años. 
Los promotores tienen que justificar la evolución futura de sus ingresos teniendo en cuenta las estrategias que han definido y los elementos externos identificados en el análisis del entorno, como la por ejemplo la estacionalidad de las ventas, o la reacción de la competencia.

Los documentos contables que deben completar, comprender e interpretar son:

El balance de situación, como la foto fija del patrimonio de un negocio en un momento determinado de tiempo.

La cuenta de resultados o de pérdidas y ganancias para conocer la evolución de los beneficios esperados en el periodo de tiempo analizado.

El presupuesto de tesorería para identificar las necesidades de liquidez a lo largo de todo el proceso y garantizar los pagos diarios que deben acometer los emprendedores.

Los estudiantes de periodismo tienen serias dificultades a la hora de afrontar este apartado debido a la aversión que suelen tener a los cálculos numéricos, hay que utilizar muchos ejemplos, ser muy didáctico y paciente para que adquieran los conocimientos básicos para comprender los documentos contables. Es importante no ofrecerles herramientas informáticas (hojas de Excel preparadas para hacer los planes financieros) antes de haber comprendido la función y el funcionamiento que tienen los modelos contables.

\section{Plan de acción}

Para el buen funcionamiento de la actividad el futuro empresario ha de establecerse un calendario de actuación para las distintas acciones que sean necesarias en la puesta en marcha del proyecto empresarial.

En este calendario, que debe realizarse detallando las distintas acciones de manera mensual, tiene que incluir cada actividad, la fecha de ejecución y el responsable de acatarla. Hay que realizar un cronograma lo más detallado posible de las acciones que es necesario 
emprender para poner en marcha el negocio y sus primeros pasos.

\section{Conclusiones}

La enseñanza en emprendimiento en las facultades de periodismo brinda una oportunidad para formar periodistas con un conocimiento holístico de las organizaciones. Las metodologías participativas contribuyen a la combinación de los contenidos teóricos tradicionales en economía de la empresa, con la necesaria exploración del entorno en busca de innovaciones e información que les permita identificar y justificar las decisiones estratégicas a tomar en sus propuestas de negocio. Con esta forma de enseñanza, basada en el proyecto de un plan de negocio, se logran dos importantes objetivos. Primero que los estudiantes comprendan de forma práctica el funcionamiento de las organizaciones periodísticas. Segundo, generar una actitud positiva de los estudiantes frente al emprendimiento y la innovación y estimularlos para que sean proactivos frente a la situación actual, tomando iniciativas y asumiendo el fracaso como parte de la inversión en conocimiento. 



\title{
Experiencia en el aula. La asignatura de Creación de Empresas Informativas
}

\author{
Dr. FJ Paniagua Rojano [CV] [ORCID] [GS] \\ Profesor Contratado Doctor. Facultad de Ciencias de la \\ Comunicación. Universidad de Málaga (España) \\ fjpaniagua@uma.es
}

\section{Introducción}

$\mathrm{D}$ ESDE su irrupción en 2008, la crisis económica ha golpeado de manera exagerada a los medios de comunicación. En el Informe Anual de la Profesión Periodística 2011, Farias (2011:15) describe cómo en los últimos años la profesión pasó del intrusismo a la precariedad laboral, y de la precariedad al paro, hasta llegar a la situación actual, en la que la estabilidad y los problemas de independencia centran las principales preocupaciones de los periodistas.

Casero Ripollés (2013), que describe y define el perfil del emprendedor citando, entre otros, a Audet y Couderet (2012) Obschonda et all. (2010), Rauch y Frese (2007), Pfeilstetter, 2011), Austin, Stevenson et al. (2006), Defourny y Nyssens (2010), propone la incorporación del emprendimiento como competencia docente y formativa en el ámbito de la Empresa Periodística con el apoyo en "metodologías y estrategias docentes para incentivar y motivar al alumnado hacia el autoempleo". (2013:686) 
El Informe de la Profesión Periodística (2013) recoge un censo de hasta 288 medios creados entre 2008 y 2013, apoyados en su mayoría en el formato digital e Internet y alguno en papel, bajo la forma jurídica de sociedad limitada, autónomos o asociación, y financiados, mayoritariamente, por publicidad, patrocinio, micromecenazgo o venta de ejemplares.

La adaptación al Espacio Europeo de Educación Superior (EEES) ha supuesto una profunda renovación del sistema universitario español, al primar la práctica sobre la teoría, al adoptar grupos reducidos en detrimento de las macroclases y al apoyarse en las nuevas tecnologías (Roses, Gómez y Farias, 2012). En este nuevo contexto se han redefinido los roles del alumno y del profesor, donde el estudiante ha pasado a tener un papel mucho más activo en su propio proceso de aprendizaje.

"Shuell resumía en 1986 los cinco rasgos más importantes que debe cumplir el aprendizaje en un sistema de enseñanza orientado al protagonismo del estudiante: aprendizaje activo, aprendizaje autorregulado, aprendizaje constructivo, aprendizaje situado y aprendizaje social. (...) A estos cinco rasgos deberíamos añadir la importancia de generar en los estudiantes universitarios las competencias necesarias para garantizar su aprendizaje permanente" (Peinado, Fernández et al., 2013: 121 122).

Ante la rapidez de los cambios en nuestra sociedad, la universidad como institución educativa, debe ofrecer a los alumnos las herramientas y capacidades necesarias para que sean aprendices a lo largo de toda su vida. La competencia clave es el aprendizaje permanente: han de combinar conocimientos, capacidades y actitudes adecuadas para una determinada situación.

De entre ellas, y por la propia naturaleza de nuestra asignatura, vamos a destacar la competencia del desarrollo del espíritu de empresa, entendido éste como la habilidad de la persona para transformar las ideas en actos y está relacionado con la creatividad, la innovación y la asunción de riesgos, así como con la habilidad para planificar y 
gestionar proyectos con el fin de alcanzar objetivos. Además, se le considera el cimiento de otras capacidades (Peinado, Fernández et al., 2013: 126).

En esta línea, el grado en Periodismo en la Universidad de Málaga (UMA) señala entre sus competencias específicas: el conocimiento de la estructura, funcionamiento y la gestión de las empresas, con especial atención a los medios de comunicación, la empresa publicitaria y la empresa de relaciones públicas; y, el conocimiento de los distintos perfiles profesionales y salidas profesionales de los periodistas.

La importancia de esta asignatura en el plan de estudios del grado de periodismo radica en que

"el conocimiento de la dimensión empresarial de los medios permite al estudiante integrarse profesionalmente con mayor eficacia en estas organizaciones, le aporta técnicas que facilitan su capacidad para asumir en un futuro funciones directivas $y$, ante las importantes transformaciones que experimenta en la actualidad la comunicación social, le proporciona alternativas como el autoempleo y otras salidas profesionales- que le permiten aprovechar las nuevas oportunidades laborales" (Peinado y Fernández Sande, 2011).

Por ello, una de las alternativas laborales sería buscar una salida profesional a través del autoempleo. "No es una tarea sencilla para los recién titulados enfrentarse a nuevos proyectos, pero sí es cierto que es una de las principales oportunidades que se están detectando en la actualidad" (Sabés y Verón, 2012: 165).

\section{Estudio del caso de la asignatura Creación y Gestión de Empresas Informativas en la Universidad de Málaga}

En el curso 2013/2014, se matricularon en la asignatura de Creación y Gestión de Empresas Informativas 58 alumnos, de un máximo de 60 plazas ofertadas, de los cuales, 30 eran mujeres y 28 hombres. Tres de los matriculados eran estudiantes de Séneca (2) y Erasmus Mundi (1). La metodología combina criterios cualitativos y cuantitativos. 
El detalle de la metodología propuesta puede consultarse en el artículo original anteriormente citado.

\section{Principales resultados}

\subsection{Respecto a la asignatura}

En cuanto a la valoración de la asignatura, la mayoría de los estudiantes valoran de manera muy positiva su experiencia en la materia. Tal es así, que el 100 por cien considera muy interesante tanto los contenidos como el programa de la misma, y el 95,6 por ciento la recomendaría a otros compañeros.

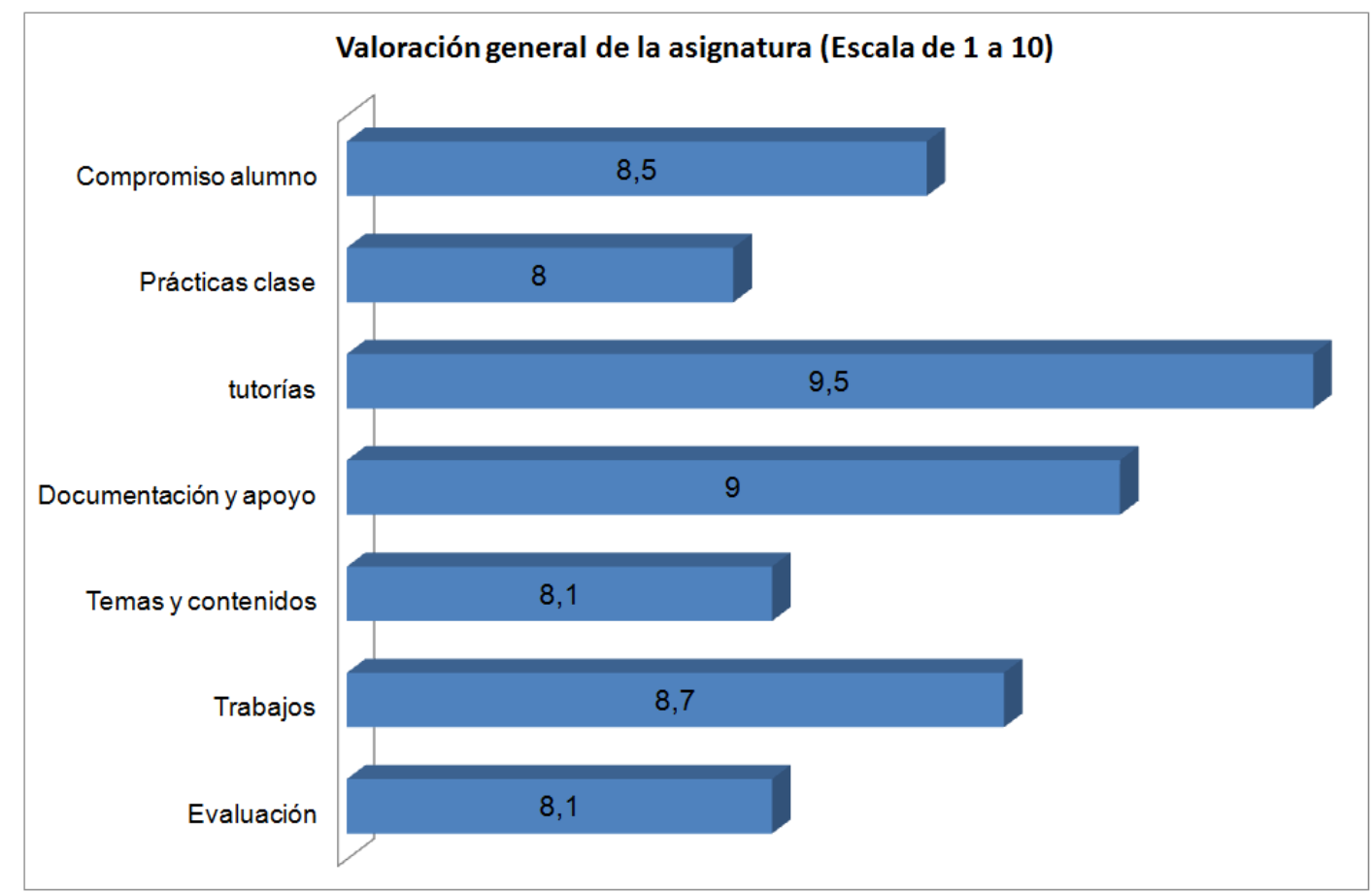

Ilustración 1. Fuente: Encuesta a estudiantes a través del campus virtual. Elaboración propia

En este sentido, los estudiantes consultados en el encuentro cualitativo, destacan la conexión de la asignatura con la realidad y la actualidad de la profesión; al tiempo que aseguran, que tras haber cursado esta materia más de uno se plantearía ser su propio jefe y 
crear una empresa periodística, si bien alguno confiesa que ya lo había pensado antes.

Otros también destacan que, a pesar de que la asignatura tan sólo ocupa un cuatrimestre y que es un periodo de tiempo muy corto para este tipo de contenidos, se obtiene una visión global del mundo empresarial, centrado el ámbito de la comunicación. Los alumnos también señalaron que en esta asignatura tuvieron la posibilidad de poner en práctica conocimientos y destrezas adquiridas en otras materias, remarcando así la relación transversal entre asignaturas.

Estudiante 9. "Más que teoría, en esta asignatura hemos visto lo que hay fuera, y nos ha gustado el carácter práctico de la asignatura"

Estudiante 3. "Gracias a esta asignatura, algunos hemos pensado en la posibilidad de que podemos ser nuestro propio jefe. Tú mismo puedes crear una empresa y no tener que ir a buscar un puesto de trabajo. Y trabajar en lo que te gusta $y$ poder vivir de ello"

Estudiante 1. "Yo creo que lo mejor de la asignatura es que al final tienes una visión de la empresa al completo, desde que se toma la decisión de crearla hasta diseñar su plan de difusión, identificar sus públicos, o pensar en su viabilidad. Es decir, ver la realidad que hay fuera"

Estudiante 4. "Nos ha dado una visión más transversal y hemos entendido conceptos vistos en otras asignaturas"

Respecto a la valoración que realizan de la asignatura (ilustración 2), el alumnado resalta la importancia de las tutorías de grupo con el profesorado, así como la documentación de apoyo y materiales (páginas web, archivos de vídeo y audio, etc.) facilitados a través del campus virtual; aspectos que son evaluados con un 9,5 y un 9 sobre 10, respectivamente. Esta puntuación coincide con la opinión mayoritaria de los participantes en el grupo de discusión, donde destacan además el buen funcionamiento de las tutorías y la utilidad 
del material facilitado, aunque reconocen no haberle sacado todo el provecho posible.

Estudiante 3. "Las tutorias en grupo han funcionado bien, porque en ellas podiamos analizar los errores y el planteamiento del trabajo"

En cuanto a la valoración de los trabajos propuestos por el profesorado, éstos obtienen una media de 8,7 sobre 10 . Tal y como pudimos constatar en los grupos de discusión, los estudiantes afirman tener una experiencia positiva, tanto en el caso del trabajo individual como en el proyecto de empresa. Aún así, en este balance global los alumnos también hacen autocrítica, sobre todo en aspectos como la elección de la temática del proyecto de empresa periodística, ya que varios grupos se dejaron llevar más por gustos y preferencias personales, que por las salidas laborales o por las necesidades del mercado.

Estudiante 6. "Yo el trabajo individual lo vi útil, porque acceder a nuevos medios es muy útil, porque nos facilita nuevos puntos de vista, información sobre cómo enfocar nuestra empresa..."

Estudiantes 3 y 4. "Cogimos el proyecto sobre cultura, porque era un campo que nos gustaba, y creíamos que en Málaga, además, es un sector con fuerza, y pensamos que babia más nicho de mercado. Otra cosa es la demanda real en la calle. Aunque la necesidad también bay que crearla." Estudiante 1. "Nosotros elegimos el tema por hacer algo serio de verdad y porque creemos que no existe en Málaga."

Estudiante 8 "Yo lo bice porque no hay nada en el mercado y porque el unico caso que conozco, funciona, pero tiene carencias."

Estudiante 5. "La idea la tenía desde hace tiempo. Y creemos que no bay nada en el mercado, asi que puede tener nicho de mercado. Y, hasta puede que más adelante retomemos la idea para ponerla en marcha de verdad"

De esta forma, los estudiantes participantes en el grupo de discusión proponen algunos cambios en cuanto a trabajos de clase se refiere, 
que, en su opinión, mejorarían la asignatura. Así, por ejemplo, sugieren anticipar la fecha de entrega del trabajo individual y que además se analicen en clase los resultados del mismo, con el fin de enriquecer después el trabajo grupal. Igualmente, un alumno incluso, haciendo autocrítica, asegura que se debería incentivar y premiar la creatividad en los formatos de entrega de los trabajos.

Estudiante 5. "Cambiaría que el trabajo individual que se entregara y se evaluara antes, porque puede sugerir muchas ideas para tu proyecto de empresa."

Estudiante 1. "Yo creo que estaría bien que se analicen y se expongan en clase ejemplos de proyectos que han surgido en los últimos años."

Estudiante 5. "Dedicar una clase a poner en común las conclusiones obtenidas de las entrevistas o los reportajes sobre empresas surgidas durante la crisis."

Estudiante 5. "Hacer el trabajo final por fases me parece bien planteado. Ahora bien, yo aprovecharía más las clases prácticas en ver casos de análisis de la competencia, elaboración de presupuestos..."

Por otro lado, los alumnos evalúan su nivel de compromiso con la materia con un 8,5 sobre 10 . Respecto al sistema de evaluación, si bien los estudiantes afirman estar de acuerdo de manera general con el planteamiento del profesorado, algunos consideran que, en cuanto al trabajo en grupo (diseño de un proyecto de empresa), el peso o la importancia que tiene la evaluación a propuesta de la clase (sus compañeros) en el cómputo global de la nota es excesivo, al considerar que alguno se puede dejar llevar más por quién o quiénes son los autores del trabajo (factor amistad) que por el contenido y la calidad del proyecto presentado.

Estudiante 3. "Me parece bien la forma de evaluar. Que nos evalúe tanto el profesorado como los compañeros de clase. Además somos jóvenes y la forma de pensar es la misma y la afinidad de edad siempre aporta ideas y su evaluación es interesante en ese sentido. Es un punto a favor para poder encauzar el proyecto." 
Estudiante 1. "Lo veo bien, siempre que los estudiantes no se dejen influenciar por las amistades a la hora de evaluar a sus compañeros." Estudiante 3. "Debemos ser responsables en la evaluación y no dejarnos llevar."

Estudiante 8. "El que coincidan varios proyectos de la misma temática te ayuda, porque hay más competitividad y ves antes los fallos, y te esfuerzas más en buscar diferencias..."

Estudiante 2. "La situación de incertidumbre laboral nos condiciona mucho y por eso somos más críticos y estamos más concienciados a la hora de valorar los proyectos."

Al finalizar la asignatura, la mayoría de los estudiantes reconoce que ésta les ha resultado provechosa, hasta tal punto que, antes de cursarla, solo un 39 por ciento había pensado alguna vez la posibilidad de crear una empresa periodística, frente al 61 por ciento que nunca lo había pensado; y ahora, una vez finalizada la materia, un 91 por ciento sí se plantea esta opción como salida laboral. Un dato a tener en cuenta sobre todo en un momento como el actual, donde las opciones del "microperiodismo especializado" son mayores que las de trabajar en un grupo multimedia.

Estudiante 3. "No me lo habia planteado, porque antes pensaba en trabajar en un medio ya existente, y coger experiencia antes de plantearme esta opción. Ahora bien, durante el curso, en la asignatura, con los trabajos y las charlas, sí que nos entró un poco el 'gusanillo'. Entonces nos pensamos buscar un nicho de mercado no demasiado explotado y, ¿por qué no? Es probable que nos abra otras posibilidades en un momento de incertidumbre.

Estudiante 4. "Hasta cuarto curso no teníamos muchos conocimientos de cómo poner en marcha una empresa, ni de que esta opción también estaba presente para los periodistas. Cuando empiezas la carrera no piensas en iniciar un proyecto desde cero." 
Estudiante 3. "A pesar de ser, en principio, contenidos lejanos a nuestra carrera, una vez que conoces este otro lado de la profesión, empiezas a planteártelo."

Estudiante 5. "Ya sea de manera real o artificial, todos hemos pensado alguna vez crear nuestra propia empresa periodística. Una vez cursada la asignatura tienes muchos más conocimientos, pero al final lo que importa es la viabilidad económica. Es básico en cualquier empresa."

Estudiante 1. "Si, nos lo habiamos planteado antes. Porque nos gustaba la idea de crear un medio más social, que se preocupe por otros temas fuera de la agenda institucional, como el medio ambiente, temas sociales. Un medio enfocado más a una población reducida o segmentado en una microtemática, por los barrios de la ciudad... La asignatura nos ayudó a matizar en esta posibilidad."

Estudiante 2. "Si lo habiamos pensado. Creo que por la circunstancias actuales de incertidumbre en la profesión, ya que incluso es difícil acceder a unas prácticas. Habiamos pensado alguna vez crear un medio de este tipo, y una vez cursamos la asignatura de Creación de Empresas nos hemos animado más."

Estudiante 6. "Conocer las ayudas, subvenciones, los incentivos de las instituciones, nuevas formas de financiación... Todo eso nos viene bien, y nos da otro punto de vista. No sabiamos que existian. Nadie nos habia puesto en contacto con esa realidad."

Estudiante 5. "La economía es un condicionante importante para decidir crear una empresa. Si no tienes respaldo, es probable que no salga adelante el proyecto. Evidentemente lo importante primero es la idea, que funcione, pero en un tiempo razonable debe ser rentable."

Estudiante 7. "Sin viabilidad económica, el proyecto se convierte más bien en un bobby en lugar de una empresa"

Estudiante 2. "Creo que lo primero es el tema. Buscar un tema que funcione, y a partir de ahi, buscar la rentabilidad." 
Esto confirma las hipótesis planteadas en el presente trabajo, que los estudiantes de Periodismo, a priori, no se plantean el autoempleo como salida laboral, probablemente, porque eligieron esta titulación influenciados por el componente de mitificación de la profesión periodística. Pero que si se les incentiva durante sus estudios, y con alguna materia específica en la que se les forme en contenidos más relacionados con la empresa y el emprendimiento, muchos pueden cambiar de opinión y plantearse la creación de una empresa periodística como salida profesional.

En lo que respecta al rendimiento del alumnado en la asignatura, en general, se puede considerar satisfactorio, si se tienen en cuenta las calificaciones finales. De los 52 evaluados en la primera convocatoria, un 51 por ciento obtuvo un notable, mientras que un 19 por ciento sobresaliente -tres de ellos matrícula de honor-, un 12 por ciento un aprobado y un 10 por ciento suspendió -la mayoría por no entregar (o hacerlo tarde) el trabajo individual-.

\subsection{Sobre el trabajo individual}

Uno de los trabajos que se planteó al alumnado para su evaluación fue la realización de un reportaje o una entrevista en formato escrito o audiovisual sobre una empresa periodística creada durante la actual crisis económica (2008-2013) y que en la actualidad esté funcionando. Este apartado, titulado "Cómo crear una empresa y sobrevivir en el intento", tenía como primer objetivo motivar al estudiante y despertar el interés por la asignatura y sus contenidos, toda vez que en esta tarea podía conocer de primera mano cómo a pesar de la compleja situación económica nacen medios de comunicación..

Entre los objetivos que se perseguían con esta activad estaban, en primer lugar, analizar diferentes elementos y contenidos estudiados en la asignatura, tales como la forma jurídica de las empresas creadas, el análisis del contexto, sus fortalezas y debilidades, sus formas de financiación, éxitos y fracaso, etc. Y, en segundo lugar se pretendía 
que el estudiante se familiarizara y trabajase en la documentación necesaria para un proyecto de empresa.

Así, inicialmente, el profesorado ofertó en el campus virtual hasta 28 ejemplos de medios creados entre 2008 y 2013 en España, y el propio alumnado fue completando esta lista, incrementando así las opciones de elección, siendo el abanico de posibilidades al final de 39 empresas, que se fueron completando con listados como los publicados en el Informe Anual de la Profesión Periodística 2013 y el blog Periodismo emprendedor del profesor de la Universidad de Castilla la Mancha, Juan Luis Manfredi.

La media de la nota de la clase en este trabajo es de 6,88 sobre 10 , si bien en este sentido conviene destacar, que en general los trabajos están bien en su contenido, pero solo el 59 por ciento optó por una presentación más elaborada y trabajada en formatos audiovisual o periódico, y esto influyó en la nota media final.

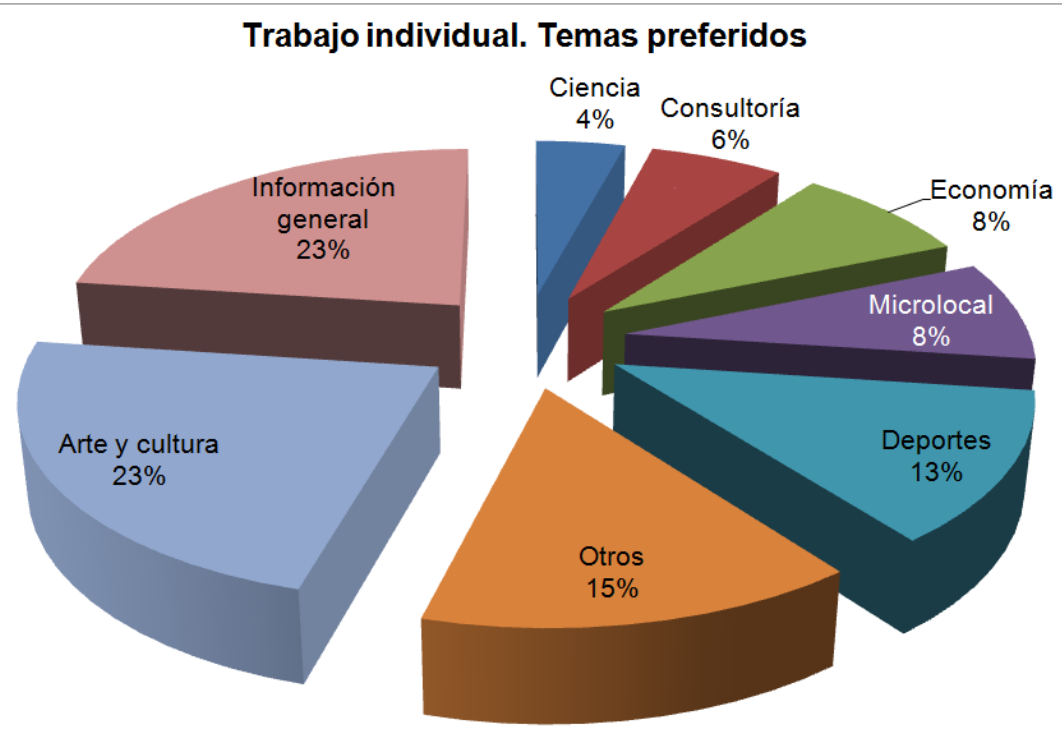

\section{Ilustración 2. Fuente y Elaboración propia}

La mayoría de los estudiantes optaron por realizar esta tarea sobre medios de comunicación de reciente creación dedicados a la información general (23 por ciento), y especializados en arte y cultura (23 por ciento). Por su parte, un 13 por ciento hizo lo propio con 
medios deportivos y un 8 por ciento con medios de información microlocal y económica.

Respecto a las dificultades encontradas, varios estudiantes señalan que no todos corrieron la misma suerte a la hora de contactar con profesionales que trabajasen o dirigiesen empresas creadas durante la crisis fundamentalmente, por la falta de colaboración de los profesionales con los estudiantes a la hora de contactar con ellos o facilitar información.

Estudiantes. "Hemos tenido dificultades para contactar con los nuevos medios, suponemos que por problemas de horario de trabajo"

Estudiante 5. "En mi caso tuve problemas y falta de colaboración. Incluso me dijeron que ni en una auditoría le hacian tantas preguntas..."

\subsection{Sobre el proyecto de empresa}

Para el trabajo colectivo, elaborar un proyecto de empresa informativa, que sea viable en la actualidad y dentro del marco jurídico español, se crearon 16 grupos de trabajo, con una media de 4/5 estudiantes cada uno. En dicho trabajo, se debía reflexionar y proponer: misión y visión de la empresa, forma jurídica, análisis del contexto, cobertura y competencia de la empresa, plan de difusión y marketing; definir las secciones, contenidos y servicios; y elaborar un presupuesto y un plan de viabilidad financiera.

De entre los proyectos empresariales propuestos por los alumnos destacan: varias revistas digitales de contenidos culturales y de ocio (Culmumanía, Cultura Próxima, Cultura Somos, Changuay, Recorre Málaga); o de información general y local (Faro XIX, Zoombuzzy Crónica M); deportiva (11 amigos); un periódico universitario para estudiantes Erasmus (No so far away); una revista digital centrada en el periodismo humano y las historias de las personas (Yast Amazing Stories); una radio local online (Radio 29); una revista de moda (Pasarela España); una revista digital educativa para adolescentes (Entérate); y, una consultoría (Socialwords). 


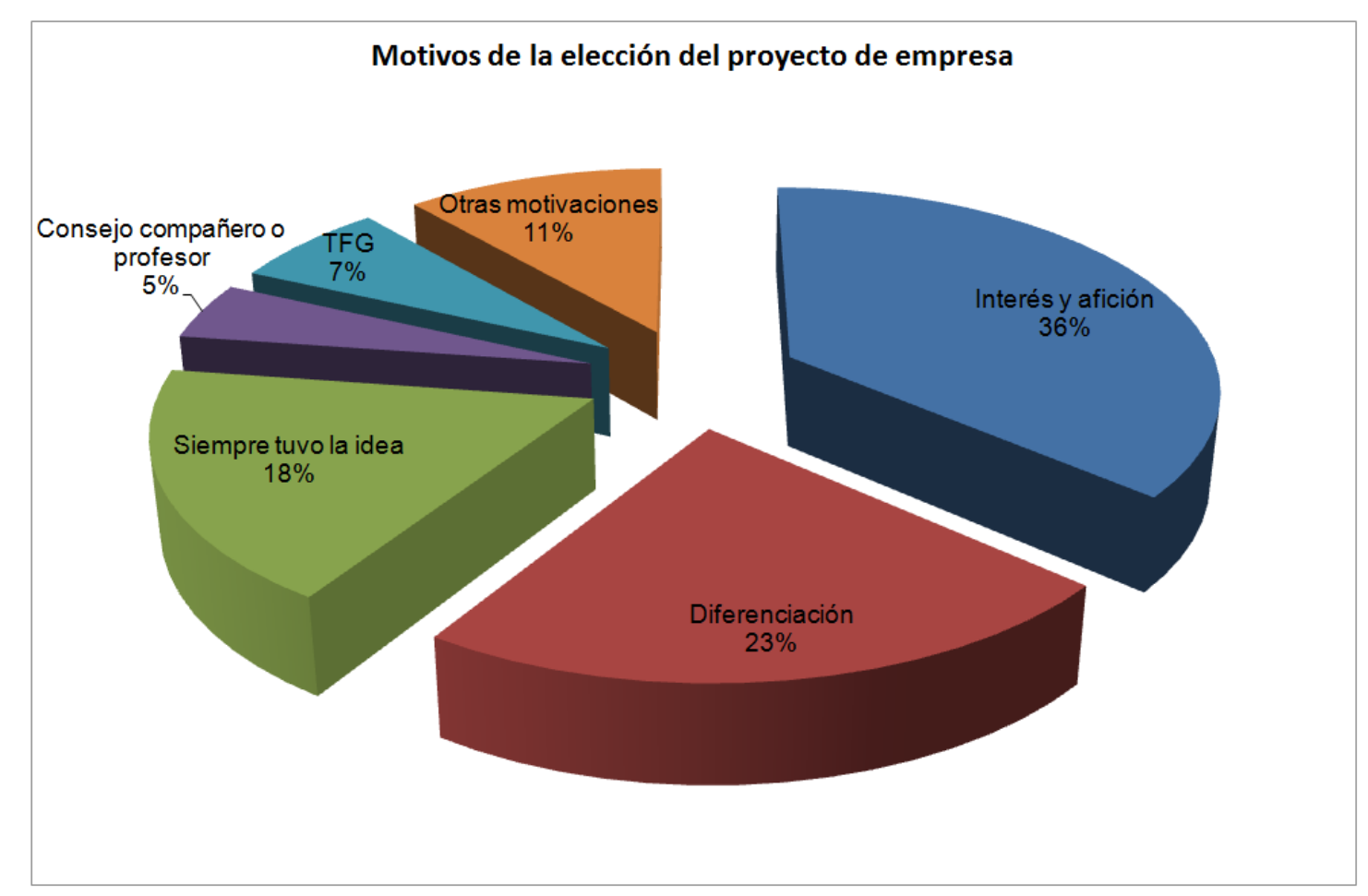

Ilustración 3. Fuente: Encuesta a estudiantes a través del campus virtual. Elaboración propia

En la elección de la temática de la empresa los estudiantes se guiaron por una serie de motivaciones: el 100 por cien de los grupos lo hicieron movidos por intereses y aficiones personales; un 62,5 por ciento lo hizo por diferenciarse de otros proyectos; mientras que el 50 por ciento aludió que siempre tuvo la idea de crear una empresa similar. 


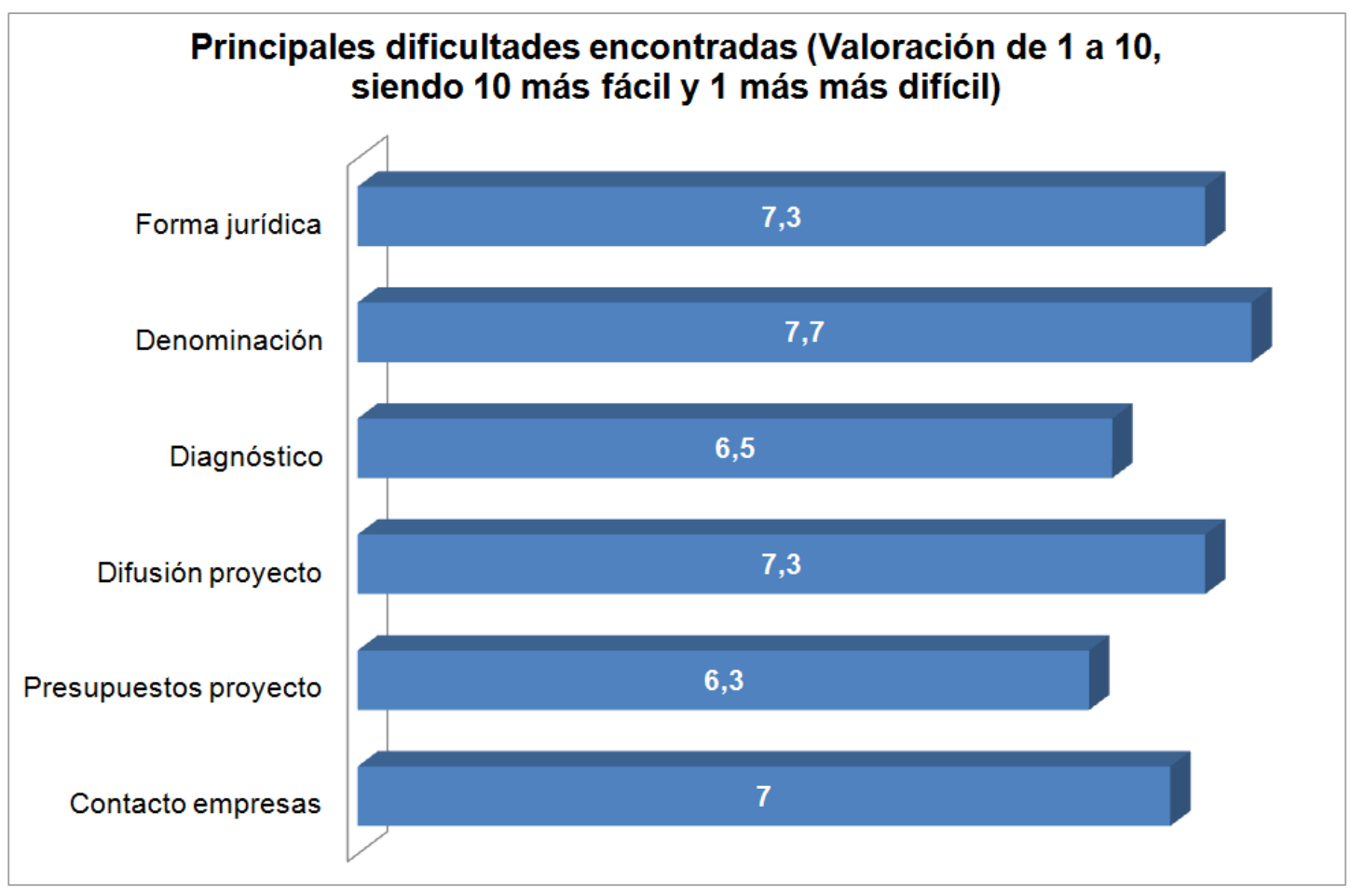

\section{Ilustración 4. Fuente: Encuesta a estudiantes a través del campus virtual. Elaboración propia}

Respecto a las dificultades encontradas en la realización del trabajo, los estudiantes destacan, fundamentalmente, la elaboración de los presupuestos y el plan de viabilidad así como el análisis del contexto y de la competencia. Estos datos nos hacen reflexionar sobre la necesidad de reforzar los contenidos económicos en los próximos cursos.

Estudiantes. "La mayor dificultad fue elaborar los presupuestos. Tenemos una deficiencia importante en economía y no es fácil cuadrar ingresos y gastos. También es dificil calcular el feedback que tendriamos.."

Estudiantes. "El análisis de la competencia y del contexto fue complicado. Nos falta conocer mejor herramientas y fuentes de información para documentarnos."

Estudiante 1. "No siempre es fácil encontrar herramientas para valorar a la competencia." 
El proyecto empresarial, que suponía el 60 por ciento de la calificación final de la asignatura, se evaluaba de la siguiente forma: Una nota propuesta por el profesorado de la asignatura, con un peso final del 30 por ciento en la calificación, una nota propuesta por la clase una vez expuestos los proyectos y difundidos en páginas web, blogs y redes sociales; y una nota puesta por los integrantes de cada grupo a sus compañeros y compañeras de proyecto.

Así, la media de la nota final de la clase en este apartado fue de 7,77 sobre 10. Ahora bien, si observamos las calificaciones otorgadas de manera diferenciada por alumnos y profesores, vemos que el alumnado fue, en general, crítico con los trabajos, donde la nota media otorgada por la clase en conjunto fue de un 6,5; por su parte, la nota media otorgada por el profesorado fue de un 8,07; mientras que los grupos se puntuaron internamente con una media de 8,5 .

Cabe resaltar como reflexión final, que en general la motivación del alumnado con esta tarea fue bastante alta, hasta tal punto que cada grupo o proyecto acudió a tutorías hasta en $7 / 8$ ocasiones, y algunos estudiantes a título individual o por el proyecto hizo lo propio 5/6 veces, sobre todo por el interés en continuar con el proyecto una vez finalizada la asignatura. Esta idea refuerza la necesidad de incentivar al alumnado con contenidos y asignaturas relacionadas con la creación de empresas periodísticas, en las que se les presenten alternativas a las salidas profesionales tradicionales.

Como herramienta de apoyo a la docencia y complemento del campus virtual, durante el curso se utilizaron también Twitter y Facebook como instrumentos de comunicación interna de la clase. En el caso de Twitter, se creó una lista con los estudiantes matriculados y el profesorado, que usaban el hashtag \#CyGEmpInf para el seguimiento de la información relacionada con la asignatura. En este caso, se usó Twitter como tablón de anuncios fundamentalmente en la primera fase de la docencia, y tanto estudiantes como profesor (e incluso profesores de otras asignaturas) compartieron enlaces de artículos, iniciativas, proyectos y bibliografía 
de interés para la materia. Igualmente se incentivó el debate entre profesionales del sector en la provincia de Málaga y el alumnado.

En la segunda fase, una vez creados y puestos en marcha los proyectos empresariales de cada grupo, se usó también Twitter para la presentación de las iniciativas e incluso para el plan de difusión de cada proyecto, siempre con la etiqueta indicada para que el resto de la clase pudiera seguir la información. Trece de los proyectos empresariales propuestos por el alumnado en la asignatura crearon un perfil en Twitter para la difusión de la iniciativa entre sus compañeros.

En esta etapa, se creó también una página de Facebook, en la que cada grupo aprovechó para la difusión entre sus compañeros de su proyecto. Todos los estudiantes implicados en la asignatura siguieron como fans la página de Facebook, utilizada exclusivamente para la difusión de los proyectos de empresa propuestas. Así, cada grupo compartió enlaces a sus páginas web o blogs, anuncios de difusión y/o su identidad corporativa, un vídeo corporativo de presentación o simplemente post con mensajes destinados a sus compañeros.

Facebook, probablemente, fue la red social que más motivó a los estudiantes, ya que la mayoría tienen cuenta y se manejan mejor en esta red. La mayoría de los proyectos de grupo abrieron su propia página en Facebook con el objetivo de dar a conocer su iniciativa tanto a sus compañeros de clase como a sus seguidores; e incluso, la mayoría compartió en sus cuentas personales sus proyectos de la asignatura, despertando en algún caso el interés en su entorno.

\section{Conclusiones}

Tras una revisión bibliográfica primero, y el estudio de las respuestas de los estudiantes, tanto en la encuesta como en el grupo de discusión, después, parece claro que cada vez más, asignaturas como Creación y Gestión de Empresas resultan necesarias, ya no en la titulación de Periodismo, sino en todas o casi todas las titulaciones universitarias, y más si cabe, en un momento como el actual, en el que 
el modelo de negocio informativo está sufriendo unos cambios profundos a causa no solo de actual crisis económica, sino también por los cambios de hábitos de consumo de la información en la audiencia y la aparición de los nuevos medios que ofrecen nuevas posibilidades de generar contenidos informativos y nuevas formas de negocio.

No obstante, se observa entre el alumnado una serie de carencias formativas en relación con esta materia, como por ejemplo en contenidos relacionados con la economía, la empresa, la elaboración de presupuestos o el análisis del contexto y la competencia para poder poner en marcha una iniciativa empresarial. Esto implica la necesidad de mejorar la coordinación.

Llama la atención, según los resultados de los trabajos propuestos por los estudiantes y las respuestas de la encuesta, el escaso interés por la especialización en materias, que a día de hoy, por sus características y relación con el entorno, puedan tener más salidas profesionales, como por ejemplo en los ámbitos turístico o sanitario.

Por este motivo, se sugiere una mayor coordinación con otras disciplinas, para buscar sinergias y complementos en la asignatura de Creación y Gestión de Empresas Informativas, toda vez que el origen de cualquier empresa periodística está en los conocimientos previos de las primeras.

Incluso, puede resultar de interés la búsqueda de sinergias entre diferentes titulaciones de la oferta académica de la Universidad, e intentar en algún momento del curso unir a estudiantes de diferentes carreras con el objetivo de fomentar la creación de empresas interdisciplinares, o bien, de incluir a una persona de comunicación en cada proyecto empresarial, ya que de alguna manera toda iniciativa necesita de la comunicación.

Asimismo, resulta recomendable estimular la relación entre universidad y empresa, con el objetivo de acercar nuevos proyectos informativos a los estudiantes y viceversa. En este caso, se observa 
que la iniciativa propuesta de realizar un trabajo de documentación sobre empresas nacidas durante la crisis y que sobreviven en el intento, ha sido bien valorada por los estudiantes, que se apoyaron en esta tarea, bien para conocer otras alternativas a los medios tradicionales, bien para documentarse para el proyecto empresarial del trabajo en grupo e incluso, en algún caso, para hacer contactos con empresas en las que poder trabajar u optar a una beca de prácticas.

Igualmente, es necesario trabajar en la conexión con la sociedad y las instituciones que fomentan el emprendimiento en el entorno más cercano, a través de jornadas, encuentros o seminarios, que ayuden a conocer mejor la normativa, posibles ayudas, subvenciones $\mathrm{y}$ diferentes fórmulas de financiación, que los estudiantes, en su mayor parte, desconocen y que pueden resultar útiles para incentivar la puesta en marcha de proyectos empresariales.

Por último, se sugiere la creación de un observatorio de autoempleo periodístico, con el objetivo de poder realizar un seguimiento de los egresados que opten por esta opción laboral y poder analizar su evolución, que además puede servir de estímulo entre el alumnado.

\section{Referencias bibliográficas}

ANECA (2005): Libro Blanco. Titulos de grado en Comunicación. Madrid: Agencia Nacional de Evaluación de la Calidad y Acreditación.

Arquero, J.L. (2006): "Estilos de aprendizaje y tolerancia a la ambigüedad de los estudiantes universitarios. Diagnóstico y reflexiones ante el EEES”. Revista de Enseñanza Universitaria, 28. Sevilla (España), pp. 7-17, recuperado el 18 de diciembre de 2013, de http://institucional.us.es/revistas/universitaria/28/01.pdf.

Campos Freire, F. (2010): "Los nuevos modelos de gestión de las empresas mediáticas”. Estudios sobre el Mensaje Periodístico. Vol. 16, Madrid: Servicio de Publicaciones de la Universidad Complutense, pp.13-30, recuperado el 22 de marzo de 2014 de, http://revistas.ucm.es/index.php/ESMP/article/view/ESMP101011 $\underline{0013 \mathrm{~A} / 11317}$ 
Casero Ripollés, A. y Cullell-March, C. (2013): "Periodismo emprendedor. Estrategias para incentivar el autoempleo periodístico como modelo de negocio". Estudios sobre el Mensaje Periodístico. Vol. 19, Madrid: Servicio de Publicaciones de la Universidad Complutense, pp.681-690, recuperado el 22 de marzo de 2014 de, http://revistas.ucm.es/index.php/ESMP/article/view/42151/40130

Esteban, C. (2012): "Las nuevas profesiones del Periodismo" Cerezo, J. (2012) El futuro del periodismo. Madrid: Cuadernos Evoca Comunicación e Imagen, pp.5-10, recuperado el 20 de marzo de 2014 de, http://www.evocaimagen.com/cuadernos/cuadernos7.pdf

Farias, P. (Dir.) (2008): Informe anual de la profesión periodística. Madrid: Asociación de la Prensa de Madrid, pp- 68-70

---- (2009): Informe anual de la profesión periodística, Madrid: Asociación de la Prensa de Madrid, p.: 126

--- (2011): Informe anual de la profesión periodística. Madrid: Asociación de la Prensa de Madrid, pp-15-18

Gómez, M.; Roses, S. y Farias, P. (2012): "El uso académico de las redes sociales en universitarios”. Comunicar, 38. Huelva (España), pp.131-138, recuperado el 20 de enero de 2014, de http://www.revistacomunicar.com/index.php?contenido=detalles\&n umero=38\&articulo $=38-2012-16$. DOI:

http://dx.doi.org/10.3916/C38-2012-03-04

Ministerio de Educación y Ciencia (2005): Espacio Europeo de Educación Superior. Madrid: MEC.

Palacios Llanos, L. (2013): Informe Anual de la Profesión Periodística 2013. Madrid: Asociación de la Prensa de Madrid, pp. 74-83

Peinado-Miguel, F.; Fernández, M.; Ortiz, MA. y Rodríguez, D. (2011): "Hacia un aprendizaje activo de la Empresa Informativa en el EEES. Aplicación del podcasting y otras herramientas de comunicación 2.0”, en Razón y Palabra, 75. México: TEC de Monterrey, recuperado el 8 de noviembre de 2013, de http://www.razonypalabra.org.mx/N/N75/varia 75/varia3parte/38 Peinado V75.pdf. 
--- (2013): “Aprendizaje e innovación: una propuesta metodológica desde la Empresa Informativa", en Revista Latina de Comunicación Social, 68. La Laguna (Tenerife): ULL, pp. 119-144, recuperado el 8 de noviembre de 2013, de

http://www.revistalatinacs.org/068/paper/971 Complutense/05 Pe inado.html.

Sabés, F. y Verón, J.J. (2012): "Universidad y empresa ante la doble crisis del periodismo tradicional. Propuestas y reflexiones sobre la modificación sustancial del escenario periodístico. El clúster periodístico". AdComunica. Revista Científica de Estrategias, Tendencias e Innovación en Comunicación, 4. Asociación para el Desarrollo de la Comunicación adComunica, Universidad Complutense de Madrid y Universitat Jaume I, Castellón, pp. 151-170, recuperado el 20 de enero de 2014, de

http://repositori.uji.es/xmlui/bitstream/handle/10234/53539/74123-1-PB.pdf?sequence $=1$.

Sánchez Tabernero, A. (2008): "Luces y sombras de un sector en crisis". FARIAS BATLLE, P. (2008): Informe Anual de la Profesión Periodística 2008. Madrid: Asociación de la Prensa de Madrid, , p. 25

Santamaría, F. (2010): "Evolución y desarrollo de un Entorno Personal de Aprendizaje en la Universidad de León". Digital Education Review, 18. Barcelona: UB, pp. 48-60, recuperado el 8 de noviembre de 2013, de http://greav.ub.edu/der/index.php/der/article/view/171/300.

Yuste, B. y Cabrera, M. (2014): Emprender en Periodismo. Nuevas oportunidades para el profesional de la información. Madrid: Editorial UOC, pp. $65-73$ y $87-132$ 


\title{
Las nuevas competencias de los graduados universitarios en Periodismo
}

\author{
Francisco Cabezuelo Lorenzo (Universidad de Valladolid)
}

La crisi consiste appunto nel fatto che il vecchio muore e il nuovo non può nascere: in questo interregno si verificano i fenomeni morbosi più svariati."

(Antonio Gramsci)

\section{Introducción y justificación}

Q IN DUDA alguna, vivimos tiempos de cambio, cambio $\checkmark$ constante o permanente. Y en este contexto estamos: analizando un período que da lugar a las interpretaciones más variopintas. La industria de la comunicación entra en una nueva encrucijada sin haber salido todavía de la anterior (Carvajal Prieto, 2012: 01). Surgen así nuevas secciones, rediseños y maquetaciones, contenidos, formatos, $y$ aunque nadie se pare a pensarlo, surgen también nuevas necesidades y/o nuevas demandas a las que dar respuesta. Detrás de todos estos cambios se encuentra un profesional de la comunicación que debe buscar en su caja de herramientas los recursos profesionales con los que enfrentarse con éxito a los nuevos retos.

Desde el respecto a la pluralidad de las más diferentes concepciones de la investigación y de la docencia universitaria en el área de las Ciencias de la Comunicación, este trabajo pretende dar respuesta a 
estos interrogantes y abrir también otros nuevos para el debate sobre las competencias del periodista e incluso para la puesta en práctica de nuevas metodologías didácticas. El hasta ahora tradicional proceso de enseñanza-aprendizaje se resiente y da lugar a nuevo entorno en el que las competencias digitales son vitales desde la entrada de los alumnos el primer día de clase a las aulas de las facultades de Ciencias de la Información y la Comunicación (Sierra Sánchez y Cabezuelo Lorenzo, 2009: 01). Además, este trabajo presta una atención especial al desarrollo de competencias digitales, altamente necesarias para los futuros profesionales del mañana que se forman hoy en nuestras aulas.

Del mismo modo, no hay que olvidar que el trabajo del profesional de la comunicación va vinculado a una alta responsabilidad social. He ahí la importancia de su formación en valores y de la exigencia de calidad y rigor en su quehacer diario, independientemente de su medio, ya que "tanto periódicos y revistas como los programas informativos o de entretenimiento de medios como la radio, la televisión, etc., o portales de noticias en Internet, intervienen activamente en la generación de opinión y en la construcción de la realidad” (Caro González, García Gordillo, Jiménez Marín, 2007: 395).

\section{Marco teórico e interrogantes para la reflexión}

Con motivo de la puesta en marcha del Espacio Europeo de Educación Superior (EEES), conocido popularmente como 'Plan Bolonia', la academia española, en general, y la propia de las Ciencias de la Comunicación, en particular, se han puesto a reflexionar en los últimos años, como nunca antes lo habían hecho, sobre el concepto de competencias en la formación de nuestros futuros profesionales. Así, autores como Sierra Sánchez y Cabezuelo Lorenzo (2010) lo hicieron sobre las competencias y los perfiles profesionales en general 
de las Ciencias de la Comunicación. Otros autores como Noguera Vivo, Grandío Pérez y Torrado Morales (2011: 317) han reflexionado sobre las competencias específicas en el área de la Comunicación Audiovisual. Casero Ripollés, Ortells Badenes y Doménech Fabregat (2013) hicieron también lo mismo sobre las competencias específicas en el campo del Periodismo. Y finalmente en el área específica de la Comunicación Digital, se encuentran los trabajos de Cabezuelo Lorenzo y Torrecillas Lacave (2012: 53).

Partiendo de esta literatura en lengua española y de trabajos precedentes en lengua inglesa, sobre todo de documentos legales, se ha puesto patas arriba el modelo de enseñanza-aprendizaje en el mundo de las Ciencias de la Comunicación, alcanzando finalmente algunas cotas de innovación desconocidas hasta este momento. Ahí entra el juego el valor de la formación en competencias.

En este contexto surgen varios interrogantes para la reflexión. ¿Qué competencias y habilidades necesita el nuevo profesional de la comunicación en la actual sociedad digital? ¿En qué se diferencia la formación por competencias de la educación impartida hasta el momento en nuestras facultades? ¿Cómo se forman nuestros alumnos? ¿Cómo se formarán a partir de ahora los futuros profesionales? ¿Qué ventajas e inconvenientes tienen estas nuevas fórmulas? Y en el caso de la nueva rama de la Comunicación Digital, ¿qué competencias y habilidades deben diferenciar a nuestros titulados? ¿Cómo formar en competencias digitales? Estos interrogantes y otros tantos surgirán durante este trabajo.

\section{Un nuevo marco académico en un nuevo contexto socioeconómico}

Entre 2008 hasta 2013, el paro registrado de periodistas se ha visto incrementado en un 132 por ciento. Cuando empezó la crisis, había 
4.556 periodistas dados de alta en el Servicio Público de Empleo Estatal, y a finales del año pasado eran ya 10.560, según se recoge en el Informe Anual de la Profesión Periodística 2013 (Palacios, 2013: 28). Desde su irrupción en 2008 , la crisis económica ha golpeado de manera exagerada a los medios de comunicación (Paniagua Rojano, Gómez Aguilar y González Cortés, 2014: 549). El cambio del contexto empresarial del periodismo, las nuevas demandas laborales a sus trabajadores y la emergencia de nuevos perfiles profesionales afecta, de manera directa, a la formación de futuros periodistas (Casero Ripollés, Ortells Badenes y Doménech Fabregat, 2013: 54).

Ante esta situación, y aunque nadie parece tener hasta ahora las claves de la solución, se hace más que necesaria una reconsideración de las salidas profesionales de los periodistas, que quizás, deberían enfocar más sus opciones a trabajar en pequeños medios, e incluso, a veces, "microespecializados", en lugar de seguir aspirando a ejercer en los grandes medios, en su mayoría pertenecientes a las grandes corporaciones, y emprender proyectos e iniciativas, que probablemente garanticen más independencia y la posibilidad de ofrecer un mejor servicio de información plural a la ciudadanía, tal y como ésta demanda, para un buen funcionamiento democrático, de acuerdo con los argumentos de Paniagua Rojano, Gómez Aguilar y González Cortés (2014: 550).

Ante estos retos, el EEES propone una nueva metodología de enseñanza-aprendizaje e invita a la implantación de un modelo basado en el desarrollo de las competencias cuya finalidad es dotar a los alumnos de unas competencias que les permitan seguir aprendiendo y encontrar por sí mismos los caminos del conocimiento y la resolución de problemas. Igualmente, busca proporcionar una educación técnica y dotar de una capacitación a los futuros profesionales, dotándoles de habilidades combinables que sirvan tanto para la esfera académica como laboral. La educación por competencias, además de reconocer el resultado de los procesos escolares formales, también reconoce los 
conocimientos, habilidades y destrezas adquiridos fuera de las aulas universitarias.

Así, lo importante es dotar al alumno de unas competencias para la solución de problemas específicos más allá de dotarle de una preparación abstracta que no le capacite para salir airoso de retos académicos y profesionales. Se trata de hacerle capaz ante los avatares de la vida laboral que le espera - con suerte- a la salida de las aulas. Del mismo modo, se espera que el alumno pueda compaginar formación y vida laboral. De hecho, el EEES considera acertadamente que la formación es constante y se produce a lo largo de la vida (Sierra Sánchez y Cabezuelo Lorenzo, 2009: 02). Bolonia implica una transformación radical en los planteamientos didácticos. En los tiempos que corren todos nos vemos obligados, especialmente aquellos que compaginamos actividad profesional y académica, a una constante actualización. El dedicarse a la formación de los futuros profesionales de la comunicación nos fuerza a los profesoresinvestigadores a estar permanentemente en estado de alerta, de reconversión e indagación de nuevas y viejas herramientas.

Hoy nos encontramos una evolución imparable en el contexto tecnológico. No sabemos hacia dónde nos conduce este camino, pero está claro que el periodista debe estar al corriente de estos cambios y tiene que saber adaptarse al nuevo medio si quiere sobrevivir en él de una forma digna. Atrás quedaron la unidireccionalidad y los clásicos esquemas de emisor-receptor-mensaje (Sierra Sánchez y Cabezuelo Lorenzo, 2009: 03). Tal y como se afirman Flores Vivar, Martínez Gutiérrez y Cabezuelo Lorenzo (2012: 137) es necesaria la integración de las tecnologías de la información y de la comunicación en el devenir diario de nuestras facultades de Ciencias de la Información y de la Comunicación. En este sentido, en muchas de nuestras facultades, se han puesto en marcha algunos proyectos de innovación docente pioneros encaminados a la creación de facultades 3.0, es 
decir, centros de estudio con una perfecta integración de las redes sociales como herramientas de trabajo tanto en tareas académicas como de promoción universitaria (Torrecillas Lacave y Cabezuelo Lorenzo, 2011).

\section{Perfiles profesionales}

El Libro Blanco de los Estudios de Comunicación de la Agencia Nacional de Evaluación, Calidad y Acreditación (ANECA) estimó en 2005 a través de una comisión de supuestos expertos estos perfiles profesionales para el Grado en Periodismo:

- Redactor/a de información periodística en cualquier tipo de soporte. Profesional del periodismo en cualquier soporte mediático tradicional o electrónico que desarrolla su actividad mediante los géneros creando contenidos periodísticos. Comprende las tareas de redactor, reportero, presentador y director de uno o de varios de ellos, incluido el diseño, escritura y ejecución de guiones de reportajes y documentales audiovisuales o multimedia.

- Redactor/a o responsable de prensa o comunicación institucional. Profesional de un gabinete de prensa o comunicación de una institución pública o privada para coordinar o ejecutar cuantos trabajos de carácter informativo o comunicativo necesite la entidad.

- Investigador/a, docente y consultor/a de comunicación. Especialista en investigación y análisis de fenómenos y procesos de comunicación para todo tipo de organizaciones públicas y privadas, capacitado para las tareas de asesoría, consultoría y mediación. Docente en las enseñanzas superiores o medias para impartir materias de comunicación y nuevas tecnologías de la información y la comunicación. 
- Gestor/a de portales y editor/a de contenidos. Profesional en la redacción y ejecución de trabajos de edición en general para empresas editoras o creadoras de producciones culturales e informativas. Especialista en el tratamiento, la gestión y la edición de todo tipo de contenidos por medio de sistemas preferentemente digitales.

Sin embargo, ante esos cuatro cajones teóricos, la realidad profesional es más bien la que retratan Bárbara Yuste y Marga Cabrera (2014: 6573), que sí describen de manera mucho más realista los que son, a día de hoy, los nuevos perfiles del periodista, entre los que destacan: arquitecto de la información, gestor de comunidades o community manager, copy, digitalizador, diseñador web, editor de web, especialista en marketing digital, experto en accesibilidad, experto en analítica web, experto en metadatos, experto SEM y SEO, experto en usabilidad, gestor de contenidos, guionista multimedia, montador/maquetador, realizador de vídeo, responsable de contenido y responsable de reputación digital. Muy lejos y muy atrás quedan ya los minoritarios perfiles clásicos de redactor en medios generalistas. Aunque siguen existiendo, las ofertas de trabajo que surgen hoy corresponden sólo a perfiles digitales.

\section{La formación en competencias}

La definición más completa de competencia en el sentido holístico del término es la que aporta Sergio Tobón (2004: 47) cuando afirma que las competencias se entienden como procesos complejos que las personas ponen en acción-actuación- creación, para resolver problemas y realizar actividades (de la vida cotidiana y del contexto laboral-profesional), aportando a la construcción y transformación de la realidad, para lo cual integran el saber ser (automotivación, iniciativa y trabajo colaborativo con otros), el saber conocer (observar, explicar, comprender y analizar) y el saber hacer 
(desempeño basado en procedimientos y estrategias), teniendo en cuenta los requerimientos específicos del entorno, las necesidades personales y los procesos de incertidumbre, con autonomía intelectual, conciencia crítica, creatividad y espíritu de reto, asumiendo las consecuencias de los actos y buscando el bienestar humano. Tres tipos de saberes se requieren para la adquisición de una competencia: saber ser, saber conocer y saber hacer. La conjunción y el equilibrio de estos tres tipos de saberes garantizan que un individuo/alumno ha adquirido competencia.

La competencia profesional se relaciona con el saber hacer algo a partir de unos conocimientos disciplinares. De tal manera que la competencia profesional capacita al individuo para resolver problemas o situaciones reales en el entorno de trabajo profesional (Sierra Sánchez, Sotelo González y Cabezuelo Lorenzo, 2010: 11). En este sentido, siguiendo el saber oriental de Confucio (551 AC-478 AC), al que se le atribuye la máxima de que "aprender sin reflexionar es malgastar la energía", la formación en competencias tiene también detractores. Recibe críticas de autores que echan de menos o demandan que no desaparezcan contenidos teóricos que también siguen siendo necesarios y útiles. Así aparecen voces a favor de disciplinas como la Ética o la Historia, ya que el profesional de la comunicación no sólo tendrá que desarrollar trabajos, tendrá que tomar decisiones, para los que no solo hacen falta competencias. También hacen falta valores. Tal y como recuerda Manfredi Sánchez (2009: 141), "las empresas periodísticas se sustentan sobre un modelo que puede conducir al conflicto de intereses, que consiste en la capacidad que tiene un elemento ajeno a la empresa de intervenir en el desarrollo corporativo o en la toma de decisiones". Y en ese caso, son tan necesarios o más los valores que las competencias. 


\section{Las competencias de los comunicadores según la ANECA}

¿Están preparados los actuales planes de estudio para dotar de estas competencias a los periodistas digitales del mañana? El estudio de las competencias ayuda a dar respuesta a estos interrogantes. Veamos en primer lugar cuáles son las competencias sobre las que se fundamenta el proceso de enseñanza-aprendizaje en los estudios de Periodismo. Es posible hablar de competencias generales de la titulación, profesionales, académicas y transversales. Las competencias generales de la titulación son:

A1. Conocimiento de los procesos informativos y comunicativos.

A2. Conocimiento y aplicación de las tecnologías y de los sistemas utilizados para procesar, elaborar y transmitir información.

A3. Conocimiento del uso correcto oral y escrito de la lengua propia.

A4. Conocimiento de lenguas extranjeras para poder analizar hechos $\mathrm{y}$ temas generales.

A5. Conocimiento y evolución histórica de las modalidades y tradiciones periodísticas.

A6. Conocimiento del contexto local, autonómico, nacional e internacional y de su evolución histórica reciente.

A7. Conocimiento de la estructura de los medios de comunicación y de sus principales formatos.

A8. Conocimiento de la ética y deontología profesional del periodismo así como del ordenamiento jurídico de la información.

A9. Conocimiento de las teorías sobre la publicidad, las relaciones públicas y la comunicación corporativa.

A10. Conocimiento del impacto social de las tecnologías informativas.

A11. Conocimiento de la estructura, funcionamiento y gestión de la empresa de comunicación.

A12. Conocimiento de los principales debates y acontecimientos mediáticos. 
Por otro lado, encontramos, las competencias específicas de la titulación. Éstas a su vez pueden ser divididas en competencias profesionales y académicas. Entre las profesionales se encuentran:

B1. Capacidad y habilidad de exponer razonadamente ideas con fluidez y eficacia comunicativa.

B2. Capacidad para leer y analizar textos y documentos especializados.

B3. Capacidad básica para comprender la producción informativa o comunicativa, escrita o audiovisual, e inglés estándar.

B4. Capacidad para comunicar en el lenguaje propio de cada uno de los medios de comunicación tradicionales.

B5. Capacidad para utilizar las tecnologías y técnicas informativas y comunicativas.

B6. Capacidad para utilizar los sistemas y recursos informáticos.

B7. Capacidad para el diseño de los aspectos formales y estéticos.

B8. Capacidad para la ideación, planificación y ejecución de proyectos informativos o comunicativos.

B9. Capacidad y habilidad para el desempeño de las principales tareas periodísticas.

B10. Habilidad para buscar, seleccionar y gestionar cualquier tipo de fuente o documento.

B11. Capacidad para analizar y procesar información y comunicación en diferentes soportes.

B12. Capacidad de experimentar e innovar mediante el conocimiento y uso de técnicas y métodos aplicados. 


\section{Las competencias del profesional de la comunicación en la sociedad digital}

Con mucha anticipación en el tiempo, algunos pioneros como Quim Gil ya elaboraron un perfil muy detallado de lo que debe ser un profesional de la comunicación digital como nuevo escenario del Periodismo. De su propuesta destacan algunas características que agrupables en cuatro bloques:

1. El periodista digital ofrecerá explícitamente contenidos relacionados con su fecha de vigencia. En principio, un buen medio digital está ofreciendo contenidos plenamente actuales. Con la información existente en la Red, los "lectores" desean tener constancia de que la información que están consultando es vigente. "Vigente no implica necesariamente que sea "reciente". El periodista digital trabajará con formatos abiertos, en los que sea posible modificar y ampliar la información. El periodista digital debe ser capaz de trabajar con este tipo de informaciones abiertas. Continúa siendo apreciada la obtención del scoop, pero en un medio como la Red la cotización del scoop se deprecia a las pocas horas. Un día después de su publicación, un scoop debería estar contextualizado, enlazado, comentado e interpretado. Es tarea del periodista digital organizar esta convergencia de información, opinión, feedback, interpretación, contextualización y valoración transversal. Para trabajar eficientemente sobre todas estas fuentes de información es necesario de nuevo disponer de algún sistema de base de datos, puesto que las capacidades del trabajo artesano tienen un límite. El periodista digital diseñará la información en base a diversas capas de profundidad. Por ejemplo, disponiendo de una primera capa actualizada pero superficial ofrecida 
gratuitamente, y de posteriores capas con acceso restringido de pago.

2. El periodista digital concebirá su trabajo desde una perspectiva multimedia, atendiendo a elementos como el diseño del interfaz y de la estructura de contenidos, así como la integración de textos, imágenes, sonido, bases de datos, programas, etc. A la práctica esto conlleva un trabajo en equipo y en red mucho más integrado del que han conseguido los medios convencionales en sus redacciones y estudios, donde es habitual que profesionales muy diversos trabajen codo a codo, pero en un proceso en cadena, compartimentado. El buen periodista digital deberá sacar provecho de las estructuras hipertextuales de información para ofrecer unos contenidos personalizables, flexibles, ampliables, actualizables, interactivos. El periodista digital debe trabajar a fondo la memoria sin límites de Internet, de nuevo inviable en los medios tradicionales, a la hora de contextualizar información, ofrecer backgrounds, utilizar archivos y hacer público el acceso a bases de datos en estado puro.

3. El periodista digital debe localizar todas las fuentes que le interesen, debe procesar la información que le ofrecen, las debe contextualizar y las debe clasificar por unos criterios de prioridad. También debe discriminar entre las fuentes originales y las que utilizan información de segunda mano. Debe recordar que hay fuentes fuera de Internet y buscarlas. Debe encargarse de la recopilación activa de información no digital y su posterior digitalización e introducción a la Red. Tiene que ofrecer a su clientela el acceso a todas las fuentes originales que muestren públicamente sus contenidos, dándoles pie a que amplíen la información si lo desean. Debe 
saber diferenciar el valor de cada fuente $y$ ordenar adecuadamente los enlaces que utiliza u ofrece a sus lectores. Además, debe comprobar que las fuentes son en realidad quienes dicen ser. Su selección de fuentes será una garantía para su clientela y realizará consultas a las fuentes a petición de los públicos.

4. El periodista digital trabajará contenidos especializados dirigidos de forma personalizada a individuos o colectivos (micro y nano audiencias). La personalización no sólo afecta a los contenidos en sí, sino a su formato digital: versiones aptas para todos los navegadores, aptas para banda ancha, sólo texto, etc. El periodista digital no sólo tendrá que certificar sus fuentes, sino que también tendrá que certificar su propia identidad hacia su clientela. De nada sirve que un periodista digital compruebe que una web si luego otra persona le suplanta ante su audiencia. El periodista digital debe buena parte de su existencia a su eficiencia ante esta nueva capacidad de la "audiencia", inexistente en el periodismo tradicional. Las audiencias juegan un nuevo y cada vez más importante rol. Como afirma Noguera Vivo (2010: 652), el progresivo aumento de los niveles de participación de la audiencia, definida incluso desde su papel de emisora y productora, es una característica natural de la Web 2.0 que los medios de comunicación no pueden obviar. De hecho, las reformulaciones a las que el periodismo se ha visto obligado por esta nueva realidad han llegado a la misma redacción del medio. Las audiencias participativas pueden serlo incluso antes de que haya noticia, en la planificación de la agenda o en la búsqueda de fuentes. 


\section{Propuestas prácticas}

El sistema educativo está obligado a no volver la espalda a la realidad social de cada momento y a tratar de capitalizar en beneficio de sus funciones las oportunidades que se le presenten. Dos de los más inmediatos retos del sistema educativo actual son: primero, responder adecuadamente a la demanda de alfabetización digital de los jóvenes en un entorno cada vez más multimedia y, segundo, incorporar en sus metodologías docentes las nuevas herramientas venidas de la mano del progreso tecnológico (Sotelo González, 2009: 126). Además, las universidades deben considerar el uso sistemático de las TICs como parte estratégica esencial de sus procesos comunicativos. (Tapia Frade, Herranz de la Casa y García González, 2010: 108). Ante la rapidez de los cambios en nuestra sociedad, la universidad como institución educativa, debe ofrecer a los alumnos las herramientas y capacidades necesarias para que sean aprendices a lo largo de toda su vida. En este sentido, las administraciones señalan que las competencias clave para el aprendizaje permanente son todas aquellas que las personas precisan para su realización y desarrollo personales, así como para lograr una ciudadanía activa, la inclusión social y el empleo. (Paniagua Rojano, Gómez Aguilar y González Cortés, 2014: $553)$.

Hoy en día, además de las propuestas hechas hace tiempo por Quim Gil, se imponen también las competencias aplicadas a las redes sociales, convertidas en nuevas herramientas puestas en manos de los periodistas y protagonistas de los nuevos debates en la opinión pública. ¿Cuánto durarán las redes sociales? ¿Seguirán existiendo Facebook y Twitter dentro de 25 años? ¿Cómo serán? Como ya han demostrados algunos trabajo, como Noguera Vivo (2013: 93), Twitter es hoy en día una herramienta que "refuerza la figura del periodista como gatekeeper" al tiempo que muestran un nuevo periodismo 
"centrado en el usuario." En este contexto, se proponen varias alternativas.

a) Desarrollo de redacciones reales (talleres): Algunas universidades, tanto públicas como privadas, pero sobre todo las segundas, que gozan de mayor cintura o flexibilidad para algunas cosas que las anquilosadas grandes universidades públicas han puesto en marcha talleres realmente dinámicos en los que la asignatura se complemente absolutamente con el trabajo real en un medio de comunicación, como es el caso de la 'Escritura para los Medios' y el medio digital multimedia 'www.onceu.es' puesto en marcha en la Universidad San Pablo CEU de Madrid.

b) Puesta en marcha de planes reales de negocio en el seno de materias ligadas al Periodismo Emprendedor o Empresa Informativa. Como afirma Manfredi Sánchez (2013), los profesores estamos cansados de corregir prácticas con poco valor añadido (un resumen de un libro, un test o un ejercicio cien veces repetido). Es mejor aprovechar la evaluación continua para entregar un plan de empresa. Al final del semestre, el alumno habrá tenido 15 semanas de tutoría y aprendizaje orientado.

c) El trabajo de fin de grado como oportunidad no sólo para la investigación o la reflexión teórica, sino para la puesta en práctica de los conocimientos prácticos adquiridos, es decir, las competencias reales. Son muy útiles las propuestas presentadas en el volumen coordinado por Carmen Marta Lazo (2009).

d) Nuevos métodos de evaluación basados en competencias, no en conocimiento adquirido y olvidado tras la evaluación. El listado de competencias (tanto propias de la titulación como las 
académicas o profesionales) debe estar integrado y dar sentido a las pruebas de evaluación (si las hay) y posterior calificación. Como afirma el proverbio oriental, "dime y lo olvido, enséñame y lo recuerdo, involúcrame y lo aprendo".

e) Puesta en marcha de actividades universitarias vivas, es decir, que fomentan el emprendimiento en el entorno más cercano, a través de jornadas, encuentros o seminarios, que ayuden a conocer mejor la normativa, posibles ayudas, subvenciones y diferentes fórmulas de financiación, que los estudiantes, en su mayor parte, desconocen y que pueden resultar útiles para incentivar la puesta en marcha de proyectos empresariales.

\section{A modo de conclusión}

A pesar de que con la reforma llegada con el EEES, la universidad española fue capaz de replantearse muchas cosas, sigue sin estar en sintonía con las nuevas necesidades del mercado laboral y de las demandas sociales. Los nuevos planes de estudio deben estar orientados a la adquisición progresiva de competencias profesionales, ya que un mayor conocimiento y adquisición de las mismas ayuda a aumentar las posibilidades de éxito en la búsqueda de un empleo. Sin embargo parece que queda mucho por hacer, ya que todavía incluso existe una gran confusión terminológica y conceptual sobre la idea de la formación en competencias y lo que ello significa. Esta realidad, junto a otros factores, ha hecho que la implantación de Bolonia haya sido caótica en muchas universidades españolas.

Aunque nuestros alumnos acarrean durante sus años de formación preuniversitaria y universitaria una gran cantidad de carencias formativas de todo tipo, pero sobre todo en materia de Economía, Empresa y Emprendimiento, la crisis ha despertado la necesidad de despertar la competencia para poder poner en marcha iniciativas 
empresariales que sirven de alternativa al desempleo. Si el primer esfuerzo ha venido de los recién egresados, el siguiente debe venir de los hoy todavía alumnos y sus docentes. Es precisa la coordinación de los profesores que imparten las asignaturas relacionadas con periodismo especializado, el periodismo digital y los nuevos medios, e incluso con los de otras materias con el fin de encontrar sinergias que mejoren la inserción laboral de nuestros alumnos.

Algunos autores hablan incluso de la búsqueda de sinergias entre diferentes carreras con el objetivo de fomentar la creación de empresas interdisciplinares, o bien, de incluir a una persona de comunicación en cada proyecto empresarial, ya que de alguna manera toda iniciativa empresarial tiene necesidades de comunicación tanto interna como externa. Asimismo, resulta recomendable estimular la relación entre universidad y empresa, con el objetivo de acercar nuevos proyectos informativos a los estudiantes.

Entre las conclusiones, se plantea también un reto. ¿Cómo conseguir convertir las actuales facultades de Ciencias de la Comunicación en auténticos talleres de comunicación digital en los que existan redacciones al más puro estilo profesional? Facilitar aprendizajes conceptuales y procedimentales tiene una fuerte componente técnica de la ciencia pedagógica; pero incitar a adoptar actitudes positivas exige necesariamente el testimonio personal. Como afirma la máxima atribuida a Albert Einstein, "el aprendizaje es experiencia, todo lo demás es información".

\section{Referencias}

ANECA (2005): Libro Blanco de las Titulaciones de Grado en Comunicación. Madrid, 2005.

CABEZUELO LORENZO, F. \& TORRECILLAS LACAVE, T. (2012): "La formación de nuevos perfiles profesionales en 
comunicación digital y la implementación del EEES”, en VERÓN LASSA, J. J. \& SABÉS TURMO, F. El periodismo digital analizado desde la investigación procedente del ámbito académico. Asociación de la Prensa de Aragón (APA). ISBN 978-84-87175-47-3. Págs. 119-128.

CARO GONZÁLEZ, F. J. et ALT. (2007): “Techo de cristal en las empresas periodísticas: percepción de las habilidades y capacidades de la mujer en las tareas de dirección" (Págs. 395-407), en Ambitos Revista Internacional de Comunicación (ISSN 1139-1979). No 16. Sevilla.

CARVAJAL PRIETO, M. (2012): “Estrategias de distribución del contenido periodístico en dispositivos móviles. Análisis comparativo de los principales editores de prensa española”, en VV. AA. Actas del IV Congreso Internacional de la Sociedad Latina de Comunicación Social: Comunicación, controly resistencias. ISBN 84-15698-06-2

CASERO-RIPOLLÉS, A., ORTELLS-BADENES, S. \& DOMÉNECH-FABREGAT, H. (2013): "Las competencias profesionales en periodismo: una evaluación comparativa", en Revista Historia y Comunicación Social (ISSN: 1137-0734). Vol. 18. N Esp. Dic. (2013). Págs. 53-64.

http://dx.doi.org/10.5209/rev_HICS.2013.v18.44311

FLORES VIVAR, J. M., MARTÍNEZ GUTIÉRREZ, F. \& CABEZUELO LORENZO, F. (2012): "El conocimiento integrado de las TICs en las facultades de comunicación” (Pág. 137-162) en TÚÑEZ LÓPEZ, M. (Coord.): Viejo Periodismo, Nuevos Periodistas. Cuadernos Artesanos de La Latina, Tenerife. ISBN: 978-84-940111$0-8$.

GIL, Q. Diseñando el periodista digital (I). Sala de Prensa. http://www.saladeprensa.org/art89.htm [Consultado el 10 de octubre de 2014].

MANFREDI SÁNCHEZ, J. L. (2013): “Cómo la universidad puede estimular el emprendimiento”. http://www.contunegocio.es/recursos- 
humanos/universidad-puede-estimular-emprendimiento/ (26.11.2013)

MANFREDI SÁNCHEZ, J. L. (2009): "Indicadores de la RSC en la empresa periodística” (Págs. 137-148), en “Ámbitos: revista internacional de comunicación’. Nº 18 . Universidad de Sevilla.

MARTA-LAZO, C. [Coord.] (2009): El EEES y el Proyecto Final en los Grados de Comunicación. Editorial Fragua. ISBN: 978-84-7074-357-3

NOGUERA VIVO, J. M. (2010): "Panorámica de la convergencia periodística: los caminos hacia la redacción Google”, en 'El Profesional de la Información' (ISSN 1386-6710). Vol. 19. Nº Págs. 652-657.

NOGUERA VIVO, J. M., GRANDÍO PÉREZ, Ma M. \& TORRADO MORALES, S. (2011): “Competencias digitales para los nuevos entornos dentro de los estudios de grado en Comunicación Audiovisual", en Innovación Educativa (ISSN 1130-8656). No 21. Págs. 317-327.

NOGUERA VIVO, J. M. (2013): "How open are journalists on Twitter? Trends towards the end-user journalism", en 'Comunicación y Sociedad/Communication \& Society’ (ISSN 0214-0039). Vol. 26. No 1. Págs. 93-114.

PALACIOS LLANOS, L. (2013): Informe Anual de la Profesión Periodística 2013. Madrid: Asociación de la Prensa de Madrid, pp. 7483

PANIAGUA ROJANO, F. J., GÓMEZ AGUILAR, M. \& GONZÁLEZ CORTÉS, E. (2014): “Incentivar el emprendimiento periodístico desde la Universidad", en Revista Latina de Comunicación Social. ISSN-e 1138-5820, Nº 69, 5, 2014, págs. 548-570.

SIERRA SÁNCHEZ, J.\& CABEZUELO LORENZO, F. (2010) [Coords.]: Competencias y perfiles profesionales en los estudios de Ciencias de la Comunicación. Editorial Fragua, Madrid. ISBN 978-84-7074-398-6. 
SIERRA SÁNCHEZ, J., SOTELO GONZÁLEZ, J. \&

CABEZUELO LORENZO, F. (2010): “Competencias profesionales y empleo en el futuro periodista: el caso de los estudiantes de la Universidad Cardenal Herrera CEU” (Págs. 8-19), en @tttic-Revista d'innovació educativa (ISSN-e 1989-3477).

SIERRA SÁNCHEZ, J. \& CABEZUELO LORENZO, F. (2009): "Postperiodismo y formación en competencias digitales bajo el paraguas de Bolonia" en Actas del I Congreso Internacional de la Sociedad Latina de Comunicación Social. La Laguna (Tenerife). Coord. J. M. de Pablos Coello. ISBN 978-84-9941-001-2

SOTELO GONZÁLEZ, J.(2009): "Del e-learning al m-learning: una academia en cada iPhone", en Telos: cuadernos de comunicación e innovación. ISSN 0213-084X. No 81. Págs. 122-128.

TAPIA FRADE, A., HERRANZ DE LA CASA, J. Mª \& GARCÍA GONZÁLEZ, J. (2010): "El uso de las TICs en la comunicación interna de la universidad. El caso de la UEMC", en Doxa Comunicación: Revista interdisciplinar de estudios de comunicación y ciencias sociales. ISSN 1696-019X. Núm. 10. Págs. 107-124.

TOBÓN, S. (2004): Formación basada en competencias. Pensamiento complejo, diseño curricular y didáctica. Bogotá: Ecoe Ediciones.

TORRECILLAS LACAVE, T. \& CABEZUELO LORENZO, F. [Coords.] (2012): Las redes sociales y las nuevas herramientas digitales al servicio de la innovación docente en la enseñanza-aprendizaje de las Ciencias de la Comunicación. Proyecto de innovación docente para la creación de la una Facultad 3.0. CERSA, Madrid. ISBN 978-84-15341-67-3

YUSTE, B. Y CABRERA, M. (2014): Emprender en Periodismo. Nuevas oportunidades para el profesional de la información. Madrid: Editorial UOC, Págs. 65-73 y 87-132 


\title{
El valor y uso de Twitter en la enseñanza del periodismo ${ }^{8}$
}

\author{
JL Rojas Torrijos Orcid GS Profesor Asociado. Facultad de \\ Comunicación. Universidad de Sevilla (España) jlirojas@,us.es
}

\section{De sistema operativo del periodismo a herramienta docente}

L

A ECLOSIÓN de las redes sociales ha traído consigo una transformación en los procesos tradicionales de producción y distribución de las noticias. Estos nuevos espacios digitales han construido una nueva relación bidireccional fundamentada en la interacción directa y sin filtros entre emisores y destinatarios, que han pasado a participar de forma activa y a tomar la iniciativa en la elaboración de los contenidos y a convertirse así en fuentes periodísticas.

En medio del nuevo paradigma que es internet, el periodismo ha encontrado en Twitter uno de sus principales y más eficaces recursos

\footnotetext{
${ }^{8}$ Extracto del artículo: FJ Paniagua Rojano, M Gómez Aguilar, ME González Cortés (2014): "Incentivar el emprendimiento periodístico desde la Universidad". Revista Latina de Comunicación Social, 69, pp. 548 a 570. http://www.revistalatinacs.org/069/paper/1024 UMA/27es.html DOI: 10.4185/RLCS-2014-1024
} 
a la hora de dar a conocer y proyectar sus contenidos. La red de microblogging, basada en mensajes escuetos de 140 caracteres, entronca con la tradición periodística de comunicar con claridad, concisión, brevedad y celeridad, lo que le ha servido a los medios de comunicación como herramienta idónea para abrir sus tentáculos informativos y sacar el máximo provecho de sus posibles aplicaciones a la hora de ofrecer determinadas coberturas y de llegar más y mejor a la audiencia a través de un feedback permanente que además favorece la generación de más tráfico de visitas hacia la web.

Twitter, que ya ha sido definido por la propia vicepresidenta de Global Media de la compañía, Katie Jacobs", como "el sistema operativo del periodismo", se está imponiendo en la actualidad, merced a su amplitud, su dinamismo y su adaptabilidad a los dispositivos móviles, como la plataforma preferida por instituciones y servicios de noticias para dar avances de primicias o para informar in situ y en directo desde los lugares de la noticia. Consecuentemente, se ha erigido como fuente de información se referencia y habitual para el resto de medios. Twitter anticipa la noticia que luego será ampliada y actualizada en webs, emisoras de radio, programas de televisión y, posteriormente, en las páginas del periódico.

Otra gran ventaja de la 'plataforma del pajarito' es que facilita el acceso a la información y a un enorme volumen de fuentes de todo tipo en tiempo real. Es una herramienta muy potente para conocer y para compartir contenidos con compañeros de profesión y expertos, y también, en el caso de los periodistas, para hallar datos valiosos, claves o posibles enfoques que aporten singularidad y originalidad a las informaciones que se van a publicar. En este sentido, esta

\footnotetext{
${ }^{9}$ Declaraciones recogidas en el portal clasesdeperiodismo.com y disponibles en la siguiente dirección:

http://www.clasesdeperiodismo.com/2014/09/06/twitter-es-el-sistemaoperativo-de-noticias $/$ ?utm_medium $=$ twitter\&utm_source $=$ twitterfeed [texto recuperado el 4 de noviembre de 2014]
} 
plataforma se comporta más como una red de información que como una red social realmente, de ahí que los periodistas la prefiramos a otras como Facebook para dar proyección a nuestra actividad profesional y a nuestra marca personal.

Lo cierto es que Twitter por su claro ADN periodístico ofrece también valiosas posibilidades para su aplicación en el ámbito educativo en general y en la enseñanza de futuros periodistas en particular. La incorporación de esta herramienta a las aulas de las facultades de Comunicación es algo más que un complemento al temario de la asignatura; constituye una vía para traer la actualidad a clase ilustrando y renovando los contenidos más teóricos con estudios de casos y, además, una manera de incentivar la implicación en la asignatura del alumnado, que, en su mayor parte, dispone de cuenta en esta red y, por tanto, está familiarizado con su uso.

Por tanto, la aplicación de la red de microblogging en la enseñanza del periodismo se presenta para el docente como una valiosa oportunidad para amenizar sus clases y hacerlas más participativas, promoviendo el aprendizaje cooperativo y mejorando las competencias comunicativas del alumnado. Al mismo tiempo su empleo ha de plantearse como un reto, como una forma de microinnovación en el aula que sirva para adaptar la metodología docente a las características de la sociedad actual y a los hábitos de comportamiento y de consumo de información de unos alumnos que han crecido inmersos en la tecnología digital.

A continuación, ofrecemos una breve guía con los pasos que puede seguir un profesor de periodismo para poder extraer el máximo aprovechamiento de Twitter a través de las diferentes técnicas docentes utilizadas. Destacamos sus principales usos y aplicaciones, que siempre irán en función del carácter más teórico o más práctico de la asignatura y, sobre todo, del tipo de lección que se imparta, ya sea clase magistral, sesión académica práctica, exposición individual o grupal, autorización específica o charla o 
ponencia de un personaje invitado.

\section{Cómo sacarle partido en el aula}

El objetivo principal de usar Twitter como parte de la asignatura es convertirlo en fuente de conocimiento actualizado y compartible y en un espacio propicio para incentivar el debate, la participación y la implicación del alumnado en la materia, desarrollando técnicas y habilidades periodísticas y alimentando su espíritu crítico. Para ello, es preciso acometer los siguientes pasos:

\subsection{Crear una cuenta específica para la asignatura}

La denominación en este caso no es una cuestión baladí. Deberá referenciar el nombre o las iniciales de la asignatura para que desde el primer día el alumnado la asocie como parte de su tarea cotidiana. Será el sitio de referencia para el trabajo práctico de la materia (para apuntes, calificaciones y otro tipo de anuncios ya contamos con la plataforma de enseñanza virtual de la Facultad), el centro de operaciones en el que el profesor ha de hacer confluir sus aportaciones con las de los estudiantes.

En la presentación de la cuenta a los alumnos el primer día de clase se explicarán sus funcionalidades. Una buena manera de promover participación en la cuenta es hacerla evaluable y computable como parte práctica de la asignatura.

\subsection{Dotarla de contenido}

La cuenta de Twitter de la asignatura ha de servir para llevar al aula el estado del arte de tu área de conocimiento. En el caso de las asignaturas de periodismo, se darán a conocer los últimos proyectos surgidos o las iniciativas más innovadoras, así como favorecer el análisis y el debate a partir de la publicación de enlaces a artículos, noticias, reportajes, entrevistas o estudios relevantes. 
Para empezar a dotarla de contenido, lo mejor es hacer una buena selección de cuentas a las que seguir (profesores universitarios, grupos de investigación, periodistas, instituciones o medios de comunicación) y que sean de interés para la asignatura, de forma que sus publicaciones aparecerán automáticamente en su nuestra cronología o timeline (TL) y nos servirán de guía para tuitear o retuitear contenidos que aporten valor añadido.

A medida que nuestro perfil en Twitter se vaya definiendo, la misma plataforma nos irá recomendando otras cuentas relacionadas que podremos ir añadiendo. Se trata de una herramienta en continua construcción que ha de ir nutriéndose a lo largo del curso.

\subsection{Organizar las fuentes en listas}

Cuando crece el número de cuentas a las que seguimos en Twitter se hace mucho más difícil la monitorización de los mensajes y la curación de contenidos. Por eso una manera de optimizar el uso de esta herramienta es la creación de listas como vía para agrupar fuentes especializadas y facilitar la búsqueda de enlaces útiles que aportar a la asignatura.

Además, los alumnos podrán suscribirse a estas listas temáticas y acceder de esta forma a la visualización de la misma cronología que el profesor. Compartir el acceso simplificado a listas de fuentes bien clasificadas y al hilo de la actualidad invita a la conversación on line y al debate dentro del aula.

\subsection{Utilizar etiquetas o hashtags}

El signo almohadilla (\#) se utiliza en Twitter para encabezar junto a una palabra o una frase corta una etiqueta o hashtag, que sirve para introducir categorías en el mensaje. Sirve no solo para agrupar tuits bajo una misma temática que son enlazables al mostrarse como un hipertexto y, por tanto, fácilmente localizables en el buscador de la 
plataforma, sino también para dar la clave que permite la correcta interpretación del mensaje.

También es útil porque su inclusión vertebra el debate y evita repetir de nuevo frases o ideas, ahorra espacio, al quedar todos los tuits enlazados y contextualizados dentro de una misma conversación. En la planificación de la asignatura conviene pensar en etiquetas (\#fuentes, \#ética, \#léxico, \#vistoenclase ...) que nos habrán de servir para conducir conversaciones desde la cuenta de Twitter y que posteriormente facilitarán la recuperación de la información para la medición de los resultados.

La creciente popularidad de Twitter ha permitido que este canal de comunicación sea cada vez más utilizado en todo tipo de estrategias sociales, también para la difusión de actos académicos. Así se retransmiten por tuits en tiempo real las intervenciones en coloquios, conferencias y congresos para su difusión pública más allá del espacio físico en el que estos se celebran, se intercambian opiniones y se generan conversaciones entre los asistentes a estos eventos y entre aquellas otras personas que no han podido asistir presencialmente a los mismos o se realizan entrevistas (se ha desarrollado una nueva modalidad, la 'twittervista', con preguntas y respuestas formuladas con un máximo de 140 caracteres).

Estas múltiples aplicaciones de Twitter también pueden ser aprovechadas por los docentes universitarios como para vía útil para difundir y compartir conocimiento, y, sobre todo, como foro para la participación del alumnado y la construcción de un debate dentro y fuera del aula, que además pueda extenderse más allá de las horas lectivas.

\section{Cuándo y cómo lo utilizamos}

La aplicación de las utilidades que ofrece la plataforma de microblogging a ser posible se hará en función del tipo de clase que organicemos y 
del temario que estemos impartiendo. De esta forma, se optará en cada momento por la estrategia social más eficaz y productiva tanto para el profesor como para el alumnado.

\subsection{En la clase magistral}

En esta modalidad de lección se imparten los conocimientos teóricos fundamentales que los alumnos deben adquirir. Para facilitar su desarrollo, se suelen poner a disposición de los alumnos esquemas teóricos de cada tema en la plataforma virtual del centro, así como textos de referencia que les permiten completar y profundizar en aquellos aspectos en los que estén más interesados.

En estos casos, Twitter puede constituirse como una fuente de material de apoyo a la docencia al aportar artículos o documentos interesantes que se enlazarán en la cuenta de la asignatura antes o después de la lección magistral. No basta con remitir a los apuntes tradicionales, sino que es preciso que el alumnado los complete y enriquezca a partir de su iniciativa. Para ello hay que estimular el entrenamiento en el manejo de fuentes con herramientas útiles, como es el caso de Storify.

\subsection{En las sesiones académicas prácticas}

En este tipo de clases se expondrán casos de estudio como, por ejemplo, proyectos o iniciativas que resulten especialmente significativas o novedosas en los medios informativos nacionales e internacionales, con el fin de facilitar la comprensión de los conocimientos teóricos y, al mismo tiempo, acercar la asignatura a la realidad de las empresas periodísticas.

También en este caso, resulta muy útil buscar contenidos relevantes y tuitear o retuitear en la cuenta enlaces a noticias que ilustren el estudio de casos que se quiera realizar. Podrá hacerse o bien a priori anunciando con una etiqueta que se trata de textos que se analizarán 
en clase o bien a su término a modo de ampliación de los contenidos (\#vistoenclase).

\subsection{En exposiciones y debates}

Individuales o en grupo, las exposiciones en clase de partes del temario favorecen el intercambio de opiniones críticas tanto entre profesorado y alumnado como entre el alumnado. También en este caso, Twitter ofrece la oportunidad de enlazar noticias relacionados con el tema de la asignatura, de modo que luego provoquen el debate y lo prolonguen más allá del horario lectivo. De esta forma, se trabaja en el alumnado la competencia de argumentar y defender tesis con brevedad y concisión.

\subsection{Ponencias o charlas de invitados}

Un formato cada vez más utilizado es contar con la presencia de una persona invitada para dar una charla o ponencia con el objetivo de que este exponga su experiencia profesional y entable después una conversación con los alumnos. Esta modalidad de lección es una oportunidad para hacer prácticas con los estudiantes a través de Twitter.

La más habitual es poner como tarea que tuiteen a la cuenta de la asignatura las ideas más destacadas que se extraigan de las palabras de la persona invitada. Así se trabajan varias competencias en el alumnado, sobre todo desarrollar su capacidad de análisis y síntesis, y la de elaboración de titulares. Es un verdadero ejercicio periodístico, hasta el punto de que determinadas charlas o conferencias se prestan para simular incluso una rueda de prensa en el aula.

También en estas situaciones, y con el fin de aglutinar el debate y generar interacción con otros usuarios más allá de la universidad, es una opción muy recomendable la de crear un etiqueta asociada a cada charla, la cual deberá escribirse en todos los tuits que se envíen sobre la misma. De esta manera, será más fácil seguir la conversación y, 
para el profesor, más fácil hacer una evaluación posterior del ejercicio práctico desarrollado por sus alumnos.

\subsection{Tutorías específicas}

Individuales o en grupos reducidos, las tutorías específicas sirven para discutir los trabajos o prácticas que se hayan planteado durante el curso. Para resolver las posibles dudas del alumnado, a través de Twitter el profesor también puede aportarles material de ayuda que pueda servir para anticipar posibles soluciones e incluso preparar o canalizarlas con vistas a la tutoría.

\section{Retroalimentación y medición de resultados}

La aplicación de Twitter como apoyo a la metodología docente requiere para su efectividad de un seguimiento continuado por parte del profesor con el objetivo de obtener el feedback necesario que permita evaluar los resultados y tener en consideración esa experiencia para cursos venideros y para otras asignaturas.

Una vez que se crea una cuenta, se organizan las listas de fuentes y se tuitean noticias y se reenvían mensajes, es necesario realizar una labor de monitorización del comportamiento social de cada alumno para comprobar cuál ha sido su respuesta y el grado de participación en el uso de la herramienta con vistas a su aprovechamiento en la asignatura.

Si se trata tan solo de una experiencia piloto, la medición de resultados nos debe aproximar a la conclusión de su utilidad práctica para el desarrollo de la asignatura, más allá de que la participación del alumnado haya podido ser desigual. Si ya se ha superado esta fase inicial y se ha explicitado dentro del planeamiento docente que la realización de prácticas en esta plataforma y la participación con mensajes y conversaciones en general son cuestiones evaluables, será preciso definir con claridad y cuantificar qué parte de la nota está en juego. 
Twitter, como toda novedad, debe atravesar una necesaria fase de experimentación, que pasa también por explicar su funcionamiento. Muchos alumnos de periodismo todavía le dan a esta red un uso más personal que académico. Se trata, por tanto, de que hagamos ver desde la docencia todo el potencial educativo y profesional que tiene esta herramienta, tanto para ampliar conocimientos sobre la nueva realidad periodística y mejorar el aprendizaje práctico realizando coberturas, como para incentivar en el alumnado su espíritu emprendedor, que deberá aprovechar su presencia en Twitter para comenzar a construirse su propia marca personal con la que hacer contactos y granjearse una reputación en su camino a la empleabilidad.

\section{Para ampliar conocimientos, una bibliografía práctica}

Como colofón, mostramos a continuación una breve lista de seis publicaciones recientes en España que muestran todas las posibilidades que ofrecen las redes sociales en general y Twitter en particular para su mejor aprovechamiento a un nivel profesional y académico:

Cobo, Silvia (2012). Internet para periodistas. Kit de supervivencia para la era digital. UOC.

Guembe, Javier (2011). Twitter para Dummies. CEAC Polo, Juan Diego (2009). Twitter para quien no usa Twitter.

(Puede descargarse de forma gratuita en Bubok.com) Querales, Lenis y Rivero, Salomón (2012). El microblogging en la educación: Twitter como herramienta de apoyo educativo. Editorial Académica Española.

Rodríguez, Óscar (2011). Twitter: aplicaciones profesionales y de empresa. Anaya Multimedia

Tascón, Mario y Abad, Mar (2011). Twittergrafía: el arte de la nueva escritura. La Catarata. 


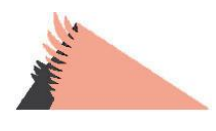 \\ Epílogo
}

\author{
Juan Luis Manfredi Sánchez \\ José María Herranz de la Casa \\ Francisco J Paniagua Rojano
}

\begin{abstract}
D ESDE 2008, han aparecido en España más de 400 nuevos medios. El conjunto de estas iniciativas se ha denominado periodismo emprendedor. Se caracteriza porque el promotor y el accionariado se corresponde con los propios periodistas y otros inversores ajenos a los grandes grupos de comunicación. Una segunda clave es la apuesta por un modelo digital en detrimento de las estructuras analógicas (papel y otros costes fijos derivados de la distribución, promoción y ventas). La tercera clave es el uso intensivo de las redes sociales y la marca personal del periodista como motor de la promoción empresarial. Esta transformación afecta también a la narrativa, esto es, a la forma en que contamos y explicamos las noticias. En este nuevo entorno estratégico, los periodistas tienen que aprender nuevas habilidades y cambiar su mentalidad, para adaptarse a los cambios en la industria periodística.
\end{abstract}

Ahí es donde las Universidades en general y las Facultades de Periodismo en particular tienen una oportunidad para la innovación. En junio de 2014, 30 profesores de Periodismo procedentes de 21 universidades de España y Portugal participamos en el seminario "Periodismo emprendedor, una esperanza renovada" en la Facultad de Periodismo de la Universidad de Castilla-La Mancha. En serio y en broma, nació el "espíritu de Cuenca", el deseo de innovar y emprender en periodismo. 
El seminario como objeto formar a profesores de Periodismo de las universidades españolas para que promuevan cuatro ejes en su docencia. A saber, el periodismo, el emprendimiento, la tecnología y la libertad de expresión. Para dar forma a estas ideas, el seminario analizó el fenómeno del periodismo emprendedor, la necesidad de innovar en la formación del profesorado y del alumnado y en el uso de las tecnologías para la creación de nuevas iniciativas periodísticas.

Este libro es el primer fruto tangible del espíritu de Cuenca. En él reunimos ideas, experiencias y propuestas de trabajo con el alumnado. Las Facultades de Periodismo queremos ser partícipes de la nueva ola: por eso, los profesores y los alumnos debemos aprender a competir con nuevos productos y servicios periodísticos. Por eso es un obra orientada a la práctica para aprender a pasar de la la idea a la innovación y de ésta a la empresa.

El seminario fue financiado por la Embajada de Estados Unidos en Madrid tras la elección de la idea en un proceso competitivo a escala europea. La actividad se encaja dentro del "European Alumni Enrichment Seminar: Secretary Kerry's Forum on Yourh Employment". Asimismo, contó con el apoyo del patronato universitario "Cardenal Gil de Albornoz", la Facultad de Periodismo de la Universidad de Castilla-La Mancha y el proyecto europeo de investigación MEDIADEM (European Media Policies Revisited: Valuing \& Reclaiming Free and Independent Media in Contemporary Democratic Systems, FP7-SSH-2009-A Grant agreement 244365).
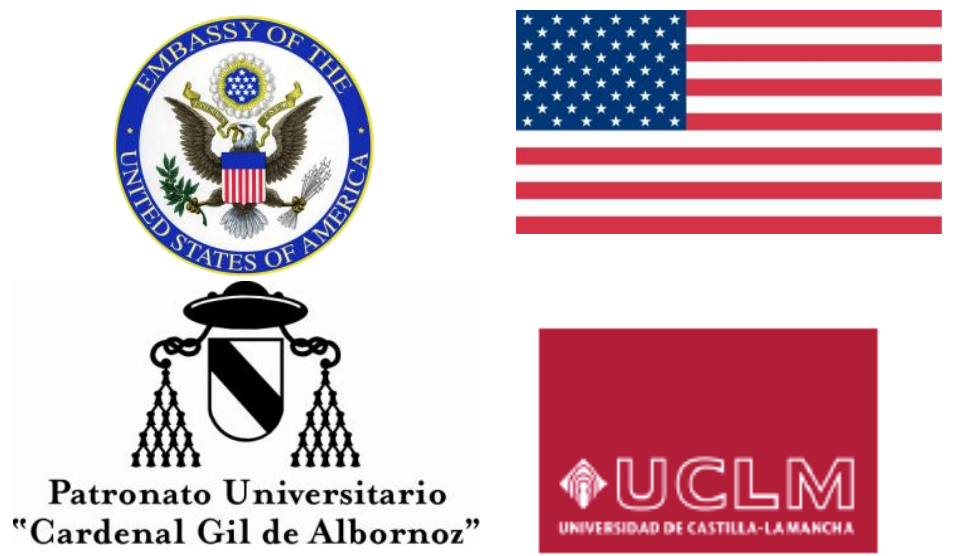


\section{Los autores}

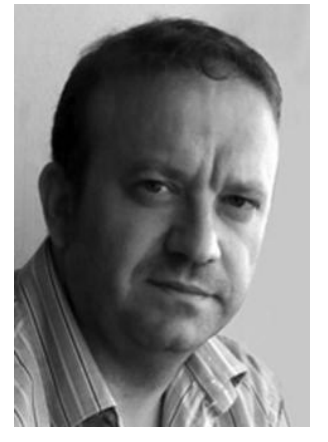

Juan Luis Manfredi Sánchez es profesor contratado doctor de Periodismo de la Universidad de Castilla-La Mancha. Es el investigador principal del proyecto "Comunicación pública, transparencia, rendición de cuentas y participación en los gobiernos locales" (CSO2013-46997-R), que versa sobre innovación, periodismo y comunicación política. Ha sido el responsable español del proyecto europeo MEDIADEM (European Media Policies Revisited: Valuing \& Reclaiming Free and Independent Media in Contemporary Democratic Systems), dentro del $7^{\circ}$ Programa Marco (FP7-SSH-2009-A Grant agreement 244365). Es el responsable del contrato de I+D "Entrepreneurial Journalism, a renewed hope" en la Universidad de Castilla-La Mancha con financiación del Departamento de Estado de Estados Unidos, germen de esta publicación. También ha publicado el manual docente "Emprendimiento e innovación en Periodismo" en el sello editorial de la Universidad de Castilla-La Mancha.

En Twitter@juanmanfredi \#periodismoemprende

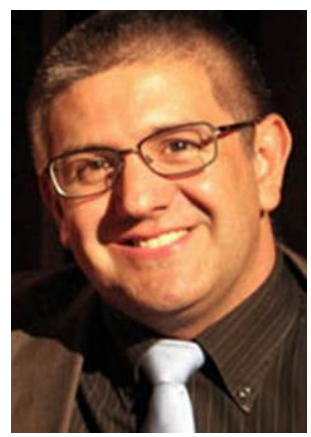

Francisco Javier Paniagua Rojano es profesor Contratado Doctor en el Departamento de Periodismo de la Universidad de Málaga, donde imparte las asignaturas de grado Comunicación Corporativa e Institucional en el Grado en Periodismo y Creación y Gestión de Empresas Informativas y de máster Estrategias de la Industria Periodística en los nuevos escenarios: Empresas y estructura profesional. Igualmente, el docente e investigador ha participado o participa en varios proyectos de investigación relacionados con el objeto de la solicitud, como por ejemplo, "Análisis crítico del sistema de medios: credibilidad e impacto en la ciudadanía (CSO2008-05125), 
entre 2008 y 2012; "Uso e influencia de los social media y la comunicación 2.0 en la toma de decisiones turísticas y en la imagen de marca de los destinos. Aplicaciones de utilidad para los destinos turísticos españoles" (CSO2012-34824), desde 2013 y actualmente vigente, ambos del Plan Nacional $\mathrm{I}+\mathrm{D}$, del Ministerio de Innovación y Ciencia.

Asimismo, ha participado en varias publicaciones relacionadas con la estructura de la profesión periodística, tanto a nivel nacional como internacional, entre las que destacan, su labor como coordinador del Informe Anual de la Profesión Periodística, entre los años 2005 y 2011, publicado por la Asociación de la Prensa de Madrid; o su aportación en la obra colectiva The Global Journalist in the 21st Century, con el capítulo "Journalism in Spain", editada por David Weaver y Lars Whillnat y publicada en Routledge.

En Twitter@FrancisPaniagua

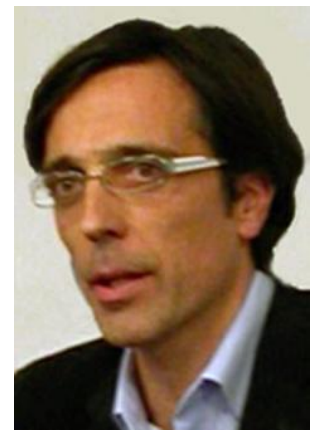

José Luis Rojas Torrijos es profesor asociado del Departamento de Periodismo II de la Facultad de Comunicación de la Universidad de Sevilla y profesor de Periodismo en EUSA Business University. Actualmente compagina su labor docente e investigadora con la de periodista en la Oficina del Portavoz del Gobierno de la Junta de Andalucía. Forma parte del Grupo de Investigación 'Estudio de Medios para un Periodismo de Calidad' de la Universidad de Sevilla, que ha formado parte de la publicación La calidad periodística (Aldea Global, 2013) con un estudio sobre las fuentes y la calidad en el periodismo digital. Asimismo, es el autor del blog http://periodismodeportivodecalidad.blogspot.com

En Twitter@rojastorrijos 


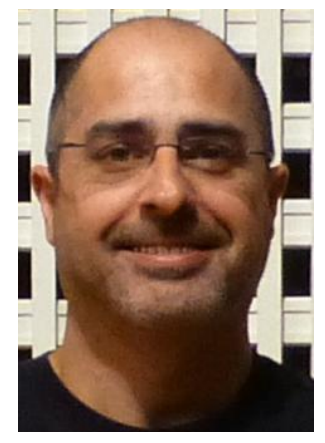

Francisco J. Caro González es Doctor en Administración de Empresas por la Universidad de Sevilla. Profesor Titular de las asignaturas Empresa Informativa y Organización y Gestión de Empresas Periodísticas. Es autor de libros como "Cambio e Innovación en la Empresa Informativa", "Gestión de Empresas Informativas" o "Emprender en Femenino en la Comunicación"

Entre sus líneas de investigación destacan los estudios de género relacionados con las empresas de comunicación, la gestión del cambio en las organizaciones y la metodología de investigación cualitativa.

Pertenece grupo SEJ115 "Gestión de la Innovación, la Calidad y el Cambio". Ha sido investigador principal del proyecto I+D+i (20072010) "Satisfacción de las necesidades informativas de las mujeres".

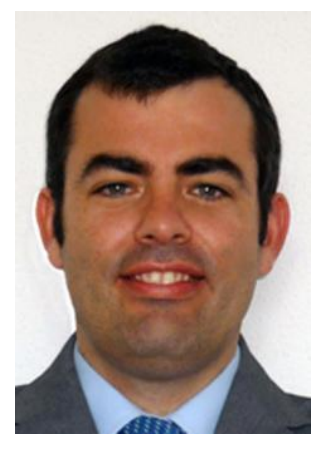

José María Herranz de la Casa es Doctor en Periodismo por la Universidad Complutense de Madrid. Ha trabajado como periodista en el diario deportivo MARCA y también ha sido profesor de la Universidad Católica de Ávila (UCAV) y de la Universidad Europea Miguel de Cervantes (UEMC), donde además desarrolló su labor como responsable del Gabinete de Comunicación. En la actualidad es profesor de la Universidad de Castilla-La Mancha en la Facultad de Periodismo de Cuenca. Es director de la publicación multimedia y proyecto pedagógico de la Facultad: El Observador de Castilla-La Mancha (http://observador.uclm.es) desde 2014. Este proyecto periodístico es una de las líneas de trabajo en periodismo emprendedor que ha puesto en marcha la Facultad y que tiene como objetivo el desarrollo de un espacio de publicación y experimentación periodística para los alumnos y profesores.

En Twitter@jmherranz 


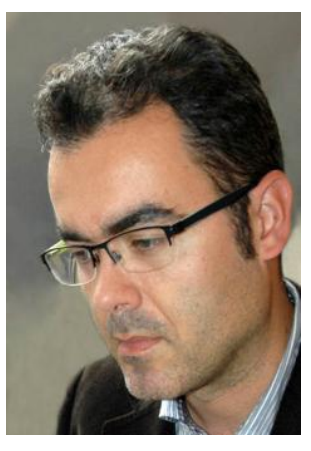

José Manuel Noguera Vivo es director del departamento de Ciencias de la Comunicación en la Facultad de Ciencias Sociales y de la Comunicación de la UCAM, donde imparte Tecnología en el área de Periodismo. Tiene más de treinta obras sobre comunicación digital y periodismo, publicadas en editoriales como Springer, Routledge, IGI Global, Dykinson, Gedisa y UOC, entre otras; así como en revistas científicas tales como El profesional de la información, Comunicación y Sociedad, Latina, Comunicazioni Sociali, Claves de Razón Práctica o Participations, entre otras. Es profesor acreditado como Titular de Periodismo por ANECA desde 2013 y tiene reconocido un sexenio de investigación activo por la CNEAI (2007-2012). Su último libro en solitario es Redes y Periodismo. Cuando las noticias se socializan (UOC, 2012). Escribe desde 2004 en su blog personal La Azotea (http://laazotea.blogspot.com.es) sobre periodismo, tecnología y universidad.

En Twitter@jmnoguera

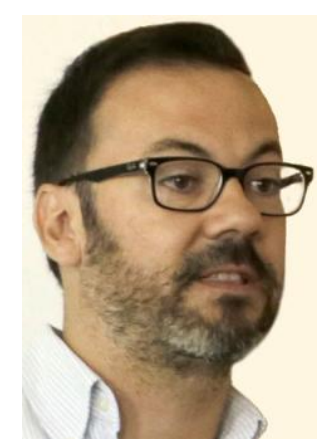

Miguel Carvajal es Profesor Contratado Doctor en la Universidad Miguel Hernández (UMH). Doctor en empresa informativa (Universidad de Navarra, 2006) y profesor visitante en Fordham University (2010), actualmente dirige el Máster en Innovación en Periodismo de la UMH y forma parte del Grupo de Investigación en Comunicación de la misma universidad. La trayectoria docente del profesor Carvajal ha estado siempre relacionada con la estructura del sistema de la comunicación y con el ámbito del periodismo. Desde 2012, es el responsable del primer proyecto formativo en español orientado a formar periodistas emprendedores mediante una titulación oficial (ANECA, 2012) de máster.

En Twitter@sintomatico 


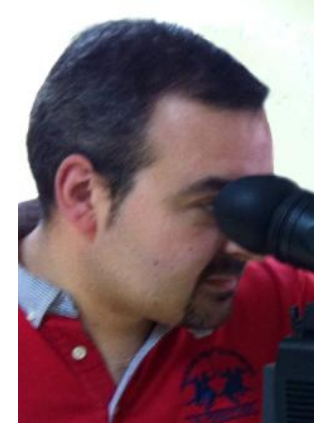

Francisco Cabezuelo Lorenzo Es profesor del área de Comunicación Audiovisual y Publicidad en la Facultad de Ciencias Sociales, Jurídicas y de la Comunicación de la Universidad de Valladolid en su campus de Segovia. Es Licenciado en Periodismo por la Universidad Complutense y Licenciado en Publicidad y Relaciones Públicas por la Universidad Camilo José Cela. Es doctor europeo por la Universidad Complutense. Ha participado en varios proyectos de $\mathrm{I}+\mathrm{D}+\mathrm{i}$ regionales, nacionales e internacionales. Cuenta con estancias académicas en University of Saint Thomas (Minnesota), en McGill (Quebec) y en Queen's University of Belfast (Irlanda del Norte) y cursos de especialización del Instituto Universitario Europeo de Florencia y la London School of Economics. Está acreditado por la ANECA como Profesor contratado doctor y cuenta con un sexenio (2007-2012) reconocido por la CNEAI. Es autor de más de una treintena de artículos publicados en revistas de Europa y Latinoamérica, y de más de 75 capítulos en obras colectivas.

EnTwitter@cabezuelotweets 